CENTER FOR POLICY RESEARCH

THE MAXWELL SCHOOL

WORKING PAPER SERIES

\title{
Still "Saving Babies"? \\ The Impact of Child \\ Medicaid Expansions on \\ High School Completion Rates
}

Lincoln H. Groves

Paper No. 181

June 2015

\section{ISSN: $1525-3066$}

426 Eggers Hall

Syracuse University

Syracuse, NY 13244-1020

(315) 443-3114/email: ctrpol@svr.edu

http://www.maxwell.syr.edu/CPR_Working_Papers.aspx 


\section{CENTER FOR POLICY RESEARCH -Summer 2015}

\section{Leonard M. Lopoo, Director Associate Professor of Public Administration and International Affairs (PAIA)}

\section{Associate Directors}

Margaret Austin

Associate Director

Budget and Administration

John Yinger

Trustee Professor of Economics and PAIA

Associate Director, Metropolitan Studies Program

\section{SENIOR RESEARCH ASSOCIATES}

Badi H. Baltagi

Robert Bifulco

Thomas Dennison

Alfonso Flores-Lagunes

Sarah Hamersma

William C. Horrace

Yilin Hou

Duke Kao

Jeffrey Kubik.

Yoonseok Lee

Amy Lutz

Yingyi Ma...

Jerry Miner
Economics PAIA

PAIA

Economics PAIA

Economics

PAIA

Economics

Economics

Economics

Sociology

Sociology

Economics
Cynthia Morrow Jan Ondrich John Palmer David Popp Stuart Rosenthal Ross Rubenstein Rebecca Schewe Amy Ellen Schwartz Perry Singleton. Abbey Steele Michael Wasylenko Peter Wilcoxen.
PAIA

Economics

PAIA

PAIA

Economics PAIA

Sociology PAIA/Economics

Economics

PAIA

Economics

.PAIA

\section{GRADUATE ASSOCIATES}

Emily Cardon

Carlos Diaz...

Alex Falevich

Lincoln Groves

Yusun Kim

Michelle Lofton

Qing Miao

Judson Murchie
PAIA Economics Economics PAIA PAIA PAIA PAIA PAIA
Sun Jung Oh Brian Ohl Laura Rodriquez-Ortiz Kelly Stevens Rebecca Wang Pengju Zhang Xirui Zhang
Social Science PAIA PAIA PAIA Sociology Economics Economics

\section{STAFF}

Kelly Bogart. Karen Cimilluca. Kathleen Nasto.
Administrative Specialist Office Coordinator Administrative Assistant
Candi Patterson. Computer Consultant Mary Santy. Katrina Wingle .Administrative Assistant Administrative Assistant 


\section{Abstract}

Precipitated by the legislative decision to decouple child Medicaid benefits from welfare receipt, the number of young children qualifying for public health insurance grew markedly throughout the 1980s and early 1990s. From a baseline of roughly $15 \%$ in the average state at the beginning of the decade, the rate increased to more than $40 \%$ of all young children in the United States by the time all federal mandates were fully enacted in 1992. This paper extends the academic literature examining early childhood investments and longer-term human capital measures by exploring whether public health insurance expansions to low-income children led to a greater number of high school completers in the 2000s. Building on the literature that uses the generosity of a state's Medicaid program as a time-varying, exogenous source of variation in a quasi-experimental design, I find a positive and statistically significant relationship between Medicaid eligibility during early childhood - defined as conception through age 5 - and longerterm high school completion rates. Completion is examined in two forms: the dropout rate and the traditional four-year high school graduation rate. Intent-to-treat estimates range from a 1.9 to 2.5 percentage point (pp) decrease in the dropout rate for each $10 \mathrm{pp}$ increase in early childhood years covered by the state-level Medicaid program. The same $10 \mathrm{pp}$ increase in child Medicaid program generosity reveals increases of 1.0 to $1.3 \mathrm{pp}$ when applied to graduation rates, indicating that completion gains are propelled by increases in traditional diplomas. Furthermore, results appear to be driven by Hispanics and white students, the two groups which experienced the greatest within-group eligibility increases due to the decoupling of child Medicaid from the Aid to Families with Dependent Children program.

JEL Codes: C23; H51; H52; H75; I21

Keywords: Child Medicaid Expansions; High School Completion; Early Childhood Investments 


\section{Introduction}

Before the 1980s, qualification for public health insurance under state-level Medicaid programs was traditionally tied to the receipt of Aid to Families with Dependent Children (AFDC) benefits, although states could voluntarily choose to cover other low-income groups, such as the medically needy or single women pregnant for the first time. As the battle between conservatives and liberals over the direction of social welfare policy and government spending unfolded during the Reagan administration (Kaiser Family Foundation, 2014), a series of significant legislative changes from 1984 to 1989 led to a decoupling of the AFDC and the child Medicaid programs. As a result, millions of low-income children became eligible for public healthcare who would not have received benefits under the old rules.

This paper examines one of the long-term effects of these expansions and focuses on a singular question: did the expansion of health insurance benefits to low-income children throughout the 1980s and early 1990s increase state-level high school completion rates around the turn of the $21^{\text {st }}$ century? Exploration of the other consequences of Medicaid expansions have received a considerable amount of attention in the academic literature, with studies examining the short-term impacts on child and maternal health (Aizer et al., 2007; Currie and Grogger, 2002; Currie and Gruber, 1994; Currie and Gruber, 1996a; Currie and Gruber, 1996b; Kaestner, 1999; Lykens and Jargowsky, 2002), the crowd-out of private health insurance (Blumberg et al., 2000; Busch and Duchovny, 2005; Cutler and Gruber, 1996; De La Mata, 2012; Gruber and Simon, 2008; Ham and Shore-Sheppard, 2005; Hamersma and Kim, 2013; Lo Sasso and Buchmueller, 2004; Shore-Sheppard et al., 2000; Shore-Sheppard, 2008), the effects on academic achievement during early childhood years (Levine and Schanzenbach, 2009), and the impacts on fertility (DeLeire et al., 2011; Zavodny and Bitler, 2010). However, this present study 
is one of the first to explore whether Medicaid expansions helped to increase the high school completion rates - the other being the NBER working paper by Cohodes et al. (2014) - and, moreover, helps to assess whether governmental investments in the form of healthcare for lowincome children can lead to improvements in long-term outcomes for this vulnerable population.

An investigation of the expansions of public health insurance to low-income families is substantively important due to the sheer size of these programs. In 1984, roughly $17 \%$ of all births in the United States were covered by Medicaid (Howell and Ellwood, 1991), while public insurance covered roughly $37 \%$ of all births after the full set of expansions was implemented in the early 1990s (MCH Update, 2003). More recently, this rate has grown to almost $48 \%$ of all U.S. births in 2010 (Markus et al., 2013). Thus, health insurance subsidized by the government covers a very significant proportion of all births in the United States and, moreover, provides access to healthcare in early childhood for a correspondingly large number of children. Access to care can allow medical professionals to diagnose and treat health issues in needy children before they become debilitating and could generate benefits beyond decreased child mortality and increased birth weight as noted in Currie and Gruber (1996b).

The link between governmental investments in the health of young, low-income children and the high school completion rates in America is an important one. As education levels and technological skills become increasingly valued in a specialized U.S. economy (Autor et al., 2008; Berman et al., 1998; Bresnahan et al., 2002), the long-term prospects for high school dropouts - both professionally and personally - are rather bleak. Not only are dropouts less likely than other workers to find stable employment (Apel and Sweeten, 2010; Rumberger and Lamb, 2003), they are also less prone to the formation of stable nuclear families (Carlson et al., 2004; Cherlin, 2010; Western and Wildeman, 2009), which can facilitate the intergenerational 
transmission of poverty (Western and Wildeman, 2009; Wilson, 1987). Moreover, those who fail to earn a degree - especially males - are much more likely to engage in criminal activities (Blanchflower and Freeman, 2000; Pettit and Western, 2004), which greatly diminishes longterm earning potential (Western et al., 2001) and contributes to the exceptionally high incarceration rates in the U.S. (Western and Wildeman, 2009). Thus, government investments in the form of early childhood health insurance for low-income children could conceivably lead to a population which is better-educated and less reliant upon social welfare programs as adults.

By exploiting the wide degree of heterogeneity in qualification standards for state-level Medicaid programs - as well as differences in the timing of Medicaid expansions and the implementation of federal mandates - this paper estimates the intent-to-treat (ITT) effect ${ }^{1}$ of Medicaid expansions to low-income children on the subsequent educational attainment of all public high school students, measured by both the state-level dropout and four-year traditional graduation rates. More specifically, this paper uses a plausibly exogenous measure of the generosity of a state's Medicaid program to estimate the causal effect of increases in the percentage of child-years potentially covered by the state's public health insurance program from conception through age $5 .{ }^{2}$ Using this simulated eligibility measure - the general form of which was first proposed by Currie and Gruber in 1994 and then subsequently adopted and adapted by a number of other researchers (see Currie and Gruber, 1994; Yelowitz, 1995; Currie and Gruber, 1996a; Currie and Gruber, 1996b; Currie and Gruber, 2001; Ham and Shore-Sheppard, 2005; Gruber and Simon, 2008; DeLeire et al., 2011, Cohodes et al., 2014) - I find that a 10 pp

\footnotetext{
${ }^{1}$ Like other papers in the literature, I consider this an intent-to-treat effect because the focus here is on eligibility and not the actual causal impact of public health insurance on the long-term graduation rates. The latter, producing treatment-on-the-treated estimates, would require a panel of individual-level data for all states, which does not exist. ${ }^{2}$ Medicaid eligibility is examined through age five for two reasons. First, this paper seeks to examine governmental investment in the form of public healthcare provided to young, low-income children before they enter primary school. Secondly, early legislative expansions to women and children in the late 1980s stipulated age 5 as the cutoff for mandatory Medicaid coverage.
} 
increase in early childhood years potentially eligible for Medicaid coverage led to a decrease in long-term high school dropout rates by 1.9 to $2.5 \mathrm{pp}$ and an increase in four-year graduation rates by 1.0 to 1.3 percentage points.

Findings are consistent across a number of alternative means to measure Medicaid eligibility and the number of years potentially covered during early childhood and, moreover, are driven by the two groups benefiting most from the public health insurance expansions: Hispanic and white students. Since the vast majority of states increased the generosity of their state-level programs by approximately 25 percentage points, this suggests that high school dropout rates decreased by roughly 4.75 to $6.25 \mathrm{pp}$, while traditional four-year graduation rates increased between 2.5 to $3.25 \mathrm{pp}$. Framing this last set of findings another way - and considering the base of roughly 3.8 million potential graduating seniors in the class of 2010 - public health insurance expansions to low-income children led to an increase of between 95,000 to 124,000 graduates

per year in the U.S. Thus, of the $6 \mathrm{pp}$ increase in the recent high school graduation rate reported by Murnane (2013), almost half of these gains can be attributed to child Medicaid expansions. These findings are both statistically and economically significant.

\section{The Medicaid Program and Eligibility Expansions}

A number of authors have detailed the history of the Medicaid program, ${ }^{3}$ as well as the coverage expansions impacting eligibility across the United States throughout the 1980s and early 1990s. Arguably, Gruber's 2003 book chapter, aptly titled "Medicaid”, provides the most

\footnotetext{
${ }^{3}$ The Medicaid program dates back to 1965 when the program was officially enacted by Congress as part of President Johnson's Great Society Program. From its inception, Medicaid was a state and federal partnership, whereby participating states received federal grants to help offset a portion of total program costs borne at the statelevel. To receive federal funds, states were required to cover select sub-populations, such as individuals qualifying for AFDC, and states could choose to add other groups it deemed as medically needy. By 1972, all states except Arizona had created state-run Medicaid programs; Arizona opted into the program on a limited scale in 1982, only to expand coverage shortly thereafter.
} 
comprehensive overview. Given these resources, this section highlights the significant

benchmarks and provisions of these public health insurance expansions that are most relevant to the fundamental research question of this paper. ${ }^{4}$ Two notes regarding the evolution of Medicaid programs are particularly important to this paper. First, the bundle of goods and services provided by Medicaid are comprehensive and standardized across all states. Secondly, increases in eligibility stem from two key legislative changes: (1) the removal of the family structure restrictions from benefit receipt, and (2) the tying of income thresholds to some function of the federal poverty level rather than the AFDC payment standard established by the state.

\subsection{The Scope of Medical Care Provided by Medicaid}

As part of the agreement to receive federal funds, the government required that states provide a relatively standardized bundle of goods and services provided under their Medicaid program. Thus, potential medical treatment received during the early childhood years should have been roughly equivalent regardless of the state of residence for children evaluated in this analysis. This is important because the quality of "treatment" evaluated in this analysis should not be strongly dependent upon geography, conditional on time. Consequently, "generosity" in this paper refers to the number of children potentially eligible for public insurance and not the quality of medical treatment possibly received.

Concerning these legislated benefits over the duration of the program, medical coverage provided has been comprehensive: the wide range of services included physician care, inpatient and outpatient hospital procedures, laboratory and x-ray services, as well as access to skilled

\footnotetext{
4 This overview draws heavily upon the historical overview provided in the Kaiser Family Foundation's publication "Medicaid: A Timeline of Key Developments" (2013) and reports published by the old U.S. General Accounting Office (1991) - a more detailed summary of the developments in Medicaid coverage can be found in Appendix A.
} 
nursing facilities. A critical component of this coverage as it applies to health investments in low-income children are the Early and Periodic Screening, Diagnostic, and Treatment (EPSDT) services, which were enacted under the Social Security Mandates of 1967, and provide preventative and treatment services including dental, vision, hearing, and mental health. As the name implies, the goals of the EPSDT program are to identify health problems starting at birth, to keep monitoring the development of the child at regular intervals, and to treat the problems once they are discovered. So, where low-income children without Medicaid benefits may wait years to receive a diagnosis and treatment, children with coverage are more likely to receive help in their infancy. In turn, this could potentially eliminate or reduce the negative impact of debilitating conditions and increase cognitive development during the formative years of early childhood.

\subsection{Determinants of Medicaid Eligibility}

During Medicaid's early period, the vast majority of those covered by Medicaid received benefits based upon their qualification for AFDC benefits within a particular state. Due to the wide range of criteria used to determine AFDC qualification, a large number of poor children were excluded from public health insurance in the early period because of family structure or income requirements legislated at the state level.

Historically, qualification for AFDC typically precluded the presence of able-bodied males within the household. This means that low-income children residing within two-parent, nuclear families were typically not eligible for Medicaid benefits and that AFDC was essentially a program for low-income, single parents. Acknowledging the distortive effects of this policy, legislative changes sought to break this link between AFDC receipt and child Medicaid by 
expanding eligibility to all children below some multiple of the federal poverty guideline, regardless of family structure type. As Figure 1 notes, Hispanic and white children are most likely to reside in two-parent, married families during their early childhood years. Thus, they are the two groups most likely to benefit from the removal of the family structure restrictions on child Medicaid receipt.

Furthermore, since individual states determined the need and payment standards under the state-level AFDC programs, there was tremendous variation in the income level that qualified single-parent families for benefits during the early period of the Medicaid program. For example, Alabama's monthly need standard for a family of 3 in 1980 was \$192 in nominal dollars, whereas the standard for a high-threshold state such as Vermont was \$670. A comparison of these values to the federal poverty guideline of approximately $\$ 520$ per month for a family of three at the same point in time reveal the potential for a significant number of poor children and families not qualifying for AFDC benefits and Medicaid simply because their states had chosen a low threshold to determine the "needy".

While minor changes to rules governing Medicaid eligibility occurred before the $1980 \mathrm{~s},{ }^{5}$ the bulk of the coverage expansions occurred during the mid to late 1980s and early 1990s which were the early childhood years for students graduating after the turn of the $21^{\text {st }}$ century. Under a number of legislative acts which sought to simultaneously limit federal expenditures and expand Medicaid coverage to needy populations during the Reagan administration, ${ }^{6}$ Medicaid

\footnotetext{
${ }^{5}$ Despite the failure of President Carter's push to expand coverage to low-income children under the age of 6 who did not qualify for insurance under current state laws in the late 1970s, the notions of separating welfare receipt from Medicaid qualification and the expansion of coverage during early childhood - defined as conception through age 5 - help set the agenda for comprehensive expansions of the 1980s.

${ }^{6}$ Important measures included the Omnibus Budget Reconciliation Act of 1981 (OBRA81), the Deficit Reduction Act of 1984, the Consolidated Omnibus Budget Reconciliation Act of 1985 (COBRA85), the Omnibus Budget Reconciliation Act of 1986 (OBRA86), the Omnibus Budget Reconciliation Act of 1987 (OBRA87), the Medicare Catastrophic Coverage Act of 1988 (MCCA88), and the Omnibus Budget Reconciliation Act of 1989 (OBRA89).
} 
eligibility was extended to a large set of low-income children during early childhood and to their mothers during pregnancy. Details of these incremental expansions have been highlighted in a number of publications (in particular, see Currie and Gruber, 1994; Yelowitz, 1995; Currie and Gruber, 1996a; Currie and Gruber, 1996b) and, thus, I refer the interested reader to Appendix A for more information regarding the key developments in Medicaid expansions to low-income children which affected cohorts examined within this analysis. The key note is that - after the full enactment of the sweeping mandates throughout the 1980s - Medicaid for children in the United States had completed its transition from an optional state program, which was typically tied to AFDC receipt, to a stand-alone program which potentially covered all children at or below some federally mandated multiple of the federal poverty line, regardless of family structure type.

\section{Theoretical Framework}

This is an early childhood investments paper which examines governmental expenditures impacting children before they enter primary school. As such, the main mechanisms through which access to public health insurance for low-income children could raise the long-term human capital accumulation is a healthier childhood and increased cognitive and non-cognitive development during the formative years of early childhood. By being able to diagnose and treat aliments afflicting low-income children earlier in their development via Medicaid's EPSDT program, low-income children with access to Medicaid may not only be better prepared to enter school because of increased development in their early years, but they might miss fewer days of school once entering primary school relative to those without access to insurance. These two factors, in turn, should increase their long-term performance relative to equivalent students 
without insurance and, perhaps, increase their odds of obtaining a high school diploma, holding all else equal.

Several studies have linked healthcare access to health improvements. ${ }^{7}$ Currie and Gruber (1996b) find that the Medicaid expansions that included pregnant women over the period 1979 to 1992 substantially decreased the incidence of infant mortality ${ }^{8}$ and decreased the probability of a low birth weight baby. This finding was confirmed by Levin and Schanzenbach (2009). While the benefits of decreased infant mortality are clear, it is important to note that low birth weight has been linked to a host of long-term health issues for the child (Barker et al., 1989; Gluckman and Hanson, 2004), as well as lower reading and math scores during childhood (Chatterji et al., 2014) and decreased levels of education and employability as adults (Currie and Hyson, 1999). In another paper, Currie and Gruber linked Medicaid expansions to increases in healthcare utilization by the low-income population (Currie and Gruber, 1996a), a finding which was confirmed again in Currie and Gruber (2001). While they report that take-up of public insurance was less than $100 \%$ - e.g., a number of families qualified for Medicaid insurance but did not formally apply for benefits - they report high levels of medical care utilization, especially preventative care delivered in the offices of physicians. Thus, low-income children appeared to be using the care afforded to them under the Medicaid expansions and received treatments in excess of what they would have experienced in the absence of the eligibility extensions.

As a result of their access to care earlier in their lifecycle, low-income insured children experience fewer avoidable hospitalizations than children without insurance (Dafny and Gruber,

\footnotetext{
${ }^{7}$ In a recent literature review, Levy and Meltzer (2008) examine the causal link between health insurance coverage and health and conclude that "the evidence available to date conclusively demonstrates that health insurance improves the health of vulnerable subpopulations such as infants, children..."

${ }^{8}$ As noted by Currie and Gruber (1996b), Medicaid expansions to pregnant women and children stemmed, in part, from a desire of politicians to address the infant mortality rate in the U.S., which was among the highest in the industrialized world.
} 
2005), which is presumably beneficial not only for the child's long-term development but can decrease the financial burden placed on the family (Gross and Notowidigdo, 2011; Finkelstein et al., 2012), as well as other consumers of healthcare services in the case of non-payment by the low-income family. Finally, a number of other studies and reviews have argued that access to medical care for low-income children improves their health during childhood. See Currie and Almond (2011), Gruber (1997), and Lykens and Jargowsky (2002) for further evidence supporting this link.

Comparatively fewer studies have examined the relationship between expansions of public health insurance and cognitive development during early childhood or other longer-term outcomes. This is due, in part, to the fact that many of the low-income children affected by Medicaid expansions are only now reaching adulthood. Levine and Schanenbach (2009) show that better health status at birth - as proxied by low birth weight and infant mortality - is related to improvements in $4^{\text {th }}$ and $8^{\text {th }}$ grade reading achievement. They use data from the National Assessment of Educational Progress (NAEP), a version of Currie and Gruber's simulated benefits, and a triple-difference identification strategy. Two other recent working papers have also investigated topics central to the theme in this one. Brown et al. (2014) use linked Internal Revenue Service data to report a positive impact of child Medicaid expansions on longer-term labor force earnings.

The current NBER working paper by Cohodes et al. (2014) is most similar in spirit to this work. They also utilize a form of Currie and Gruber's simulated Medicaid eligibility to study the effect of public health insurance expansions to low-income children aged 0 to 17 on high school and college completion rates. Using data from the 2005-2012 American Community Survey, the authors find that federal expansions led to declines in the high school non-completion rate of 
approximately 4.0 to $5.9 \%$ and, furthermore, that the gains were confined to non-whites. This analysis complements and extends Cohodes et al.'s work in a number of ways. First, this paper concentrates - and isolates - impacts of public health insurance expansions on early childhood only, as opposed to ages 0 to 17 , and exploits a longer panel to produce more precise estimates of the impacts on the public high school completion rates. The longer panel is particularly important to establish a sufficient baseline before the family structure restrictions for Medicaid receipt were rescinded which, as noted, differentially affects individual race and ethnic groups.

This paper also contains two measures of public high school completion which were not analyzed in Cohodes et al.'s work: dropout rates using Current Population Survey (CPS) data and the traditional four-year high school graduation rate using data from the Common Core of Data (CCD). In particular, the restriction of the sample to individuals born in the U.S. increases the precision of the dropout estimates, because it isolates changes in trends only applicable to students who could have qualified for the public health insurance expansions throughout their entire early childhood. Analysis of CCD data reveals that increased completion rates applies to traditional diplomas, rather than simply increases in the number of General Education Development (GED) holders. This is important because GED holders do not fare better in the labor market relative to high school dropouts (Cameron and Heckman, 1993; Boesel et al., 1998), and, consequently, gains in completion rates reveal real improvements in human capital.

Finally, unlike Cohodes et al. (2014), I find that gains in completion rates are driven by Hispanics and whites. By estimating models by race and ethnic group, the identification strategy used in this paper explicitly addresses a potential limitation of the other study, which is that gains by "non-whites" are driven by increases in the proportion of Asian students over time - which have historically had completion rates more similar to whites. In other words, the authors may be 
missing a significant compositional change correlated with Medicaid expansions within their classification of a "non-white" group. Those caveats aside, the consistency in findings across these papers indicate that benefits from child Medicaid expansions are real and substantial.

\section{Data}

Data in this analysis come from three general sources: demographic information in the Current Population Survey, education statistics from the Common Core of Data, and a database of state rules used to determine Medicaid eligibility. The first source, the CPS, is a monthly survey of roughly 60,000 dwellings across the United States conducted by the U.S. Census Bureau for the Bureau of Labor Statistics. ${ }^{9}$ While data collected in this survey serve as the basis of the government's monthly estimate of the unemployment rate, researchers frequently use it to investigate issues pertaining to educational attainment, family structure, and family income. Data from the CPS are used in two segments of this analysis. Monthly CPS data are used to calculate the dropout rates for individuals aged 18 to 20. Estimates are examined from 1994 to 2010, which allows a number of years to establish a baseline in each state before the large-scale Medicaid eligibility expansions. March CPS data are used to simulate the generosity of a state's Medicaid program by comparing family unit structure and income to eligibility rules established within a particular state. More details regarding this simulation are supplied shortly and technical details can be found in Appendix B.

The second source of data, the Common Core of Data comes from a repository of educational data maintained by the U.S. Department of Education's National Center for Education Statistics (NCES). NCES collects both fiscal and non-fiscal data from all public

\footnotetext{
${ }^{9}$ Monthly Current Population Survey data was downloaded from IPUMS-CPS. See www.ipums.org.
} 
schools in the United States on an annual basis, including the number of traditional diplomas awarded and student enrollment by grade level. Data are supplied directly from state education agencies and uploaded to the CCD; I use the public-use, state-level data in the calculation of four-year high school graduation rates. Diploma and enrollment figures were first documented by the CCD in the early 1990s which means that, given the lag structure required to measure the four-year graduation rate, the first graduation cohort for which a rate can be estimated is 1997. This allows for the construction of a minimal pre-period before the large-scale Medicaid mandates begin impacting children during early childhood years.

Finally, a number of resources were used to compile a database of the rules used to determine Medicaid eligibility for pregnant women and children in each state from 1975 to 1997 (Currie and Gruber, 1994; Hill, 1992; Kaiser Family Foundation, various publications; The National Governors Association, various publications; U.S. Department of Health and Human Services, various publications). This 20-plus year period covers the early childhood years for the graduation cohorts from the class of 1994 to the class of 2010. As with the other variables, more details regarding this database are provided in the forthcoming sections.

\section{Empirical Strategy}

This section outlines three vital components of this empirical analysis. It starts with a general discussion of the requirements for the identification of a casual effect of increased access to public health insurance for low-income children on the long-term public high school completion rates. Other portions describe the construction and findings from the two variables of central importance in this paper: the simulation of the generosity of the state-level Medicaid program, and the estimation of public high school completion rates in the United States. 


\subsection{Identification of a Causal Effect}

This paper builds off of literature which uses estimates of the generosity of a state's Medicaid program for children as a time-varying, exogenous source of variation in a quasiexperimental research design (Currie and Gruber, 1994; Yelowitz, 1995; Currie and Gruber, 1996a; Currie and Gruber, 1996b; Currie and Gruber, 2001; Ham and Shore-Sheppard, 2005; Gruber and Simon, 2008; DeLeire et al., 2011; Cohodes et al., 2014). Employing a form of the methodology adopted by these authors, I combine fixed-effects modeling with simulated Medicaid eligibility - using a nationally representative sample of CPS data and the eligibility requirements of state-level programs - to investigate the causal impact of healthcare expansions to low-income children on the subsequent high school completion rates. Exploiting the timing of Medicaid expansions to women and children, which varied significantly across geographic areas in terms of the percentage of the population potentially eligible, I estimate an intent-to-treat (ITT) effect of these expansions on the high school completion rates. The general estimation strategy can be written as follows:

(1) $(\text { Completion Rate })_{s c g}=\alpha+\beta\left(\begin{array}{c}\% \text { Early Childhood Years } \\ \text { Eligibile for Medicaid }\end{array}\right)_{s c g}+\delta_{s}+\zeta_{c}+\xi_{g}+\varepsilon_{s c g}$

where: Completion Rate is measured by either the CPS dropout or CCD graduation rate for a given state (s), cohort (c), and race/ethnic group (g);

\% Early Childhood Years Eligible for Medicaid is the percentage of all early childhood years potentially eligible for Medicaid under existing state laws for a particular race/ethnic group in a graduation cohort;

$\boldsymbol{\delta}_{\mathrm{s}}, \zeta_{\mathrm{c}}$, and $\xi_{\mathrm{g}}$ are state, cohort, and race/ethnic group fixed effects, respectively, $\boldsymbol{\varepsilon}_{\text {scg }}$ is the error term, which is clustered at the state level, and all models are weighted by the number of relevant individuals residing in a state for a particular cohort and group.

The major challenge in this research is to construct a plausibly exogenous measure of the generosity of a state's Medicaid program during early childhood. Since this variable is the key to 
my identification strategy and any causal claims, I discuss issues in estimation and potential empirical solutions, as well as describe - in detail and in a separate section - the estimation procedure used to simulate this variable. As is common in quasi-experimental research designs, two major sources of bias in the estimation of $\beta$ are particularly relevant: (1) simultaneity between the outcome and main explanatory variables, and (2) other forms of omitted variable bias.

The main concern with using actual Medicaid use rather than a measure of the generosity of the rules governing access to the state-level plan is that strategic behavior by local residents can lead to changes in Medicaid enrollment (e.g., local residents choose an income level to qualify for benefits), yet this does not represent a real change in access to public healthcare. Consequently, and considering the within-estimator specified in the fixed-effects model above, an "effect" could be attributed to this strategic behavior by the child's parents, which could be influenced by third factors impacting completion rates. ${ }^{10} \mathrm{~A}$ more convincing independent variable is one which is exogenously determined from the vantage point of the aggregated individuals within a state. Therefore, a covariate based upon the series of federal mandates leading to legislative changes in access to state-level child Medicaid programs could provide an exogenous measure of program generosity.

Restating the problem more generally, actual Medicaid use is probably correlated with other factors impacting early childhood health, the probability of family income falling below specified income levels, and high school completion rates. Consequently, Medicaid utilization is likely endogenous; DeLeire et al. (2011) provide a comprehensive, recent discussion of why

\footnotetext{
${ }^{10}$ One example: parents' education level, which may be a function of the ability endowments they bestow to the child, affects their potential earnings level. This, in turn, could influence their choice of an income level, one which qualifies them for the public insurance program.
} 
other techniques must be employed. Given this issue of endogeneity, I adopt a form of the methodology established in the literature and use individual-level data to simulate the percentage of all March CPS sample children who would have qualified under a state's eligibility requirements in a given year, regardless of where they reside. This procedure yields a measure of the state plan's generosity because it is not dependent upon the characteristics or choices of the residents currently living within that state but simply the eligibility requirements established by the state legislators, ${ }^{11}$ which were determined, in part, by federal mandates. Details regarding these simulations are provided in the next subsection and, moreover, a host of alternative estimation strategies are examined in the robustness checks section to analyze the sensitivity of my estimates to different simulation choices.

Other types of omitted variables can result in biased estimates of the relationship between Medicaid expansions and the high school completion rates. To isolate a causal effect after constructing the plausibly exogenous measure of the generosity of a state's Medicaid program, other variables potentially linked with Medicaid eligibility during the formative early childhood years and graduation rates more than a decade later must be included. Unfortunately, it is theoretically unclear as to what variables could be correlated and when they should be measured. Given this conceptual ambiguity, I choose to address these other forms of omitted variable bias through a variety of econometric demeaning techniques - including fixed effects and time trends - and to test the sensitivity of my finding under a range of definitions of Medicaid generosity.

Fixed effects address a number of potentially relevant, unobserved factors in this analysis. Given that states can differ in their historical completion rates for a variety of reasons,

\footnotetext{
${ }^{11}$ In addition, the values produced in the simulation are meaningful in a statistical sense, especially when considering a within-state analysis. For example, a simulated value of $20 \%$ means that the program is twice as generous as programs where only $10 \%$ of the early childhood years for a given cohort are potentially coverable by Medicaid.
} 
state-specific fixed effects can be used to account for factors which are time-invariant within a given state (such as general levels of spending per pupil or general marginal propensities of graduation). Race/ethnic group fixed effects hold constant for historical gaps in high school completion rates which may affect black, Hispanic, and white students at an aggregated level (e.g., across the entire U.S.), regardless of the time period. Extending these two constructs, staterace fixed effects are an even more flexible form of state-specific and race/ethnic group fixed effects. They control for differential graduation levels by race/ethnic groups residing within the same state. In other words, this functional form allows whites in Alabama to have historically different graduation rates than black students in that same state and, importantly, this racial differential - if existing - can vary in magnitude by the individual state.

Cohort-specific fixed effects can be used to control for macro factors affecting graduation trends in a particular year, such as the economy or binding federal education mandates. Modeling with state, cohort, and race/ethnic group fixed effects - which are indicated by $\boldsymbol{\delta}_{\mathbf{s}}, \zeta_{\mathbf{s}}$, and $\xi_{\mathrm{g}}$ in Equation 2 - imply that identification of an impact rests upon the comparison of graduation rates within a state for cohorts exposed to varying levels of Medicaid generosity during early childhood, while simultaneously controlling for (1) unobserved factors affecting all students at a macro level within a chosen cohort, and (2) general differentials in propensities to complete high school for each race/ethnic group. Stated differently, if all states are experiencing increases in both high school completion and Medicaid eligibility (which they generally are), then identification of a positive estimate of $\beta$ occurs only if states with greater increases in the generosity of their state Medicaid programs also experience larger increases in their long-term high school completion rates. Modeling with state-race fixed effects is interpreted similarly, but identification now occurs from changes within a state-race group rather than only a state. 
In addition to controlling for time-invariant unobservables, other strategies account for the possibility that graduation rates are evolving differently across states. State-specific time trends identify impacts of Medicaid expansions only when high school completion rates exceed the level which would have been expected after controlling for the existing trends in completion. ${ }^{12}$ Secondly, state-cohort fixed effects fully drop the linearity assumption implicit in the use of time trends. Under this specification, an effect is identified when increases in Medicaid generosity to a particular race or ethnic group residing within a state result in greater than anticipated gains in the high school completion rates, after accounting for all other factors. In other words, it can test whether the group receiving the greatest gains in access to public healthcare also experience the largest increases in completion rates. When included with the other techniques discussed above, this specification is the most stringent test of an effect and, potentially, the most convincing estimate of a causal impact because it can capture time-varying, unobserved factors at the state-level. All of these fixed-effects methods can significantly reduce the probability of an important omitted variable biasing estimation relative to the form presented in equation 1 above.

\subsection{Medicaid Eligibility Simulations}

Having addressed the challenges in estimating a causal relationship between increases in the generosity of state-level child Medicaid programs and longer-term high school completion rates, it is useful to discuss a few elements of the simulation process. Appendix B contains a number of technical details required to accurately estimate the generosity of the state-level Medicaid program - as proxied by the percentage of children in a graduation cohort who would

\footnotetext{
${ }^{12}$ Since the panel of data used in this analysis is long, I allow for quadratic time trends. Results are similar in magnitude when estimated with linear time trends.
} 
have been eligible for Medicaid during their early childhood years. This section broadly covers two steps used in this process: (1) the construction of a Medicaid eligibility rules database, and (2) the simulation of program generosity using CPS sample data.

The first step in the Medicaid eligibility simulation process is to properly document and categorize the large volume of legislative changes affecting qualification for child Medicaid and Aid to Families with Dependent Children (AFDC) from 1975 to 1997, which covered the early childhood years for the graduation cohorts from 1994 to $2010 .{ }^{13}$ Over the range analyzed, there was a large degree of heterogeneity in the laws governing qualification for Medicaid benefits for both pregnant women and children. Timing and stipulations governing the access to care appeared to be essentially random from the perspective of individuals living within a state until the federal mandates became binding at various junctures. And, as noted, the removal of the family structure restrictions is particularly important for certain race/ethnic groups. These differences provide the exploitable source of variation which can identify coefficients in a causal analysis.

Once this database of state-level requirements for Medicaid qualification is compiled, the second major phase is to use data from the March CPS to estimate the generosity of a state's Medicaid program during a cohort's early childhood years. Like other researchers in the academic literature - most notably Currie and Gruber (1994, 1996a, 1996b), I use a national sample of March CPS children age 0 to 5 - e.g., all children regardless of their original home state and early childhood age ${ }^{14}$ - and statistically ask the question: conditional on their family

\footnotetext{
${ }^{13}$ See Table 1 for more detail regarding the ages and years required to estimate eligibility for all cohorts in the sample.

${ }^{14}$ Parents in the CPS data appear to become wealthier as their children age. Thus, to avoid eligibility changes resulting from a changing demographic, the same sample of children aged 0 to 5 are used to simulate eligibility for all early childhood years estimated from a single March CPS following the mapping outline in Table 1.
} 
structure and family income level, would they have qualified for Medicaid had they lived in a particular state in a given year? ${ }^{15}$ As Table 1 outlines, I perform this exercise for seven different CPS years for a single cohort - from conception through age 5 - and then take the simple average of these seven years to define the variable \% of Early Childhood Years with Medicaid Eligibility. ${ }^{16}$ Mathematically, this calculation for a particular state (s) and graduation cohort (c) can be written as follows:

(2) $\left(\begin{array}{l}\% \text { Early Childhood Years } \\ \text { with Medicaid Eligibility }\end{array}\right)_{s c}=\frac{1}{7}\left[\sum_{y=c-19}^{c-13} \frac{\sum_{i=1}^{n} \text { CPS Weight } t_{i} * \text { Medicaid Eligibility }_{s}}{\sum_{i=1}^{n} C P S \text { Weight }_{i}}\right]$

where: the simulation is estimated from cohort $\mathrm{c}=1994$ to $\mathrm{c}=2010$;

i represents an individual March CPS observations from year (y) for a child aged 0 to 5; Medicaid Eligibility is an indicator variable which is 1 when the family unit or individual child qualified for Medicaid benefits under a particular state (s) legislative thresholds and 0 otherwise; and

CPS Weight are person weights reported by the March CPS.

The corresponding output from Equation 3 is the average number of child-years potentially coverable by a state Medicaid program for a nationally representative sample of children. This is a plausibly exogenous measure of the generosity of a state's Medicaid program during early childhood for reasons outlined earlier in this text. Moreover, the simulation methodology outlined above can be easily altered to estimate eligibility by race and ethnic group.

The simulation contains three assumptions which are important to disclose. To start, the use of equal weights for each early childhood year contains the implicit supposition that each

\footnotetext{
${ }^{15}$ Families were defined by the most disaggregated units identified within the CPS data. Total family income less certain time-varying disregards were compared to income thresholds established by the individual state.

${ }^{16}$ The CPS and CCD do not provide the individual-level data required to simulate early childhood eligibility. As such, I need to make the assumption that students graduate, on average, at age 18 and benefits during early childhood are covered by the March CPS years as outlined in Table 1 . This assumption should not be problematic so long as the age composition of the graduation class is not changing greatly from the class of 1994 to the class of 2010 in a given state. Moreover, the size of the expansions in the latter period, the smoothing of the estimates over the seven early childhood years, and the use of the within-estimation in the fixed-effects estimation should further mitigate any concerns over this procedure.
} 
year of potential Medicaid coverage is uniformly important to a child's development and longterm probability of high school completion. This enters equation 2 through the $1 / 7$ term. Although insurance coverage could be more important earlier in a child's development, it is theoretically unclear how the years from conception through age 5 should be weighted. Due to this ambiguity, I examine other potential measures to test the sensitivity of my preferred estimation strategy.

Two other assumptions stem from the lack of administrative or individual-level data following the potential graduate from early childhood through their high school years. The first is that any potential distortions in estimation from individuals migrating from state to state are minimal. Selective migration towards states with more generous Medicaid programs would cloud the relationship between those with eligibility increases and those not benefiting from legislative changes. Most likely, this would lead to attenuation bias in estimation due to misclassification error. Secondly, as an important reminder, I make the additional assumption that potential graduates would have finished at age 18, on average, as outlined in Table 1. This allows me to match the early childhood years in a consistent manner across cohorts but could also lead to misclassification error and attenuation bias in estimation if this central tendency is changing over time.

Those caveats aside, the simulated percent of early childhood years with Medicaid eligibility are shown, by state and for all children, in Appendix Table C1. Some important items to recall when interpreting these numbers: simulated values are estimated by graduation cohort and the value reported is the number of child-years potentially covered by Medicaid from conception through age 5. Estimates are a quantifiable and comparable measure of a state Medicaid program's generosity over time. Examples can help clarify the interpretation of this 
variable: $10.9 \%$ for Alabama's class of 1997 indicates that $10.9 \%$ of the early childhood years for the national sample of CPS children would have been covered under Alabama's eligibility requirements for child Medicaid. Under the eligibility simulation method established in the literature, the same exact CPS children are also run through the eligibility requirements for all other states in the same year and, as in places like California at $20.2 \%$ or Arizona at $4.4 \%$, the percent of child-years covered can be higher or lower depending upon the state-level eligibility requirements. Thus, these simulations quantify the generosity of coverage in the various statelevel Medicaid programs for the same set of low-income children during early childhood. In this table, all states experience a marked increase in the percentage of early childhood years covered, which occur, in part, as the federal coverage minimums become binding.

Similar tables were generated by race and ethnic group and are shown in Tables C2 through $\mathrm{C} 4$ in the appendix. These are the simulated values used in the core empirical modeling. ${ }^{17}$ Figure 2 summarizes these tables with an aggregated depiction of the increases in the generosity of the average state's Medicaid program during early childhood for all U.S. states and by race and ethnic group. Not surprisingly, access to public health insurance increases markedly over time. Another striking feature of this graph is the change in eligibility impacting the average Hispanic student. Over the period examined, Hispanic students were often raised in families with marital patterns most resembling whites, but with incomes most closely characterized by blacks. Thus, their estimated Medicaid eligibility during early childhood begins closer to whites. However, as family structure restrictions from child Medicaid are lifted, the fraction of early childhood years increases markedly for Hispanics and converges toward blacks at the end of the sample. This is an important source of exploitable variation.

\footnotetext{
${ }^{17}$ Other methods of Medicaid eligibility simulation are examined to reveal the sensitivity of estimates to key modeling choices.
} 


\subsection{The Outcome Variables: High School Completion Rates in the United States}

The primary goal of this paper is to investigate the causal impact of a single public policy decision - the expansion of health insurance coverage to low-income children - on long-term dropout and traditional four-year high school graduation rates. Given this singular objective, the next two sub-sections bypass the multitude of factors affecting completion trends over the past several of decades. ${ }^{18}$ Instead, the first section describes important choices made in the construction of the two rates, as well as outlines the strengths and weaknesses of each measure. More technical details regarding the construction of both measures can be found in Appendix B. The second sub-section contains a general discussion of the trends in U.S. dropout and traditional four-year high school graduation rates from the mid-1990s into the 2000s.

\subsubsection{Estimation of Dropout and Graduation Rates}

Despite being a widely reported statistics used as a barometer for the effectiveness of the public school system, estimation of U.S. high school completion rates is not straightforward, primarily due to conceptual ambiguities and data limitations. ${ }^{19}$ Given these challenges, I present and discuss two measures of public high school completion, each of which has strengths and weaknesses. Analyzing both constructs together exposes the true nature of the relationship between child Medicaid expansions and the long-term human capital investments of low-income children.

\footnotetext{
${ }^{18}$ For those interested in other factors affecting dropout rates in the United States, see the relatively recent, thorough review by Rumberger and Lim (2008). Murnane (2013) also provides a comprehensive analysis of the challenges and trends associated with the public high school graduation rate.

${ }^{19}$ For a comprehensive discussion of the challenges associated with the estimation of completion rates, please see Heckman and LaFontaine (2010).
} 
As previously noted, cohort-specific dropout rates were computed using monthly data taken from the Current Population Survey. As with the Medicaid eligibility simulations, Table 1 outlines how individuals of a particular age were assigned to a graduation cohort, which is defined by when the average student would have turned 18 . Two other conditions were used to estimate the dropout rate. ${ }^{20}$ Instead of using only age 18 in the construction of dropout rates, the CPS estimates were smoothed by using all sample individuals aged 18 to 20 . This approach yields a more accurate estimation of dropout rates for minority groups living in predominately white states because the sample size is greatly increased. Secondly, since the research objective in this paper is to explore the impact of increased access to public healthcare in early childhood, dropout rates are estimated only on CPS respondents who were born in the United States. Lowincome children not born in the U.S. would most likely either (1) not qualify for public health insurance because of residency requirements, or (2) have some significant delay in access to care during early childhood. While estimates for black and white students are not impacted by this restriction, the magnitude, but not general trends, of dropout rates for Hispanics are. Again, please refer to the technical details in Appendix B for more information.

While CPS dropout rates have the advantage that one can exclude respondents not living in the U.S. at the time of their birth - and thus, those may not fully benefit from Medicaid expansions during early childhood - this measure has two other disadvantages. The first is that researchers cannot exclude the GED certificate. The GED is the most common alternative to a traditional high school diploma; however, studies have argued that GED holders do not fare any better in the labor market than high school dropouts (Cameron and Heckman, 1993; Boesel et al.,

\footnotetext{
${ }^{20}$ As is standard in the literature, a dropout is identified when the CPS respondent has less than a high school level of education and is no longer enrolled in school.
} 
1998). ${ }^{21,22}$ Consequently, care must be taken in the conclusions drawn from an analysis of dropout rates if the percentage of GED holders is increasing over time; this would indicate a decrease in the dropout rate which is not a real long-term gain in human capital.

The second limitation is that the CPS sampling design excludes institutionalized populations. This could be problematic if the sample captured by the CPS is changing significantly over time due to factors such as mass incarceration. If the boom in U.S. prison population differentially impacts racial groups or individuals on the margin of graduation, which it most likely does, then CPS estimates serve as an upper-bound of the true rates. Furthermore, rates could be artificially higher in the later period if dropouts are more likely to be excluded from the CPS sample due to these changing trends in incarceration.

Given the potential limitations of the CPS dropout rate due to the use of the 18-20 year old smoothing technique, the non-excludability of non-traditional diplomas, and the nonsampling of institutionalized populations, a second outcome variable is examined. This measure concentrates on diplomas awarded in the traditional manner: e.g., students who attended an accredited high school program and received a traditional high school diploma, as discussed in Heckman and LaFontaine (2010). Following Heckman and LaFontaine (2010), I estimate a fouryear graduation rate using diploma counts and enrollment data from the Common Core of Data. In this calculation, a graduation cohort (e.g., the Class of 2000) is defined by the number of diplomas awarded in a state in a given year. Thus, diplomas awarded are the numerator. To estimate four-year graduation rates, the number of $8^{\text {th }}$ graders enrolled in that same state 4 years

\footnotetext{
${ }^{21}$ This effect is generally attributed to the general lack of non-cognitive skills characteristically held by these individuals, such as perseverance and motivation, traits which are essential to success in the academic and professional arenas (Heckman and LaFontaine, 2010).

${ }^{22}$ Furthermore, the federal government has formally recognized the non-substitutability between GED and traditional high school diplomas by excluding GED holders from the count of high school graduates under No Child Left Behind (NCLB) measures.
} 
earlier is used as the proxy for the maximum number of potential completers. These enrollees are used as the denominator from which a four-year graduation rate can be constructed. Please see the technical appendix for more details.

While addressing the GED issue, the traditional diploma measure introduces two other limitations. First, students born outside of the United States - and, thus, most likely not qualifying for Medicaid benefits during early childhood - cannot be excluded. Secondly, an implicit assumption of using the four-year graduation measure, especially while using fixedeffects regression modeling, is that any measurement error needs to remain constant over time. When students do not all finish in exactly four years, measurement error on the outcome variable is a potential problem. ${ }^{23}$ Under this scenario, degree duration would be an omitted third factor. When correlated with the primary covariate of interest, regression estimates would be biased. Unfortunately, given data restrictions, ${ }^{24}$ there is no way to explicitly test the assumption of a constant number of years required for completion within a particular state. Thus, I discuss the direction of the potential bias later in this paper.

Neither outcome variable flawlessly captures the trends in public high school completion rates which are most relevant to the child Medicaid expansions of the 1980s and early 1990s. However, the two measures are complementary, strengthening one where the other fails. Thus, consistency in findings from the two measures would establish whether a statistically significant and robust relationship exists between public healthcare expansions to low-income children in early childhood and long-term gains in the high school completion rates.

\footnotetext{
${ }^{23}$ In other words, and illustrating via an example, so long as students take, on average, 4.10 years to graduate in Alabama over the period explored in this analysis, then the same level of mismeasurement occurs across each time period, which can be controlled for via standard econometric procedures. A concern would be that the average time towards high school completion is time-varying within a state - e.g., that the time spent towards graduation in the earlier period is statistically different from the amount required in the latter period.

${ }^{24}$ To test this proposition, one would need administrative-level data across all states over a long period of time. This data is not available at a national level.
} 


\subsubsection{U.S. Trends in the Dropout and Four-Year Graduation Rates}

Trends in 18 to 20 year old dropout rates by race and ethnic group are shown in Figure 3. As displayed, rates appear to be flat in the early period and then fall dramatically after the turn of the century. All groups experience large declines in their dropout rates. At an aggregated level, dropout rates for all students fall from approximately $14 \%$ in 1994 to $9 \%$ in 2010 . This represents roughly a $35 \%$ decline relative to the original baseline established during the period before the large-scale increases in public healthcare access to low-income children.

Figure 4 presents trends in traditional four-year high school graduation rates for the 1997 to 2010 graduation cohorts for all U.S. students, and by race and ethnic groups. Graduation rates at the aggregate level for all students have generally experienced an upward trajectory in the 2000s, starting at roughly $76 \%$ in 2000 and exceeding $82 \%$ by $2010 .{ }^{25}$ Like dropout rates, improvements were experienced by all groups: black, Hispanic, and white students all experienced marked gains in their graduation rates throughout this period. The primary objective of this paper is to measure the extent to which these advances in completion rates at statespecific levels can be attributable to early childhood Medicaid expansions.

\section{Descriptive Statistics}

Table 2 contains a series of descriptive statistics for the data used to estimate the empirical models. Results are presented for all U.S. students, as well as separately by race and ethnic group. As noted earlier, Medicaid eligibility is estimated by the group of students, which means that the fraction of black, Hispanic, and white students which would have qualified for a state's Medicaid program had they lived in a given state during early childhood varies markedly

\footnotetext{
${ }^{25}$ These trends and estimates are consistent with those presented by Heckman and LaFontaine (2010).
} 
across both group and cohort. This time-varying measure of Medicaid program generosity at the state level is the identifying source of variation exploited in this analysis, and the fraction of CPS children qualifying for the average state's Medicaid program in early childhood is contained in the third column. Medicaid eligibility rises from approximately $15 \%$ of all child-years in the first graduation cohort (1994) to above $40 \%$ by the end of the period analyzed (2010). These generosity increases represent almost 2.8 times more child-years eligible for Medicaid.

Table 2 reveals the magnitude by which Medicaid eligibility increases vary across race and ethnic groups. At the start of the time-series, the average black student in this analysis had $40.4 \%$ of their early childhood years potentially coverable by Medicaid. By 2010, this number rose to $70.0 \%$. While large in absolute magnitude, this change corresponds to less than a doubling of program generosity. Thus, the marked within-group increases in eligibility are driven by the Hispanics and white students, which were the two groups benefiting most from the decoupling of Medicaid from AFDC. In the CPS samples analyzed, the average Hispanic lived in a state where the generosity of the program increased more than threefold: from $20.7 \%$ of all early childhood years coverable in 1994 to $67.4 \%$ eligible in 2010 . Though not nearly as high in magnitude, whites also experienced a near tripling of eligibility, going from $10.8 \%$ in 1994 to $32.1 \%$ in 2010 .

As discussed in the last section, blacks, Hispanics, and whites all experienced large gains in high school completion rates over the period analyzed. This fact is confirmed by the trends shown in aggregated CPS Dropout Rates and the CCD Graduation Rates. ${ }^{26}$ However, since the

\footnotetext{
${ }^{26}$ One limitation of the CCD data is that states did not always provide complete information on diplomas awarded. For example, two states failed to report diploma counts for all students in 2004, while 3 did not report in 2006. This issue becomes more serious when examining the trends in graduation rates by race and ethnic group, where the earlier period experiences greater frequencies of non-reporting. Here, the maximum number of potential observations is $14 * 51 * 3=2142$, while only 1875 observations have valid data. A similar issue exists in the CPS data which stems from the lack of a sufficient sample of 18 to 20 year olds to calculate dropout rates for blacks and
} 
completion measures and simulated Medicaid eligibility estimates are both increasing over the period examined, it is important to use a variety of econometric techniques to de-trend the data to avoid attributing an effect to the Medicaid expansions when some other third factor is truly driving part of the relationship.

\section{Empirical Models: High School Dropouts}

To explicate findings from my empirical models, I start with the full analysis of the high school dropout rate, which constitutes the most consistent and robust finding of a causal link between child Medicaid expansions and long-term gains in high school completion rates. After dropouts, I discuss the modeling of four-year high school graduation rates, which can address whether gains in completion rates were driven by increases in traditional diplomas or by other, less valuable, forms of high school completion.

\subsection{Core Modeling}

Table 3 contains estimates of the impact of Medicaid expansions in early childhood on the subsequent high school dropout rates, which constitute the core modeling in this analysis. Model 1 estimates the functional form proposed in equation 1 above. The three other models are shown in this table are extensions of this base form: Model 2 adds state-race fixed effects, while Models 3 and 4 account for existing trends in state-level graduation rates by exploiting statespecific time trends and state-cohort fixed effects, respectively. All standard errors in estimation are clustered at the state-level to account for the fact that the state-level residuals are probably

Hispanics in select states in particular years. In both cases, the length of the panel examined should still facilitate reliable estimates from the unbalanced panel. 
not independent and identically distributed even after conditioning on the other right-hand-side variables.

Starting with the baseline presented in Model 1, there is a negative and statistically significant relationship between Medicaid eligibility expansions during early childhood and the dropout rate. However, it is easily argued that estimates from Model 1 suffer from omitted variable bias, forms of which are addressed in the other three models. Adding the state-race fixed effects in Model 2 increases the size of the estimated coefficient of interest, as well as decreases the standard error. Once accounting for state-specific time trends in high school completion in Model 3, the statistical precision of the estimate increases even further. The point estimate of 0.2422 can be interpreted as follows: a 10 percentage point increase in the Medicaid generosity of a state-level program resulted in an approximately $2.4 \mathrm{pp}$ decrease in high school dropout rates, holding all other factors constant. Moreover, using state-cohort fixed effects to account for even more of the unexplained variation in factors affecting graduation within a given state, the point estimate increases slightly to $2.5 \mathrm{pp}$. This last finding strongly suggests that the groups benefitting the most from the Medicaid expansions (e.g., Hispanics and whites) also experience the greatest decreases in the dropout rates because identification now rests upon deviations from the mean within a particular state and cohort.

Summarizing the findings from these models, estimates from the core modeling - which are all estimated with a high level of statistical precision - indicate that Medicaid eligibility expansions led to long-term decreases in the high school dropout rates, with estimates ranging from 1.9 to $2.5 \mathrm{pp}$ for each $10 \mathrm{pp}$ increase in the generosity of the state's Medicaid program. Extending this estimate to the roughly 25 percentage point increase in program generosity generally witnessed by all states during the expansion period reveals a decrease in the dropout 
rate of between 4.75 to $6.25 \mathrm{pp}$. Thus, relative to a dropout baseline of roughly $14 \%$ in 1994 , this indicates a decline of at least one third in the dropout rate, which can be attributed to Medicaid expansions. These estimates are both large and economically meaningful.

\subsection{Heterogeneity Tests}

Findings from the core empirical models and the Medicaid eligibility graphs suggest that racial and ethnic groups may be differentially impacted by the magnitude of Medicaid expansions, because each group starts with different levels of Medicaid access. ${ }^{27}$ Table 4 presents formal tests of this proposition by showing the results from group-specific modeling. As the reader may quickly note, the power of the regressions are significantly diminished in the nonpooled models because the number of observations decline by $2 / 3$. However, modeling presented - which corresponds to the first two functional forms in Table 2 - confirms intuition: decreases in dropout rates are greatest for Hispanics, who benefit the most from Medicaid eligibility expansions. Blacks gain the least in terms of their completion rates. Whites reside somewhere in the middle, as with eligibility gains, while the large standard errors on the point estimates preclude the reporting of a statistically significant relationship at conventional levels. Moving past the smaller sample and power issues, there are two other reasons why whites could gain from access to public health insurance despite this finding in the disaggregated modeling. To start, the additional fixed effects in the pooled modeling increase the precision of the estimates, yet this important source of variation cannot be identified within the single group model. ${ }^{28}$

\footnotetext{
27 This is shown most noticeably by the trends in Medicaid eligibility expansions by group (Figure 2) and from the models with state-cohort fixed effects (Model 4) in Table 3.

${ }^{28}$ To be clearer, the state-cohort fixed effects identify unobserved factors which are changing over time within the same state. Examples would be per pupil spending or graduation requirements. This potentially important source of bias cannot be accounted for in the single group modeling because there is only one observation per state and year.
} 
Moreover, since regressions are weighted by the relevant number of students, whites have a disproportionate weight in pooled modeling. Thus, if the true impact on whites was zero, the finding of a statistically significant result would not occur in the larger sample because results are driven by the central tendency for whites. These facts, when coupled with the issues previously established, indicate that whites also benefit significantly from the early childhood public health insurance expansions.

\subsection{Alternative Measures of Medicaid Eligibility, Part I: Fixed Cohort Demographics}

Given the consistency of coefficients presented in Table 3, concerns regarding estimation bias from unobserved omitted variables should be mitigated. The second major issue is to test whether choices and assumptions made while constructing the \% of Early Childhood Years with Medicaid Eligibility inadvertently drives the statistically significant relationship between expansions in public health insurance and high school dropout rates. To meet this objective, I examine eight alternative estimates of a state's Medicaid program generosity during the early childhood years, analyses which investigate whether CPS sample selection or length of potential Medicaid exposure differentially impact the estimates presented thus far. To ensure that changes in sample composition over time are not driving the findings, the first series of models examine the impact of fixing CPS demographics to a single sample of individuals choosing their family structure and income levels. The second set tests whether the duration of Medicaid exposure during early childhood matters. Having established that the dropout results are driven by Hispanics and whites, all of these robustness checks exclude black students. 
Table 5 contains estimates derived from fixing the sample to three distinct March CPS years: 1975,1980 , and $1985 .^{29}$ This set of analyses investigate whether the changing CPS sample impacts the relationship between Medicaid generosity and dropout rates by fixing the cohort demographics to a single CPS year and then using CPI adjustment factors to convert family earnings into the nominal dollars required to determine eligibility for AFDC or child Medicaid eligibility within a given state-year. ${ }^{30}$ By choosing different fixed samples, I can potentially alleviate lingering concerns of strategic behavior by a subset of families who may choose their income level in order to qualify for public assistance programs in a particular state and year.

Table 5 starts with the core modeling estimated with Hispanic and white students only. Coefficients are larger than those presented in Table 3 because black students were driving the coefficient towards zero. As shown across a variety of specifications, results from the fixed CPS sample are consistent with the limited core modeling, although the point estimates are often larger than what was previously reported for the more highly specified models. Excluding the potentially biased estimates presented in Model 1, estimated impacts range from roughly a 1.7 to 4.0 pp decrease in the high school dropout rate for each $10 \mathrm{pp}$ increase in the generosity of the state's Medicaid program.

While this methodology leads to larger estimates of the impact of Medicaid expansions, it suffers from the primary criticism that the use of a CPI inflator tacitly contains an unreasonable assumption, namely that wages - especially those for low-wage workers - rose exactly by the amount of inflation in a given year. Adjusting income under this methodology understates generosity during a high inflationary period - which corresponds to the baseline period - because

\footnotetext{
${ }^{29}$ When interpreting this table, please note that each cell represents a separate regression model.

${ }^{30}$ To inflate the fixed CPS year (e.g., 1975, 1980, or 1985) earnings to “contemporaneous" values, I use a composite CPI index created from the CPI-U-X1 and CPI-U-RS series constructed by the Bureau of Labor Statistics.
} 
the CPI adjustment factor allocates more income to low-income families then they would have reasonably earned given market constraints. ${ }^{31}$ Although limited, this approach lends support to the finding of an impact of public health insurance expansions during early childhood on the subsequent long-term completion rates; it indicates that the use of the contemporaneous CPS sample during early childhood is not arbitrarily driving the finding of a statistically significant relationship between Medicaid eligibility expansions and fewer high school dropouts. Fixing the demographics to a single year, if anything, would lead to larger estimates.

\subsection{Alternative Measures, Part II: Tests of the Potential Exposure to Medicaid}

The remaining five alternative definitions of Medicaid eligibility test what happens when the dose of Medicaid treatment is altered statistically or, in other words, as the cumulative duration of Medicaid eligibility "received" changes. Since it is theoretically unclear how much Medicaid exposure is required to produce an effect, I examine point estimates when eligibility is estimated (1) as the lower bound of coverage, which is defined as the minimum percentage of the cohort covered in any single year, (2) as the upper bound of coverage, which is the maximum percentage of the cohort covered in any single year of early childhood, (3) during the conception year only (e.g., prenatal care and birth), (4) from conception through age 2 in the traditional manner, and finally, (5) coverage from age 3 to age 5, also with the core methodology established earlier.

The latter cases are relatively straightforward in their construction and interpretation: by examining a subset of ages potentially covered during early childhood - conception year only,

\footnotetext{
${ }^{31}$ Inflation rates in the late 1970s and early 1980s often exceeded $10 \%$ in a single year and were above 5\% in a number of other years in this analysis. To maintain the assumption required by use of the fixed sample from either 1975,1980 , or 1985, low-skilled wages would also need to rise by the same amount. This assumption is implausible given sticky wages and minimum wage regulations.
} 
from conception through age 2 and from age 3 to age 5 - I examine whether eligibility in the earlier years is more important than eligibility in the latter ones. As other measures of the duration of Medicaid eligibility, I also estimate the lower- and upper-bound of any potential Medicaid coverage, which technically envelop the \% of Early Childhood Years with Medicaid Eligibility variable, which has been the focal point of this entire analysis. ${ }^{32}$ The lower-bound of any coverage is defined by the minimum percentage of the estimated eligibility for any single year of early childhood and seeks to proxy the maximum number of children within a statecohort which could have received treatment throughout the 7 years of early childhood. The second measure - the upper-bound of any coverage - attempts to measure the maximum number of children within a state-cohort who could have ever qualified for coverage during their childhood, at any time.

The second series of findings in Table 6 contain estimates from the lower-bound of the estimated Medicaid eligibility percentage in any single year, which again, seeks to proxy the maximum number of children which could have received benefits in all seven years. This measure of the cohort "always covered" during early childhood produces statistics estimated with a high degree of statistical precision and which substantiate estimates presented in other sections. The models report impacts on high school dropout rates ranging from 1.8 to $2.3 \mathrm{pp}$ for each $10 \mathrm{pp}$ increase in Medicaid program generosity. Combined with the findings from the third estimation exercise - which is a proxy for the maximum percentage of the state-cohort ever

\footnotetext{
${ }^{32}$ A numerical example should help clarify the calculation of the lower- and upper-bounds. As provided in the appendix, the estimated percent of early childhood years with Medicaid eligibility for all students in the graduating class of 1997 in Alabama was 10.9\%. This number is constructed as the simple average of the simulated eligibility for the seven years from conception through age 5 or the CPS simulated estimates of $10.7 \%, 10.5 \%, 10.5 \%, 10.0 \%$, $9.5 \%, 10.0 \%$, and $15.2 \%$, respectively. To estimate the lower-bound of coverage in any single year for a cohort, one simply takes the smallest value from the seven years; here it is $9.5 \%$. To estimate the upper-bound of coverage, one uses the maximum number of CPS respondents covered in any single early childhood year, which is $15.2 \%$. These are the lower- and upper-bounds of potential coverage because they envelop the simple average of all seven years which is used in the main modeling.
} 
potentially qualifying for Medicaid insurance - it appears that qualifying for Medicaid benefits at some point during early childhood leads to the health and cognitive development benefits outlined earlier. That stated, there is some evidence that there may be less of an impact as expansions reached the upper tail of the low-income distribution as indicated by the smaller and less precise estimates derived from the upper-bound exercise, especially in Models 1 through 3.

Finally, when potential eligibility is examined in the conception year only, from conception through age 2, and from age 3 to age 5, coefficients are essentially in line with the point estimates of $1.9 \mathrm{pp}$ to $2.5 \mathrm{pp}$ derived from core modeling. Given these findings, it does not appear that any of the periods differentially impact high school graduation rates, i.e., the choice of equal weighting to each of the early childhood years does not appear to be consequential. Thus, while the methodology presented in this paper cannot precisely identify exactly which early childhood period is most crucial - if there really is such a period - the link between eligibility expansions from conception through age 5 and the long-term dropout rates is strong and robust to a number of alternative estimation procedures.

\section{Empirical Models: Traditional Four-Year Graduation Rates}

Given the consistency and robustness of findings across the various models examining dropout rates, this section examines whether fewer high school dropouts translated into more traditional high school graduates. As noted, holders of non-traditional diplomas do not fare better in the labor market than high school dropouts. Thus, to have a real influence on the human capital accumulation of low-income children, Medicaid must alter the number of traditional diplomas instead of other vehicles to graduation, such as the GED. 
Table 7 presents a simplified version of the core modeling outlined in Table 3 . While not nearly as precise as the dropout modeling, coefficients on the Medicaid generosity variable indicate a significant and robust relationship between increases in the percentage of early childhood years with Medicaid eligibility and the long-term traditional high school graduation rate. Estimates from modeling with black, Hispanic, and white students range from a 1.0 to 1.3 pp increase in completion rates stemming from a $10 \mathrm{pp}$ increase in state program generosity. Again, extending these point estimates to the over $25 \mathrm{pp}$ increase in eligibility in the average state, this suggests an increase in the four-year graduation rates of between 2.5 to $3.25 \mathrm{pp}$ which can be attributed to Medicaid expansions.

Findings for Hispanic and white students only are very similar to the coefficients reported for the three race/ethnic groups. Though similar in magnitude to the other point estimates, Model 4 coefficients under both specifications are no longer statistically distinguishable from zero. This fact indicates that the greatest beneficiaries of the Medicaid expansions - Hispanics - may not be experiencing the largest gains in four-year graduation rates. While contrary to the other findings, this is a reminder of one of limitations of the CCD data: one cannot exclude students likely to have been ineligible for the large increases in access to public healthcare during early childhood. Thus, to the extent to which graduation rates are diluted by recent immigrants for a particular group - which they almost certainly are for Hispanics - then the estimates presented serve as a lower-bound of the true impact. Consequently, it does not seem unreasonable to conclude that the gains in the decreased dropout rates translated into more traditional diplomas and that Hispanics and whites propel this finding.

The same set of robustness checks examined with the dropout models can be applied for the four-year graduation rates. For the sake of brevity, they are not presented in this paper. In 
general, coefficients are similar to those presented in Table 7, though estimates can be less statistically significant. This precision issue highlights another advantage of the CPS dropout rate measure: it has a much longer time series at baseline, as it starts in 1994 as opposed to 1997. Recalling Figure 3, this extended period is important to establish a baseline of Medicaid program generosity within a state before the large scale public insurance expansions.

\section{Discussion and Conclusions}

Seeking to examine the long-term impact of early childhood investments by the U.S. government in the form of increased healthcare access to low-income children before they enter primary school, this paper presents evidence that the Medicaid expansions to qualifying children throughout the 1980s and early 1990s led to an increase in the high school completion rates in the 2000s. By exploiting the large degree of heterogeneity in policy implementation of the public insurance expansion mandates, as well as econometric techniques to account for otherwise unobserved factors which cause certain states or race/ethnic groups to have differential trends in graduation, I find a positive, consistent, and statistically significant relationship between Medicaid eligibility expansions during early childhood and longer-term high school completion rates.

The results presented in this paper are economically significant. For dropouts, the 1.9 to $2.5 \mathrm{pp}$ decline in dropout rates for each $10 \mathrm{pp}$ increase in public insurance program generosity translates into approximately a 4.75 to $6.25 \mathrm{pp}$ decline in overall dropout rates from 1994 to 2010. Relative to the estimated $14.4 \%$ dropout rate for all students in 1994, this suggests a 33 to $43 \%$ decrease in the number of students exiting high school without a diploma or equivalent 
degree. Furthermore, dropout impacts appear to be driven by Hispanic and white students, the two groups benefiting the most from increased within-group access to public health insurance.

To test whether these gains impacted traditional manners of high school graduation, and not imperfect substitutes such as the GED, I also examined four-year graduation rates using traditional diploma counts from the Common Core of Data. The intent-to-treat estimates of a 1.0 to 1.3 percentage point increase in four-year graduation rates for each $10 \mathrm{pp}$ increase in childyears potentially covered by a state's Medicaid program implies that - on a base of roughly a 25 pp increase for the average state - there were 95,000 to 124,000 more graduates across the U.S. in 2010 due to public health insurance expansions and healthier low-income children. Moreover, improvements appear to be shared by all race and ethnic groups. This exercise confirms that gains from public healthcare access did not stem from non-traditional means of high school completion, which further indicate that these advances represent real improvements in long-term human capital accumulation for a potentially vulnerable population.

This paper corroborates findings from two other recent working papers in the literature which find substantial positive impacts on educational attainment and labor market outcomes stemming from the child Medicaid expansions of the late 1980s and early 1990s (Brown et al., 2014; Cohodes et al., 2014). In particular, it complements and extends Cohodes et al. (2014) by more precisely targeting the source of the completion rate gains (Hispanic and whites), as well as deriving more precise estimates of the effect by exploiting a longer data panel and other sources of data. However, work in this arena is not without its current limitations. Important items left for future research are to unpack the mechanisms prompting these positive effects and to better understand when public insurance interventions matter the most. Stated another way, current research has not identified what exactly facilitates these increases in performance. Is it from the 
general increase in child health, increases in cognitive and non-cognitive development before entrance into primary school, the potential increase in seat-time for students who otherwise would have been battling health issues in the absence of insurance, a more positive predisposition towards academics, or other factors related to the benefits of health insurance, including income effects? Furthermore, it is still unclear as to when public insurance matters the most: is it in utero as claimed by those prescribing the fetal origins hypothesis, throughout early childhood as supported by this paper, or throughout the entire childhood (e.g,. ages 0-17) as analyzed by Cohodes et al.? Other datasets, sources, and methodologies are required to unravel these mechanisms and to evaluate when these interventions have the greatest impacts.

Finally, there may be lingering concerns over the measures of completion explored in this analysis. Presumably, arguments would be rooted in a measurement error critique, one which would have to further assume non-classical error (since classical error on an outcome variable simply leads to larger standard errors, but no bias in estimation). In the construction of 18-20 year old dropout rates, the smoothing technique would be problematic if it fails to adequately account for some time-varying aspect of completion which is correlated with treatment (e.g., early childhood Medicaid expansions). While migration to other states after high school would influence the general completion levels within a state, it is still not obvious how a source of omitted variable bias would work under this scenario, especially given the other panel data controls in the modeling.

Critiques of the four-year graduation rate could be more valid. Some race and ethnic groups - such as black and Hispanics - may take longer, on average, to graduate from high school than the standard of four years (Murnane, 2013). Consequently, these students would not count as diploma holders in time period $t$ (the numerator of the four-year graduation rate 
calculation) which is compared to the number of students enrolled in 8th grade at time period t-4 (the denominator). Like the dropout rates, this is not problematic so long as the marginal propensity of completion remains constant over the time period examined, as this constant measurement error is accounted for using the panel data techniques employed in this paper. However, it would be a concern if these tendencies are time varying and occur simultaneously with Medicaid expansions to low-income children. In other words, a biased coefficient results if blacks or Hispanics in states with large Medicaid expansions are increasingly finishing within four years and the sequence of these two events is highly correlated. Although it appears as though this issue is ignored by those using the $\mathrm{CCD}$ in the academic literature because there is no obvious solution - it would imply that the estimates derived in this analysis serve as an upperbound of the effect of Medicaid expansions. That stated, the robustness of the findings across the two definitions of completion and the various constructs of Medicaid eligibility, concerns regarding measurement error on the outcome variable should be abated.

To conclude, academic accountability studies, early childhood investments, and the impact of Medicaid expansions have all received a considerable amount of attention in the academic literature. This paper extends this work by examining how government investments in the form of increased healthcare access in early childhood for low-income children impact longer-term outcomes. Findings from this research reveal a large decline in dropout rates and a complementary increase in the four-year completion rates. For the latter, the 2.5 to $3.25 \mathrm{pp}$ increase in the high school graduation rate stemming from the increases in healthcare access, which explains the majority of the recent $6 \mathrm{pp}$ increase in the U.S. graduation rates reported by Murnane (2013). Policy implications of these findings are also meaningful given the high correlation between education and outcomes deemed generally desirable to a society: as 
individuals become more educated they are less likely to become reliant upon governmental programs as adults, less likely to engage in criminal activities, and more likely to be attached to the labor market. Thus, it appears as though the Medicaid expansions to children throughout the 1980s and early 1990s generated social benefits well beyond "saving babies" and "free healthcare" for qualifying low-income children during early childhood. 
Aizer, Anna, Janet Currie, and Enrico Moretti. 2007. "Does Managed Care Hurt Health? Evidence from Medicaid Mothers." Review of Economics and Statistics 89 (3): 385-99.

Apel, Robert, and Gary Sweeten. 2010. "The Impact of Incarceration on Employment during the Transition to Adulthood." Social Problems 57 (3): 448-79.

Autor, David H., Lawrence F. Katz, and Melissa S. Kearney. 2008. "Trends in U.S. Wage Inequality: Revising the Revisionists." The Review of Economics and Statistics 90 (2): 300-23.

Barker, D. J. P., C. Osmond, P. D Winter, B Margetts, and S. J. Simmonds. 1989. "Weight in Infancy and Death from Ischaemic Heart Disease." The Lancet, Originally published as Volume 2, Issue 8663, 334 (8663): 577-80.

Berman, Eli, John Bound, and Stephen Machin. 1998. "Implications of Skill-Biased Technological Change: International Evidence.” The Quarterly Journal of Economics 113 (4): 1245-79.

Blanchflower, David G., and Richard B. Freeman. 2000. "The Declining Economic Status of Young Workers in OECD Countries." In Youth Employment and Joblessness in Advanced Countries. University of Chicago Press.

Blumberg, Linda J., Lisa Dubay, and Stephen A. Norton. 2000. "Did the Medicaid Expansions for Children Displace Private Insurance? An Analysis Using the SIPP." Journal of Health Economics 19 (1): 33-60.

Boesel, David, Nabeel Alsalam, and Thomas M. Smith. 1998. "Educational and Labor Market Performance of GED Recipients. Research Synthesis." US Department of Education, February. http://eric.ed.gov/?id=ED416383.

Bresnahan, Timothy F., Erik Brynjolfsson, and Lorin M. Hitt. 2002. "Information Technology, Workplace Organization, and the Demand for Skilled Labor: Firm-Level Evidence." The Quarterly Journal of Economics 117 (1): 339-76.

Brown, D., A. Kowalski, and Ithai Lurie. 2014. "Medicaid as an Investment in Children: What Is the Long-Term Impact on Tax Receipts?" Yale University Working Paper. Accessed November 20. http://www.econ.yale.edu/ ak669/medicaid.latest.draft.pdf.

Busch, Susan H., and Noelia Duchovny. 2005. "Family Coverage Expansions: Impact on 
Insurance Coverage and Health Care Utilization of Parents." Journal of Health Economics 24 (5): 876-90.

Cameron, Stephen V., and James J. Heckman. 1993. "The Nonequivalence of High School Equivalents." Journal of Labor Economics 11 (1): 1-47.

Carlson, Marcia, Sara Mclanahan, and Paula England. 2004. "Union Formation in Fragile Families." Demography 41 (2): 237-61.

Chatterji, Pinka, Dohyung Kim, and Kajal Lahiri. 2014. "Birth Weight and Academic Achievement in Childhood." Health Economics 23 (9): 1013-35.

Cherlin, Andrew J. 2010. "Demographic Trends in the United States: A Review of Research in the 2000s." Journal of Marriage and Family 72 (3): 403-19.

Cohodes, Sarah, Daniel Grossman, Samuel Kleiner, and Michael F. Lovenheim. 2014. The Effect of Child Health Insurance Access on Schooling: Evidence from Public Insurance Expansions. Working Paper 20178. National Bureau of Economic Research.

http://www.nber.org/papers/w20178.

Currie, Janet, and Douglas Almond. 2011. "Chapter 15 - Human Capital Development before Age Five.” In Handbook of Labor Economics, edited by David Card and Orley Ashenfelter, Volume 4, Part B: 1315-1486. Elsevier.

Currie, Janet, and Jeffrey Grogger. 2002. "Medicaid Expansions and Welfare Contractions: Offsetting Effects on Prenatal Care and Infant Health?” Journal of Health Economics 21 (2): $313-35$.

Currie, Janet, and Jonathan Gruber. 1994. Saving Babies: The Efficacy and Cost of Recent Expansions of Medicaid Eligibility for Pregnant Women. Working Paper 4644. National Bureau of Economic Research. http://www.nber.org/papers/w4644.

— 1996a. "Health Insurance Eligibility, Utilization of Medical Care, and Child Health." The Quarterly Journal of Economics 111 (2): 431-66.

_ 1996b. "Saving Babies: The Efficacy and Cost of Recent Changes in the Medicaid Eligibility of Pregnant Women.” Journal of Political Economy 104 (6): 1263-96.

- 2001. "Public Health Insurance and Medical Treatment: The Equalizing Impact of the Medicaid Expansions." Journal of Public Economics 82 (1): 63-89. 
Currie, Janet, and Rosemary Hyson. 1999. "Is the Impact of Health Shocks Cushioned by Socioeconomic Status? The Case of Low Birthweight.” The American Economic Review 89 (2): $245-50$.

Cutler, David M., and Jonathan Gruber. 1996. "Does Public Insurance Crowd Out Private Insurance?" The Quarterly Journal of Economics 111 (2): 391-430.

Dafny, Leemore, and Jonathan Gruber. 2005. "Public Insurance and Child Hospitalizations: Access and Efficiency Effects." Journal of Public Economics 89 (1): 109-29.

De La Mata, Dolores. 2012. "The Effect of Medicaid Eligibility on Coverage, Utilization, and Children's Health.” Health Economics 21 (9): 1061-79.

DeLeire, Thomas, Leonard M. Lopoo, and Kosali I. Simon. 2011. "Medicaid Expansions and Fertility in the United States." Demography 48 (2): 725-47.

Finkelstein, Amy, Sarah Taubman, Bill Wright, Mira Bernstein, Jonathan Gruber, Joseph P. Newhouse, Heidi Allen, Katherine Baicker, and Oregon Health Study Group. 2012. "The Oregon Health Insurance Experiment: Evidence from the First Year." The Quarterly Journal of Economics 127 (3): 1057-1106.

Gluckman, Peter D., and Mark A. Hanson. 2004. "Living with the Past: Evolution, Development, and Patterns of Disease." Science 305 (5691): 1733-36.

Gross, Tal, and Matthew J. Notowidigdo. 2011. "Health Insurance and the Consumer Bankruptcy Decision: Evidence from Expansions of Medicaid." Journal of Public Economics 95 (7-8): 767-78.

Gruber, Jonathan. 1997. "Policy Watch: Medicaid and Uninsured Women and Children." The Journal of Economic Perspectives 11 (4): 199-208.

- 2003. Medicaid. Edited by Robert A. Moffitt. NBER Conference Report series. Chicago and London: University of Chicago Press.

Gruber, Jonathan, and Kosali Simon. 2008. "Crowd-out 10 Years Later: Have Recent Public Insurance Expansions Crowded out Private Health Insurance?" Journal of Health Economics 27 (2): 201-17.

Hamersma, Sarah, and Matthew Kim. 2013. "Participation and Crowd out: Assessing the Effects of Parental Medicaid Expansions." Journal of Health Economics 32 (1): 160-71.

Ham, John C., and Lara Shore-Sheppard. 2005. "The Effect of Medicaid Expansions for Low- 
Income Children on Medicaid Participation and Private Insurance Coverage: Evidence from the SIPP." Journal of Public Economics, Tax and Transfer Programs for Low-Income People, 89 (1): 57-83.

Health Care Financing Administration. "Health Care Financing Program Statistics: Analysis of State Medicaid Programs (various years).” U.S. Department of Health and Human Services.

Heckman, James J., and Paul A. LaFontaine. 2010. "The American High School Graduation Rate: Trends and Levels." Review of Economics and Statistics 92 (2): 244-62.

Henry J. Kaiser Family Foundation. 2013. "Medicaid: A Timeline of Key Developments." Accessed December 1. http://kff.org/medicaid/timeline/medicaid-a-timeline-of-keydevelopments/.

Hill, Ian. 1992. "The Medicaid Expansions for Pregnant Women and Children: A State Program Characteristics Information Base.” Health Systems Research, Inc.

Howell, Embry M., and Marilyn Rymer Ellwood. 1991. "Medicaid and Pregnancy: Issues in Expanding Eligibility." Family Planning Perspectives 23 (3): 123-28.

Kaestner, Robert. 1999. "Health Insurance, the Quantity and Quality of Prenatal Care, and Infant Health." Inquiry 36 (2): 162-75.

Kaiser Family Foundation. 2014. "Medicaid: A Timeline of Key Developments." Accessed August 26. http://kff.org/medicaid/timeline/medicaid-a-timeline-of-key-developments/.

King, Miriam, Steven Ruggles, J. Trent Alexander, Sarah Flood, Katie Genadek, Matthew B. Schroeder, Brandon Trampe, and Rebecca Vick (2010). Integrated Public Use Microdata Series, Current Population Survey: Version 3.0. [Machine-readable database]. Minneapolis: University of Minnesota.

Levine, Phillip B., and Diane Schanzenbach. 2009. "The Impact of Children's Public Health Insurance Expansions on Educational Outcomes." Forum for Health Economics \& Policy 12 (1).

Levy, Helen, and David Meltzer. 2008. “The Impact of Health Insurance on Health.” Annual Review of Public Health 29 (1): 399-409.

Lo Sasso, Anthony T., and Thomas C. Buchmueller. 2004. "The Effect of the State Children's Health Insurance Program on Health Insurance Coverage." Journal of Health Economics 23 (5): 1059-82. 
Lykens, Kristine A., and Paul A. Jargowsky. 2002. "Medicaid Matters: Children's Health and Medicaid Eligibility Expansions." Journal of Policy Analysis and Management 21 (2): 219-38.

Markus, Anne Rossier, Ellie Andres, Kristina D. West, Nicole Garro, and Cynthia Pellegrini. 2013. "Medicaid Covered Births, 2008 through 2010, in the Context of the Implementation of Health Reform.” Women's Health Issues 23 (5): e273-80.

MCH Update. 2003. "MCH Update 2002: State Health Coverage for Low-Income Pregnant Women, Children, and Parents.” http://www.nga.org/files/live/sites/NGA/files/pdf/ MCHUPDATE02.pdf.

Murnane, Richard J. 2013. U.S High School Graduation Rates: Patterns and Explanations. Working Paper 18701. National Bureau of Economic Research. http://www.nber.org/papers/w18701.

National Governors Association. Various Years. "Maternal and Child (MCH) Update." http://www.nga.org/cms/home/nga-center-for-best-practices/center-publications/page-healthpublications/col2-content/main-content-list/maternal-and-child-health-mch-up.html.

Pettit, Becky, and Bruce Western. 2004. "Mass Imprisonment and the Life Course: Race and Class Inequality in U.S. Incarceration.” American Sociological Review 69 (2): 151-69.

Rumberger, Russell W., and Stephen P. Lamb. 2003. "The Early Employment and Further Education Experiences of High School Dropouts: A Comparative Study of the United States and Australia." Economics of Education Review 22 (4): 353-66.

Rumberger, Russell W., and Sun Lim. 2008. "Why Students Drop Out of School: A Review of 25 Years of Research.” California Dropout Research Project Report, no. \#15.

Shore-Sheppard, Lara, Thomas C. Buchmueller, and Gail A. Jensen. 2000. "Medicaid and Crowding out of Private Insurance: A Re-Examination Using Firm Level Data.” Journal of Health Economics 19 (1): 61-91.

Shore-Sheppard, Lara D. 2008. "Stemming the Tide? The Effect of Expanding Medicaid Eligibility on Health Insurance Coverage." B.E. Journal of Economic Analysis and Policy: Advances in Economic Analysis and Policy 8 (2).

United States General Accounting Office. 1991. "Medicaid Expansions: Coverage Improves but State Fiscal Problems Jeopardize Continued Progress.” http:/gao.gov/products/HRD-91-78. 
Warren, John Robert. 2005. "State-Level High School Completion Rates: Concepts, Measures, and Trends." Education Policy Analysis Archives 13 (51).

Western, Bruce, Jeffrey R. Kling, and David F. Weiman. 2001. "The Labor Market

Consequences of Incarceration.” Crime \& Delinquency 47 (3): 410-27.

Western, Bruce, and Christopher Wildeman. 2009. "The Black Family and Mass Incarceration." The ANNALS of the American Academy of Political and Social Science 621 (1): 221-42.

Wilson, William Julius. 1987. The Truly Disadvantaged: The Inner City, the Underclass, and Public Policy. Reprint edition. Chicago: University of Chicago Press.

Yelowitz, Aaron S. 1995. "The Medicaid Notch, Labor Supply, and Welfare Participation:

Evidence from Eligibility Expansions.” The Quarterly Journal of Economics 110 (4): 909-39.

Zavodny, Madeline, and Marianne P. Bitler. 2010. “The Effect of Medicaid Eligibility Expansions on Fertility.” Social Science \& Medicine 71 (5): 918-24. 
Figure 1

Trends in CPS Children Aged 0 to 5 Residing in Two Parent Families: By Group

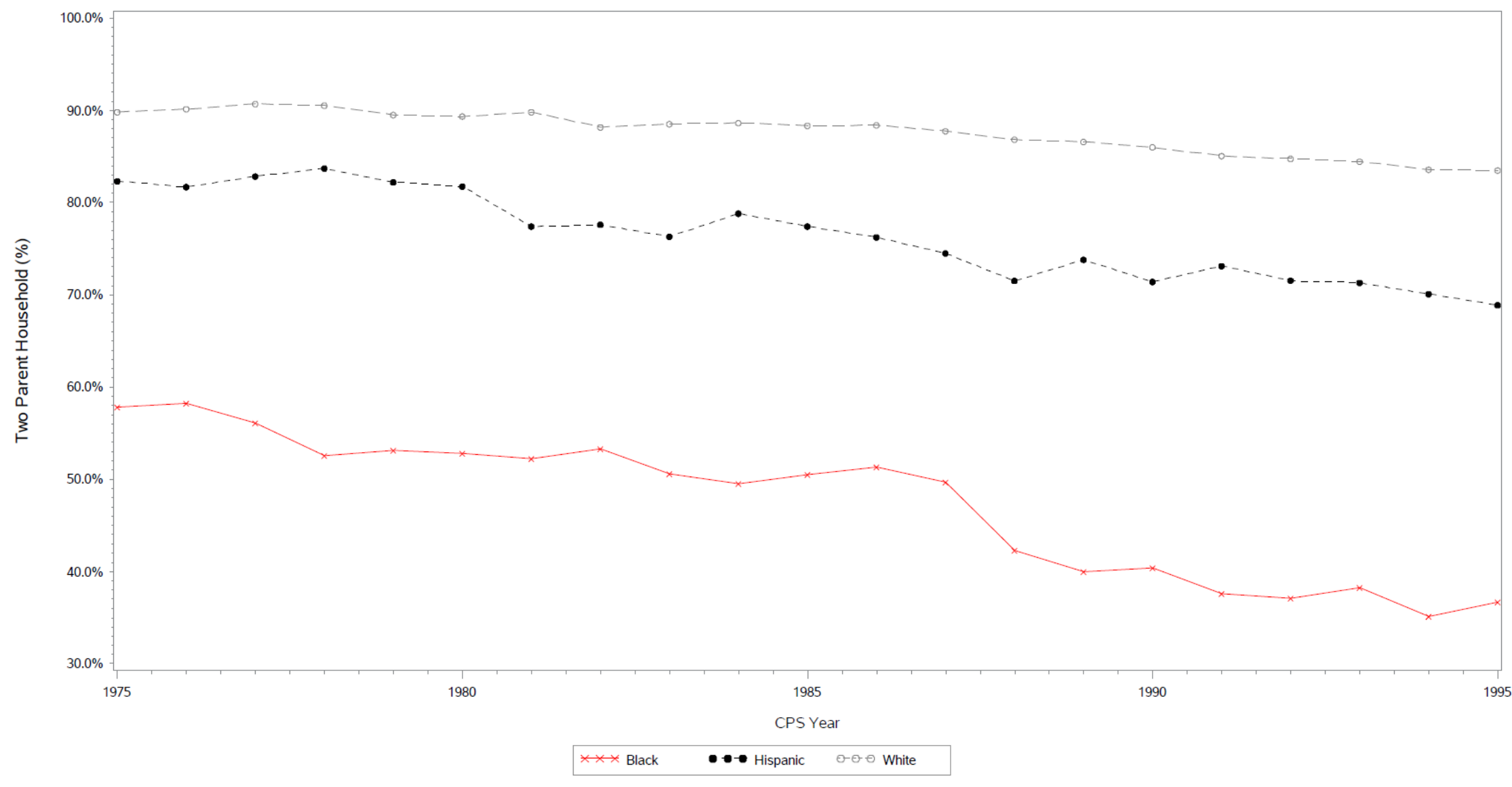


Figure 2

U.S. Trends in Medicaid Eligibility Expansions by Group

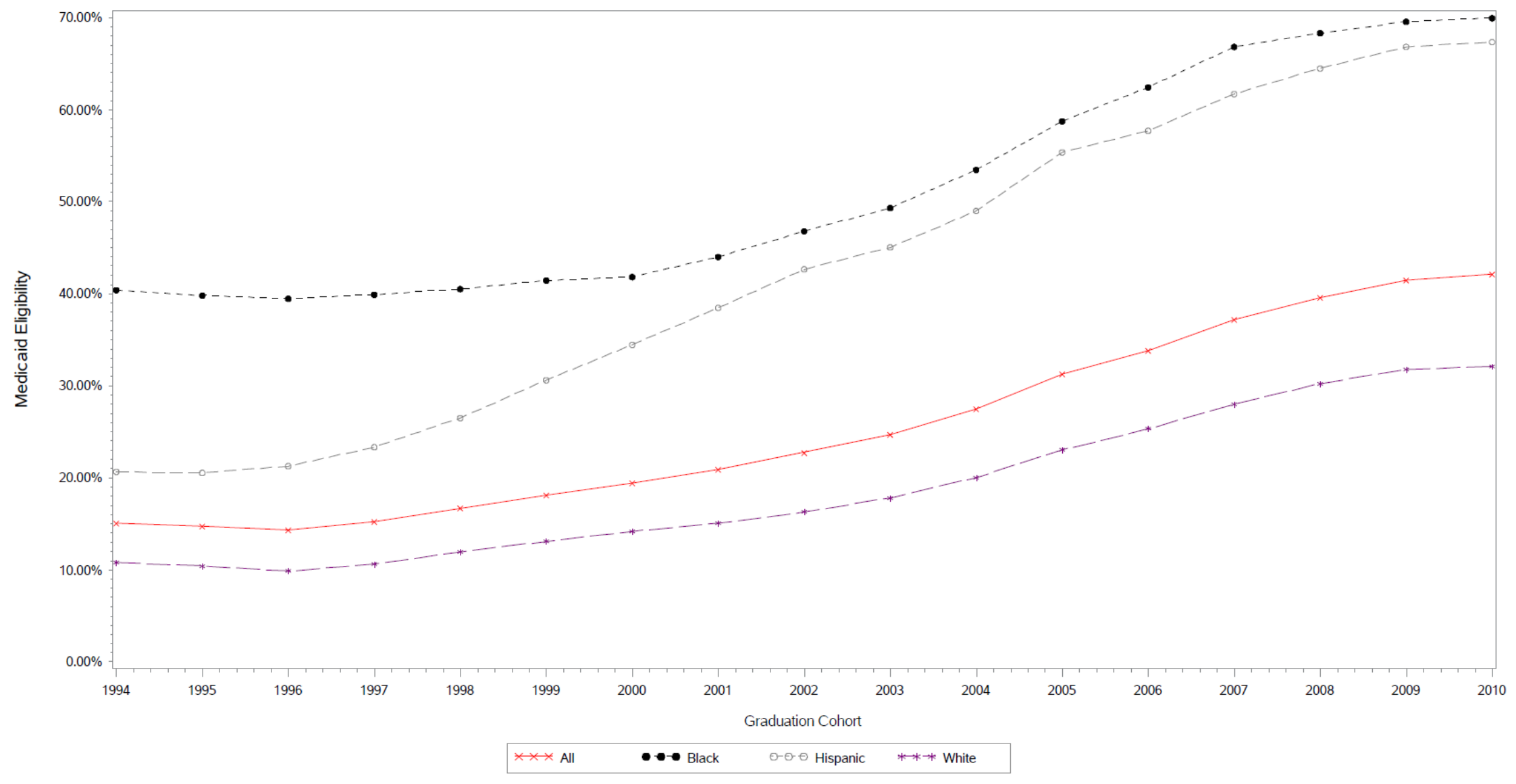


Figure 3

U.S. Trends in 18 to 20 Year Old Dropout Rate by Group

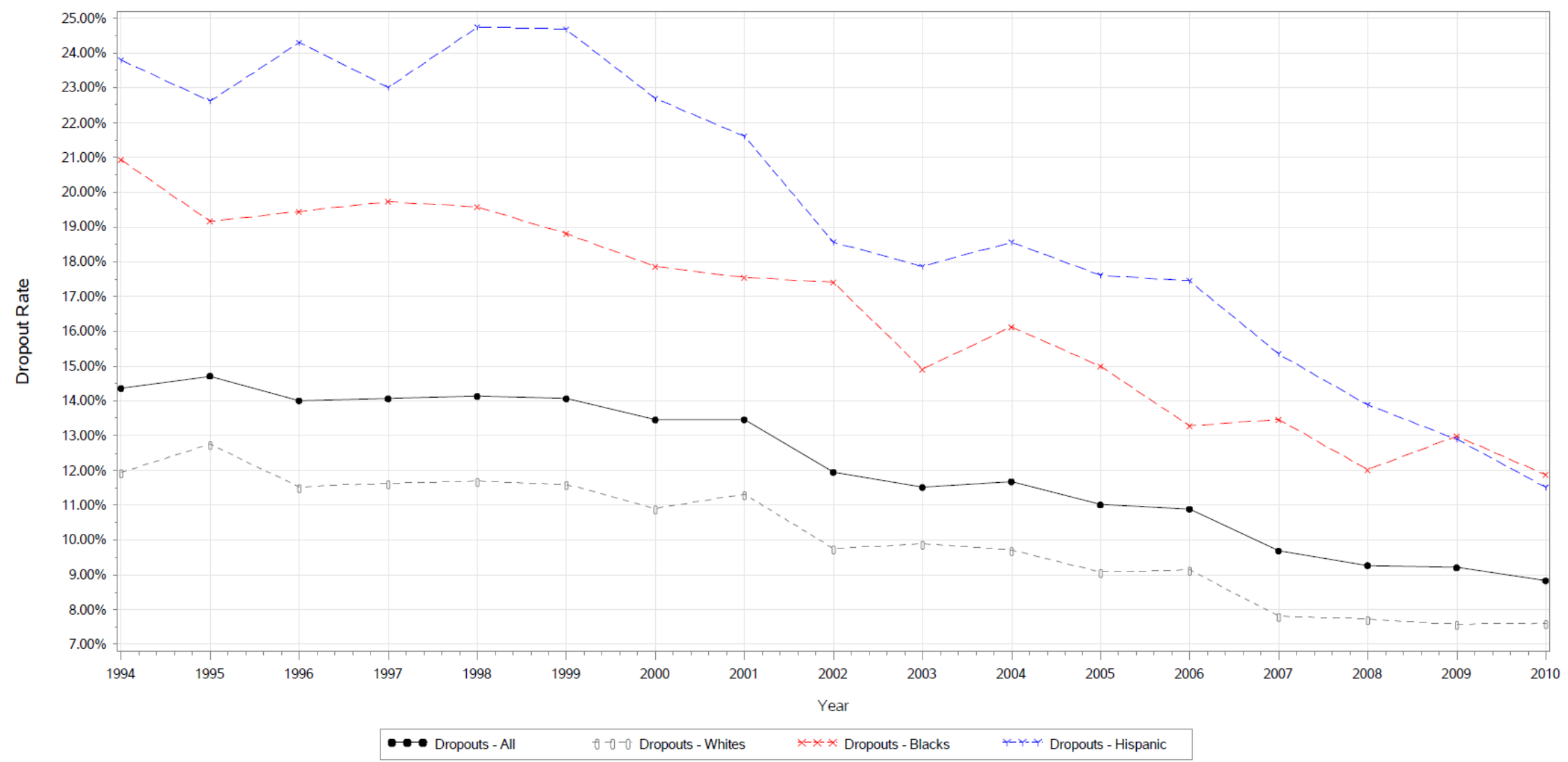


Figure 4

U.S. Trends in the Four-Year Graduation Rate by Group

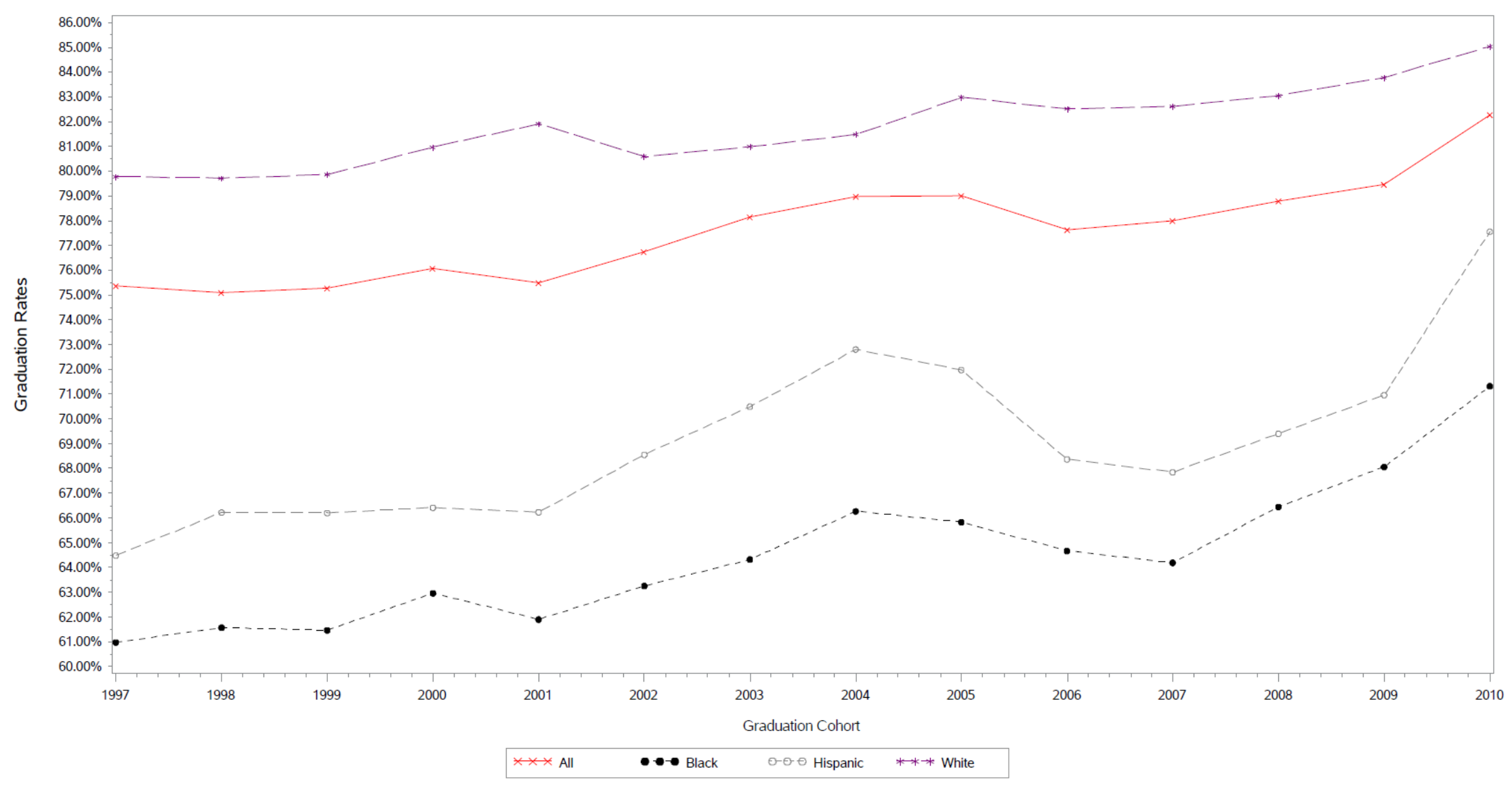


Table 1

Linking the March CPS Samples with the Early Childhood Years for a Given Graduation Cohort

\begin{tabular}{|c|c|c|c|c|c|c|c|c|c|}
\hline $\begin{array}{l}\text { Graduation } \\
\text { Cohort }\end{array}$ & Conception & Age 0 & Age 1 & Age 2 & Age 3 & Age 4 & Age 5 & $\ldots$ & Age 18 \\
\hline 1994 & 1975 & 1976 & 1977 & 1978 & 1979 & 1980 & 1981 & $\ldots$ & 1994 \\
\hline 1995 & 1976 & 1977 & 1978 & 1979 & 1980 & 1981 & 1982 & $\ldots$ & 1995 \\
\hline 1996 & 1977 & 1978 & 1979 & 1980 & 1981 & 1982 & 1983 & $\ldots$ & 1996 \\
\hline 1997 & 1978 & 1979 & 1980 & 1981 & 1982 & 1983 & 1984 & $\ldots$ & 1997 \\
\hline 1998 & 1979 & 1980 & 1981 & 1982 & 1983 & 1984 & 1985 & $\ldots$ & 1998 \\
\hline 1999 & 1980 & 1981 & 1982 & 1983 & 1984 & 1985 & 1986 & $\ldots$ & 1999 \\
\hline 2000 & 1981 & 1982 & 1983 & 1984 & 1985 & 1986 & 1987 & $\ldots$ & 2000 \\
\hline 2001 & 1982 & 1983 & 1984 & 1985 & 1986 & 1987 & 1988 & $\ldots$ & 2001 \\
\hline 2002 & 1983 & 1984 & 1985 & 1986 & 1987 & 1988 & 1989 & $\ldots$ & 2002 \\
\hline 2003 & 1984 & 1985 & 1986 & 1987 & 1988 & 1989 & 1990 & $\ldots$ & 2003 \\
\hline 2004 & 1985 & 1986 & 1987 & 1988 & 1989 & 1990 & 1991 & $\ldots$ & 2004 \\
\hline 2005 & 1986 & 1987 & 1988 & 1989 & 1990 & 1991 & 1992 & $\ldots$ & 2005 \\
\hline 2006 & 1987 & 1988 & 1989 & 1990 & 1991 & 1992 & 1993 & $\ldots$ & 2006 \\
\hline 2007 & 1988 & 1989 & 1990 & 1991 & 1992 & 1993 & 1994 & $\ldots$ & 2007 \\
\hline 2008 & 1989 & 1990 & 1991 & 1992 & 1993 & 1994 & 1995 & $\ldots$ & 2008 \\
\hline 2009 & 1990 & 1991 & 1992 & 1993 & 1994 & 1995 & 1996 & $\ldots$ & 2009 \\
\hline 2010 & 1991 & 1992 & 1993 & 1994 & 1995 & 1996 & 1997 & $\ldots$ & 2010 \\
\hline
\end{tabular}

Note: Each highlighted year corresponds to the March CPS used in estimation. 
Table 2

Completion Rates and Medicaid Expansions Aggregated Analysis

\begin{tabular}{|c|c|c|c|c|c|c|}
\hline \multirow[b]{3}{*}{ Group } & \multirow[b]{3}{*}{ Graduation Cohort } & \multirow[b]{3}{*}{ Medicaid Eligibility } & \multirow{2}{*}{\multicolumn{2}{|c|}{ CPS }} & \multirow{2}{*}{\multicolumn{2}{|c|}{ CCD }} \\
\hline & & & & & & \\
\hline & & & $\begin{array}{l}\text { CPS Dropout Rate } \\
\text { (18 to 20 } \\
\text { year olds) }\end{array}$ & $\begin{array}{c}\text { States with Sufficient } \\
\text { Obs for Estimation }\end{array}$ & $\begin{array}{l}\text { CCD Graduation } \\
\text { Rates }\end{array}$ & $\begin{array}{c}\text { States Reporting } \\
\text { Graduates in CCD }\end{array}$ \\
\hline All & 1994 & $15.1 \%$ & $14.4 \%$ & 51 & & 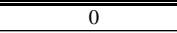 \\
\hline All & 1995 & $14.7 \%$ & $14.7 \%$ & 51 & & 0 \\
\hline All & 1996 & $14.3 \%$ & $14.0 \%$ & 51 & & 0 \\
\hline All & 1997 & $15.3 \%$ & $14.1 \%$ & 51 & $75.4 \%$ & 51 \\
\hline All & 1998 & $16.7 \%$ & $14.1 \%$ & 51 & $75.1 \%$ & 51 \\
\hline All & 1999 & $18.1 \%$ & $14.1 \%$ & 51 & $75.3 \%$ & 51 \\
\hline All & 2000 & $19.4 \%$ & $13.5 \%$ & 51 & $76.1 \%$ & 51 \\
\hline All & 2001 & $20.9 \%$ & $13.5 \%$ & 51 & $75.5 \%$ & 51 \\
\hline All & 2002 & $22.8 \%$ & $12.0 \%$ & 51 & $76.8 \%$ & 51 \\
\hline All & 2003 & $24.7 \%$ & $11.5 \%$ & 51 & $78.2 \%$ & 51 \\
\hline All & 2004 & $27.5 \%$ & $11.7 \%$ & 51 & $79.0 \%$ & 49 \\
\hline All & 2005 & $31.3 \%$ & $11.0 \%$ & 51 & $79.0 \%$ & 51 \\
\hline All & 2006 & $33.9 \%$ & $10.9 \%$ & 51 & $77.6 \%$ & 48 \\
\hline All & 2007 & $37.2 \%$ & $9.7 \%$ & 51 & $78.0 \%$ & 51 \\
\hline All & 2008 & $39.6 \%$ & $9.3 \%$ & 51 & $78.8 \%$ & 51 \\
\hline All & 2009 & $41.5 \%$ & $9.2 \%$ & 51 & $79.5 \%$ & 51 \\
\hline All & 2010 & $42.2 \%$ & $8.8 \%$ & 51 & $82.3 \%$ & 51 \\
\hline Black & 1994 & $40.4 \%$ & $20.9 \%$ & 48 & & 0 \\
\hline Black & 1995 & $39.8 \%$ & $19.2 \%$ & 46 & & 0 \\
\hline Black & 1996 & $39.5 \%$ & $19.4 \%$ & 46 & & 0 \\
\hline Black & 1997 & $39.9 \%$ & $19.7 \%$ & 49 & $61.0 \%$ & 43 \\
\hline Black & 1998 & $40.5 \%$ & $19.6 \%$ & 48 & $61.6 \%$ & 43 \\
\hline Black & 1999 & $41.5 \%$ & $18.8 \%$ & 50 & $61.5 \%$ & 46 \\
\hline Black & 2000 & $41.8 \%$ & $17.9 \%$ & 50 & $63.0 \%$ & 45 \\
\hline Black & 2001 & $44.0 \%$ & $17.6 \%$ & 49 & $61.9 \%$ & 46 \\
\hline Black & 2002 & $46.8 \%$ & $17.4 \%$ & 50 & $63.3 \%$ & 46 \\
\hline Black & 2003 & $49.3 \%$ & $14.9 \%$ & 46 & $64.3 \%$ & 49 \\
\hline Black & 2004 & $53.5 \%$ & $16.1 \%$ & 46 & $66.3 \%$ & 47 \\
\hline Black & 2005 & $58.8 \%$ & $15.0 \%$ & 48 & $65.8 \%$ & 49 \\
\hline Black & 2006 & $62.4 \%$ & $13.3 \%$ & 49 & $64.7 \%$ & 45 \\
\hline Black & 2007 & $66.8 \%$ & $13.5 \%$ & 50 & $64.2 \%$ & 48 \\
\hline Black & 2008 & $68.3 \%$ & $12.0 \%$ & 50 & $66.5 \%$ & 50 \\
\hline Black & 2009 & $69.6 \%$ & $13.0 \%$ & 48 & $68.1 \%$ & 51 \\
\hline Black & 2010 & $70.0 \%$ & $11.9 \%$ & 49 & $71.3 \%$ & 51 \\
\hline Hispanic & 1994 & $20.7 \%$ & $23.8 \%$ & 46 & & 0 \\
\hline Hispanic & 1995 & $20.5 \%$ & $22.6 \%$ & 47 & & 0 \\
\hline Hispanic & 1996 & $21.3 \%$ & $24.3 \%$ & 48 & & 0 \\
\hline Hispanic & 1997 & $23.4 \%$ & $23.0 \%$ & 46 & $64.5 \%$ & 43 \\
\hline Hispanic & 1998 & $26.5 \%$ & $24.7 \%$ & 48 & $66.2 \%$ & 43 \\
\hline Hispanic & 1999 & $30.6 \%$ & $24.7 \%$ & 48 & $66.2 \%$ & 46 \\
\hline Hispanic & 2000 & $34.5 \%$ & $22.7 \%$ & 49 & $66.4 \%$ & 45 \\
\hline Hispanic & 2001 & $38.5 \%$ & $21.6 \%$ & 50 & $66.2 \%$ & 46 \\
\hline Hispanic & 2002 & $42.7 \%$ & $18.6 \%$ & 51 & $68.6 \%$ & 46 \\
\hline Hispanic & 2003 & $45.1 \%$ & $17.9 \%$ & 50 & $70.5 \%$ & 49 \\
\hline Hispanic & 2004 & $49.0 \%$ & $18.6 \%$ & 51 & $72.8 \%$ & 47 \\
\hline Hispanic & 2005 & $55.4 \%$ & $17.6 \%$ & 49 & $72.0 \%$ & 49 \\
\hline Hispanic & 2006 & $57.7 \%$ & $17.5 \%$ & 50 & $68.4 \%$ & 45 \\
\hline Hispanic & 2007 & $61.7 \%$ & $15.4 \%$ & 51 & $67.9 \%$ & 48 \\
\hline Hispanic & 2008 & $64.5 \%$ & $13.9 \%$ & 51 & $69.4 \%$ & 50 \\
\hline Hispanic & 2009 & $66.8 \%$ & $12.9 \%$ & 51 & $71.0 \%$ & 51 \\
\hline Hispanic & 2010 & $67.4 \%$ & $11.5 \%$ & 51 & $77.6 \%$ & 51 \\
\hline White & 1994 & $10.8 \%$ & $11.9 \%$ & 51 & & 0 \\
\hline White & 1995 & $10.4 \%$ & $12.8 \%$ & 51 & & 0 \\
\hline White & 1996 & $9.9 \%$ & $11.5 \%$ & 51 & & 0 \\
\hline White & 1997 & $10.6 \%$ & $11.6 \%$ & 51 & $79.8 \%$ & 43 \\
\hline White & 1998 & $12.0 \%$ & $11.7 \%$ & 51 & $79.7 \%$ & 43 \\
\hline White & 1999 & $13.1 \%$ & $11.6 \%$ & 51 & $79.9 \%$ & 46 \\
\hline White & 2000 & $14.2 \%$ & $10.9 \%$ & 51 & $81.0 \%$ & 45 \\
\hline White & 2001 & $15.1 \%$ & $11.3 \%$ & 51 & $81.9 \%$ & 46 \\
\hline White & 2002 & $16.3 \%$ & $9.8 \%$ & 51 & $80.6 \%$ & 46 \\
\hline White & 2003 & $17.8 \%$ & $9.9 \%$ & 51 & $81.0 \%$ & 49 \\
\hline White & 2004 & $20.0 \%$ & $9.7 \%$ & 51 & $81.5 \%$ & 47 \\
\hline White & 2005 & $23.0 \%$ & $9.1 \%$ & 51 & $83.0 \%$ & 49 \\
\hline White & 2006 & $25.3 \%$ & $9.2 \%$ & 51 & $82.5 \%$ & 45 \\
\hline White & 2007 & $28.0 \%$ & $7.8 \%$ & 51 & $82.6 \%$ & 48 \\
\hline White & 2008 & $30.2 \%$ & $7.7 \%$ & 51 & $83.1 \%$ & 50 \\
\hline White & 2009 & $31.8 \%$ & $7.6 \%$ & 51 & $83.8 \%$ & 51 \\
\hline White & 2010 & $32.1 \%$ & $7.6 \%$ & 51 & $85.0 \%$ & 51 \\
\hline
\end{tabular}

Note: Aggregated Medicaid Eligibility and CPS Dropout Rates are weighted by the number of the relevant 18 to 20 year olds residing in a particular state in a given year. CCD Graduation Rates are weighted by the relevant number of enrolled 8th graders for a given graduation cohort. Please see text for more detail. 
Table 3

Estimated Impact of Medicaid Expansions in Early Childhood on High School Completion Rates

Outcome Variable = 18 to 20 Year Old Dropout Rate using CPS Data

Range Analyzed: 1994 to 2010

\begin{tabular}{|c|c|c|c|c|}
\hline & \\
\hline & Model 1 & Model 2 & Model 3 & Model 4 \\
\hline \multirow[t]{2}{*}{$\%$ of Early Childhood Years with Medicaid Eligibility } & $-0.1727 * * *$ & $-0.1906 * * *$ & $-0.2422 * * *$ & $-0.2491 * * *$ \\
\hline & [0.0441] & [0.0411] & {$[0.0498]$} & {$[0.0694]$} \\
\hline \multirow[t]{2}{*}{ Black Students } & $0.1159 * * *$ & $0.2798 * * *$ & $0.2968 * * *$ & $0.2950 * * *$ \\
\hline & {$[0.0160]$} & {$[0.0142]$} & {$[0.0175]$} & {$[0.0243]$} \\
\hline \multirow[t]{2}{*}{ Hispanic Students } & $0.1436 * * *$ & $0.1662 * * *$ & $0.1778 * * *$ & $0.1806^{* * *}$ \\
\hline & {$[0.0146]$} & {$[0.0092]$} & {$[0.0113]$} & {$[0.0157]$} \\
\hline \multirow[t]{2}{*}{ Constant } & $0.1614 * * *$ & $0.1695^{* * *}$ & $0.2166 * * *$ & $0.2131 * * *$ \\
\hline & {$[0.0045]$} & {$[0.0041]$} & {$[0.0049]$} & {$[0.0041]$} \\
\hline Number of obs. & 2526 & 2526 & 2526 & 2526 \\
\hline R-Squared & 0.6308 & 0.6930 & 0.7180 & 0.7988 \\
\hline Adjusted R-Squared & 0.6204 & 0.6710 & 0.6844 & 0.6735 \\
\hline State Fixed-Effects & $\mathbf{X}$ & $\mathbf{X}$ & $\mathbf{X}$ & $\mathbf{X}$ \\
\hline Cohort Fixed-Effects & $\mathbf{X}$ & $\mathbf{X}$ & $\mathbf{X}$ & $\mathbf{X}$ \\
\hline State-Race Fixed Effects & & $\mathbf{X}$ & $\mathbf{X}$ & $\mathbf{X}$ \\
\hline State-Specific Time-Trends & & & $\mathbf{X}$ & \\
\hline State-Cohort Fixed Effects & & & & $\mathbf{X}$ \\
\hline
\end{tabular}

Notes: Early childhood years are defined by the seven years from conception through age 5 . Regressions are weighted by the number of relevant CPS individuals aged 18 to 20 residing within a particular state for a given year and ethnic group. Standard errors are clustered at the state-level and are in brackets with statistical significance indicated as follows: $* \mathrm{p}<0.1, * * \mathrm{p}<0.05$, *** $\mathrm{p}<0.01$. 
Table 4

Estimated Impact of Medicaid Expansions in Early Childhood on High School Completion Rates

Outcome Variable = 18 to 20 Year Old Dropout Rate using CPS Data

Response Heterogeneity - Models by Race/Ethnic Group

\begin{tabular}{|c|c|c|c|c|c|c|}
\hline \multirow[b]{2}{*}{ Explanatory Variable } & \multicolumn{2}{|c|}{ Black } & \multicolumn{2}{|c|}{ Hispanic } & \multicolumn{2}{|c|}{ White } \\
\hline & Model 1 & Model 2 & Model 3 & Model 4 & Model 5 & Model 6 \\
\hline \multirow[t]{2}{*}{$\%$ of Early Childhood Years with Medicaid Eligibility } & 0.1641 & -0.0279 & -0.1141 & $-0.2797 * *$ & -0.1054 & -0.1397 \\
\hline & {$[0.1058]$} & {$[0.2135]$} & {$[0.1044]$} & {$[0.1356]$} & {$[0.0705]$} & {$[0.1237]$} \\
\hline
\end{tabular}

Number of obs.

R-Squared

$\begin{array}{cccccc}822 & 822 & 837 & 837 & 867 & 867 \\ 0.4826 & 0.5670 & 0.4896 & 0.5818 & 0.6919 & 0.7593 \\ 0.4366 & 0.4564 & 0.4451 & 0.4774 & 0.6661 & 0.7018\end{array}$

Adjusted R-Squared

0.4366

4564

$\mathbf{X}$

$\mathbf{X}$

State Fixed-Effects

Cohort Fixed-Effects

X

$\mathbf{X}$

$\mathbf{X}$

$\mathbf{X}$

X

$\mathbf{X}$

State-Specific Time-Trends

$\mathbf{X}$

$\mathbf{X}$

X

$\mathbf{X}$

$\mathbf{X}$

Notes: Early childhood years are defined by the seven years from conception through age 5 . Regressions are weighted by the number of relevant CPS individuals aged 18 to 20 residing within a particular state for a given year and ethnic group. Standard errors are clustered at the state-level and are in brackets with statistical significance indicated as follows: $* \mathrm{p}<0.1, * *$ $\mathrm{p}<0.05, * * * \mathrm{p}<0.01$ 
Table 5

Alternative Dropout Estimates - Fixed Cohort Demographics

Hispanics and White Students Only

\begin{tabular}{|c|c|c|c|c|}
\hline Medicaid Eligibility Definition & Model 1 & Model 2 & Model 3 & Model 4 \\
\hline Limited Core Modeling & $\begin{array}{c}-0.2083 * * * \\
{[0.0401]}\end{array}$ & $\begin{array}{c}-0.2149 * * * \\
{[0.0386]}\end{array}$ & $\begin{array}{c}-0.2579 * * * \\
{[0.0498]}\end{array}$ & $\begin{array}{c}-0.2624 * * * \\
{[0.0811]}\end{array}$ \\
\hline Demographics at CPS Year $=1975$ & $\begin{array}{c}-0.1680 * * * \\
{[0.0604]}\end{array}$ & $\begin{array}{c}-0.1717 * * * \\
{[0.0606]}\end{array}$ & $\begin{array}{c}-0.2943 * * * \\
{[0.0671]}\end{array}$ & $\begin{array}{c}-0.3514 * * \\
{[0.1346]}\end{array}$ \\
\hline Demographics at CPS Year $=1980$ & $\begin{array}{c}-0.1930 * * * \\
{[0.0684]}\end{array}$ & $\begin{array}{c}-0.2008 * * * \\
{[0.0692]}\end{array}$ & $\begin{array}{c}-0.3370 * * * \\
{[0.0746]}\end{array}$ & $\begin{array}{c}-0.3985^{* * *} \\
{[0.1428]}\end{array}$ \\
\hline Demographics at CPS Year $=1985$ & $\begin{array}{c}-0.2014 * * * \\
{[0.0618]}\end{array}$ & $\begin{array}{c}-0.2140 * * * \\
{[0.0614]}\end{array}$ & $\begin{array}{c}-0.3348 * * * \\
{[0.0818]}\end{array}$ & $\begin{array}{c}-0.3786^{* *} \\
{[0.1534]}\end{array}$ \\
\hline
\end{tabular}

Number of obs.

1704

1704

1704

1704

\section{State Fixed-Effects}

Cohort Fixed-Effects

$\mathbf{X}$

$\mathbf{X}$

$\mathbf{X}$

State-Race Fixed Effects

State-Specific Time-Trends

State-Cohort Fixed Effects

$\begin{array}{ll}\mathbf{X} & \mathbf{X} \\ \mathbf{X} & \mathbf{X} \\ & \mathbf{X}\end{array}$

$\mathbf{X}$
$\mathbf{X}$
$\mathbf{X}$
$\mathbf{X}$

$\mathbf{X}$

$\mathbf{X}$

$\mathbf{X}$

$\mathbf{X}$

Notes: Early childhood years are defined by the seven years from conception through age 5. Regressions are weighted by the number of relevant CPS individuals aged 18 to 20 residing within a particular state for a given year and ethnic group. Standard errors are clustered at the state-level and are in brackets with statistical significance indicated as follows: $* \mathrm{p}<0.1, * * \mathrm{p}<0.05, * * * \mathrm{p}<0.01$. 
Table 6

Alternative Dropout Estimates - Tests of the Potential Exposure to Medicaid Insurance

Hispanic and White Students Only

\begin{tabular}{|c|c|c|c|c|}
\hline Medicaid Eligibility Definition & Model 1 & Model 2 & Model 3 & Model 4 \\
\hline Limited Core Modeling & $\begin{array}{c}-0.2083 * * * \\
{[0.0401]}\end{array}$ & $\begin{array}{c}-0.2149 * * * \\
{[0.0386]}\end{array}$ & $\begin{array}{c}-0.2579 * * * \\
{[0.0498]}\end{array}$ & $\begin{array}{c}-0.2624 * * * \\
{[0.0811]}\end{array}$ \\
\hline $\begin{array}{l}\text { Lower Bound of Any Coverage: Minimum \% in any single year } \\
\text { (from conception through age 5) }\end{array}$ & $\begin{array}{c}-0.1759 * * * \\
{[0.0320]}\end{array}$ & $\begin{array}{c}-0.1820^{* * *} \\
{[0.0310]}\end{array}$ & $\begin{array}{c}-0.1834 * * * \\
{[0.0421]}\end{array}$ & $\begin{array}{c}-0.2320 * * * \\
{[0.0626]}\end{array}$ \\
\hline $\begin{array}{l}\text { Upper Bound of Any Coverage: Maximum \% in any single year } \\
\text { (from conception through age 5) }\end{array}$ & $\begin{array}{c}-0.0972 * * \\
{[0.0375]}\end{array}$ & $\begin{array}{c}-0.0974 * * \\
{[0.0368]}\end{array}$ & $\begin{array}{c}-0.0982 * * \\
{[0.0420]}\end{array}$ & $\begin{array}{c}-0.2208 * * \\
{[0.0906]}\end{array}$ \\
\hline Conception Only & $\begin{array}{c}-0.1560 * * * \\
{[0.0318]}\end{array}$ & $\begin{array}{c}-0.1620^{* * *} \\
{[0.0305]}\end{array}$ & $\begin{array}{c}-0.1760 * * * \\
{[0.0380]}\end{array}$ & $\begin{array}{c}-0.2400 * * * \\
{[0.0657]}\end{array}$ \\
\hline From Conception Through Age 2 & $\begin{array}{c}-0.2036^{* * *} \\
{[0.0331]}\end{array}$ & $\begin{array}{c}-0.2113^{* * *} \\
{[0.0314]}\end{array}$ & $\begin{array}{c}-0.2528 * * * \\
{[0.0445]}\end{array}$ & $\begin{array}{c}-0.2551 * * * \\
{[0.0742]}\end{array}$ \\
\hline Age 3 to Age 5 & $\begin{array}{c}-0.1364 * * * \\
{[0.0461]}\end{array}$ & $\begin{array}{c}-0.1377 * * * \\
{[0.0453]}\end{array}$ & $\begin{array}{c}-0.1711^{* * *} \\
{[0.0490]}\end{array}$ & $\begin{array}{c}-0.2390 * * * \\
{[0.0881]}\end{array}$ \\
\hline Number of obs. & 1704 & 1704 & 1704 & 1704 \\
\hline State Fixed-Effects & $\mathbf{X}$ & $\mathbf{X}$ & $\mathbf{X}$ & $\mathbf{X}$ \\
\hline Cohort Fixed-Effects & $\mathbf{X}$ & $\mathbf{X}$ & $\mathbf{X}$ & $\mathbf{X}$ \\
\hline State-Race Fixed Effects & & $\mathbf{X}$ & $\mathbf{X}$ & $\mathbf{X}$ \\
\hline $\begin{array}{l}\text { State-Specific Time-Trends } \\
\text { State-Cohort Fixed Effects }\end{array}$ & & & $\mathbf{X}$ & $\mathbf{X}$ \\
\hline
\end{tabular}

Notes: Early childhood years are defined by the seven years from conception through age 5 . Regressions are weighted by the number of relevant CPS individuals aged 18 to 20 residing within a particular state for a given year and ethnic group. Standard errors are clustered at the state-level and are in brackets with statistical significance indicated as follows: $* \mathrm{p}<0.1, * * \mathrm{p}<0.05, * * * \mathrm{p}<0.01$ 
Table 7

Estimated Impact of Medicaid Expansions in Early Childhood on High School Completion Rates Outcome Variable $=$ Four-Year Graduation Rates using Diploma Counts from the Common Core of Data Range Cohorts Analyzed: 1997 to 2010

\begin{tabular}{|c|c|c|c|c|}
\hline \multirow[b]{2}{*}{ Modeling with all Race/Ethnic Groups } & \\
\hline & Model 1 & Model 2 & Model 3 & Model 4 \\
\hline \multirow[t]{2}{*}{$\%$ of Early Childhood Years with Medicaid Eligibility } & $0.1061 * *$ & $0.1294 * * *$ & $0.1004 * *$ & 0.1203 \\
\hline & [0.0467] & {$[0.0464]$} & {$[0.0478]$} & {$[0.0971]$} \\
\hline Number of obs. & 1875 & 1875 & 1875 & 1875 \\
\hline R-Squared & 0.3052 & 0.3387 & 0.3525 & 0.4288 \\
\hline Adjusted R-Squared & 0.2798 & 0.2744 & 0.2453 & 0.0668 \\
\hline Modeling with Hispanic and Whites Only & Model 1a & Model 2a & Model 3a & Model 4a \\
\hline \multirow[t]{2}{*}{$\%$ of Early Childhood Years with Medicaid Eligibility } & $0.1218 * * *$ & $0.1371 * * *$ & $0.0865^{* *}$ & 0.1111 \\
\hline & [0.0413] & [0.0439] & [0.0404] & [0.1129] \\
\hline Number of obs. & 1250 & 1250 & 1250 & 1250 \\
\hline R-Squared & 0.2101 & 0.2294 & 0.2409 & 0.7572 \\
\hline Adjusted R-Squared & 0.1667 & 0.1512 & 0.0831 & 0.4708 \\
\hline State Fixed-Effects & $\mathbf{X}$ & $\mathbf{X}$ & $\mathbf{X}$ & $\mathbf{X}$ \\
\hline Cohort Fixed-Effects & $\mathbf{X}$ & $\mathbf{X}$ & $\mathbf{X}$ & $\mathbf{X}$ \\
\hline State-Race Fixed Effects & & $\mathbf{X}$ & $\mathbf{X}$ & $\mathbf{X}$ \\
\hline State-Specific Time-Trends & & & $\mathbf{X}$ & \\
\hline State-Cohort Fixed Effects & & & & $\mathbf{X}$ \\
\hline
\end{tabular}

Notes: Early childhood years are defined by the seven years from conception through age 5 . Regressions are weighted by the number of enrolled 8 th graders for a given graduation cohort residing within a particular state for a given year and ethnic group. Standard errors are clustered at the state-level and are in brackets with statistical significance indicated as follows: $* \mathrm{p}<0.1, * * \mathrm{p}<0.05, * * * \mathrm{p}<0.01$ 


\section{Appendix A \\ Summary of Key Benchmarks in Medicaid Expansions to Low-Income Children affecting the Graduation Cohorts from the Class of 1997 to the Class of 2010}

\begin{tabular}{|c|c|}
\hline Year & Development \\
\hline 1965 & $\begin{array}{l}\text { The Medicaid and Medicare programs are signed into law in June and established as a volunteer federal-state partnership } \\
\text { in which participating states receive grants to cover mandatory populations (e.g. AFDC recipients) and services. }\end{array}$ \\
\hline 1967 & $\begin{array}{l}\text { Social Security Amendments mandate Early and Periodic Screening, Diagnostic, and Treatment (EPSDT) services for all } \\
\text { children up to age } 21 .\end{array}$ \\
\hline 1972 & Excluding Arizona, all states have established Medicaid programs. \\
\hline 1981 & $\begin{array}{l}\text { Despite the Reagan Administration's failure to convert Medicaid to a block grant, the Omnibus Reconciliation Act of } \\
1981 \text { (OBRA81) decreases federal matching payments. This affects fiscal years } 1982 \text { to } 1984 \text { and leads to coverage } \\
\text { decreases in some states for single mothers pregnant for the first time. }\end{array}$ \\
\hline 1982 & Arizona becomes the last state to establish a Medicaid program. \\
\hline 1984 & $\begin{array}{l}\text { The Deficit Reduction Act of } 1984 \text { (DEFRA84) affects coverage to children under two mechanisms. First, coverage for } \\
\text { children born after September 20, } 1983 \text { is mandated for qualifying AFDC families, up through age } 5 \text {. Secondly, } \\
\text { Medicaid coverage for first-time pregnant women eligible for AFDC and pregnant women in two-parent unemployed } \\
\text { families becomes mandatory. These policies take effect in } 1985 \text { and essentially eliminate the family structure restriction } \\
\text { on Medicaid receipt for all pregnant women. }\end{array}$ \\
\hline 1985 & $\begin{array}{l}\text { Under the Consolidated Omnibus Budget Reconciliation Act of } 1985 \text { (COBRA85), coverage for all remaining AFDC } \\
\text { eligible pregnant women is now mandatory. Moreover, this act extended DEFRA } 84 \text { coverage for children up through age } \\
5 \text {, effective immediately. }\end{array}$ \\
\hline 1986 & $\begin{array}{l}\text { Under the Omnibus Reconciliation Act of } 1986 \text { (OBRA86), the federal government allows states to cover pregnant } \\
\text { women and infants (up to age 1) up to } 100 \text { percent of the federal poverty line (FPL). As another Medicaid option, } \\
\text { insurance coverage for children up to age } 5 \text { is expanded to } 100 \% \text { of the FPL which can be phased in over time. }\end{array}$ \\
\hline 1987 & $\begin{array}{l}\text { The Omnibus Reconciliation Act of } 1987 \text { allowed states to again expand medical coverage to pregnant women and } \\
\text { infants (up to age 1) for families with incomes up to } 185 \text { percent of the federal poverty line. }\end{array}$ \\
\hline 1988 & $\begin{array}{l}\text { The Medicare Catastrophic Coverage Act of } 1988 \text { (MCCA88) mandates that states begin phasing in coverage for } \\
\text { pregnant women and infants from families with income levels equal to or below } 100 \% \text { of the federal poverty line. }\end{array}$ \\
\hline 1989 & $\begin{array}{l}\text { The Omnibus Reconciliation Act of } 1989 \text { (OBRA89) further mandated coverage for pregnant women and children under } \\
\text { the age of } 6 \text { in families with income at or below } 133 \text { percent of the federal poverty line, regardless of whether they also } \\
\text { were receiving AFDC benefits. Moreover, it required coverage up to age } 6 \text { for children in families below 133\% of the } \\
\text { FPL. This act effectively decoupled Medicaid for children from AFDC. } \\
\text { Additionally - and importantly - the federal government mandated that states must treat any issues identified during } \\
\text { EPSDT screening, even if these procedure were not traditionally covered under the state's Medicaid program. }\end{array}$ \\
\hline
\end{tabular}

Primary Sources:

Kaiser Family Foundation: http://kff.org/medicaid/timeline/medicaid-a-timeline-of-key-developments/

U.S. General Accounting Office (GAO) Reports: http://gao.gov/products/HRD-91-78 


\section{Appendix B - Technical Details}

\section{Medicaid Eligibility Simulation}

Before the decoupling of child Medicaid and AFDC, the primary basis for Medicaid qualification was AFDC receipt. Given this, Medicaid eligibility determination in the early period is straightforward: only children in singleparent households qualified for care if their family income - less certain disregards - fell below the state's payment standards. As noted, these mandated thresholds varied greatly across states. During this early period, some states did make allowances for children in two parent households with an unemployed parent (AFDC-UP), as well as for "Ribicoff children" which, in this case, were typically teens who would have qualified for AFDC under their own income thresholds but did not qualify in the traditional manner due to family structure issues (e.g. they still lived with their parents). Archived documents outlined reveal states participating in these programs.

Another wrinkle in estimation during this early period was whether an unborn child counted in AFDC determination. Before DEFRA 1984, which mandated coverage of the unborn, states differed greatly in their positions especially when considering a single mother pregnant for the first time. When the unborn child did not count, these mothers typically failed to receive coverage during their pregnancy because single individuals without dependents rarely qualified for benefits. Preceding the federal mandate, a number of states incorporated programs to support single mothers pregnant for the first time at the point of verification by medical professionals. Again, there was wide variation in the implementation of these programs. All of these changes were documented and incorporated into the simulation procedure.

Finally, the last step in the collection of legislative procedures was to acquire all of the effective dates and poverty thresholds for the state Medicaid expansions to pregnant women, infants, and children in the late 1980s and early 1990s which effectively decoupled child Medicaid from AFDC. Documents outlining these transitions are obtainable through the variety of resources (see list in the data section). These documents, in turn, can then be used to compile a database of Medicaid eligibility requirements by state and year for young children in all states from 1975 to 1997.

Tables below disclose how specific rules governing qualification for either AFDC or Medicaid were handled in the simulation:

Issue: In the early period, AFDC receipt is the general basis for Medicaid receipt

\begin{tabular}{|l|l|l|l|}
\hline \hline Category & Sub-Category & Details & Source(s) \\
\hline \hline \multirow{5}{*}{$\begin{array}{l}\text { Definition of a } \\
\text { family unit }\end{array}$} & General issues & $\begin{array}{l}\text { The CPS contained detailed information intra-family } \\
\text { relationships. Thus, it is typically possible to link the } \\
\text { child to their parent(s), which can then be used in } \\
\text { establishing the size of the family unit applicable for } \\
\text { AFDC eligibility. To mitigate the issue of the } \\
\text { endogeneity of family size due to social welfare } \\
\text { policies, families with either 1, 2, or 3 children are used } \\
\text { in simulations. }\end{array}$ & $\begin{array}{l}\text { March Current } \\
\text { Population Survey } \\
\text { (various years) }\end{array}$ \\
\cline { 2 - 5 } & Unborn children & $\begin{array}{l}\text { Before DEFRA 1984 - and effective in 1985 - a limited } \\
\text { number of states counted the unborn child as part of the } \\
\text { family unit in the determination of AFDC eligibility. } \\
\text { Thus, the family size would be smaller by one for } \\
\text { pregnant women in states not counting unborn children. } \\
\text { This applies to the conception year only. }\end{array}$ & $\begin{array}{l}\text { Medicaid Program } \\
\text { Characteristics (various } \\
\text { years) }\end{array}$ \\
\hline
\end{tabular}




\begin{tabular}{|c|c|c|c|}
\hline \multirow{5}{*}{$\begin{array}{l}\text { Income } \\
\text { requirements }\end{array}$} & \multirow{4}{*}{$\begin{array}{l}\text { Earnings } \\
\text { Allowances }\end{array}$} & $\begin{array}{l}\text { Before OBRA 1981: although there were no } \\
\text { standardized allowances before 1981, Currie and Gruber } \\
\text { assume that the levels were the same as those mandated } \\
\text { under OBRA 1981. }\end{array}$ & \multirow{4}{*}{$\begin{array}{l}\text { Currie and Gruber } \\
(1994)\end{array}$} \\
\hline & & $\begin{array}{l}\text { OBRA 1981: starting in October } 1981 \text {, the standardized } \\
\text { allowances per month for work expenses was } \$ 75 \text {, while } \\
\text { states allowed up to } \$ 160 \text { per month per child for child } \\
\text { care. }\end{array}$ & \\
\hline & & $\begin{array}{l}\text { Family Support Act of 1988: effective October } 1989 \text {, } \\
\text { allowances were increased to } \$ 90 \text { per month for work } \\
\text { expenses and } \$ 175 \text { dollars per child per month for child } \\
\text { care. }\end{array}$ & \\
\hline & & $\begin{array}{l}30 \text { and One-Third: at its inception, this work incentive } \\
\text { feature allowed families to keep the first } \$ 30 \text { of earned } \\
\text { income, } 1 / 3 \text { of the remainder, while the remaining } 2 / 3 \\
\text { lead directly to a reduction in AFDC benefits. See } \\
\text { Currie and Gruber for details regarding the evolution of } \\
\text { this program. }\end{array}$ & \\
\hline & $\begin{array}{l}\text { Binding } \\
\text { Constraint for } \\
\text { Qualification }\end{array}$ & $\begin{array}{l}\text { Since the vast majority of the state's payment standards } \\
\text { were well below the needs standards, the binding } \\
\text { constraint for AFDC qualification was that a family } \\
\text { unit's gross earnings - minus earnings allowances } \\
\text { outlined in Currie and Gruber (1994) - were less than or } \\
\text { equal to the state's payment standard. }\end{array}$ & $\begin{array}{l}\text { Historical payment } \\
\text { standards were available } \\
\text { through state-level data } \\
\text { provided by the } \\
\text { University of Kentucky } \\
\text { Center for Poverty } \\
\text { Research. }\end{array}$ \\
\hline
\end{tabular}

Issue: As Medicaid becomes delinked from AFDC, other groups become eligible for coverage

\begin{tabular}{|c|c|c|c|}
\hline Category & Sub-Category & Details & Source(s) \\
\hline \multirow{4}{*}{$\begin{array}{l}\text { General } \\
\text { expansions for } \\
\text { all women, } \\
\text { infants, and } \\
\text { children. }\end{array}$} & DEFRA 1984 & $\begin{array}{l}\text { Medicaid coverage is mandated for children in AFDC } \\
\text { qualifying families born after September } 20,1983 \\
\text { through age } 5\end{array}$ & $\begin{array}{l}\text { Kaiser Family } \\
\text { Foundation }\end{array}$ \\
\hline & COBRA 1985 & $\begin{array}{l}\text { All pregnant women who meet income requirements } \\
\text { were now eligible for Medicaid, regardless of family } \\
\text { structure or the presence of other children. DEFRA } \\
\text { coverage for children is expanded for all children at or } \\
\text { below the age of } 5 \text { residing in AFDC families. }\end{array}$ & $\begin{array}{l}\text { Currie and Gruber } \\
\text { (1994) } \\
\text { Kaiser Family } \\
\text { Foundation }\end{array}$ \\
\hline & OBRA 1986 & $\begin{array}{l}\text { States were given the option to expand the income } \\
\text { thresholds for Medicaid eligibility regardless of family } \\
\text { structure type. As an option, states are allowed to } \\
\text { expand coverage to children up to age } 5 \text { residing in } \\
\text { families at or below } 100 \% \text { of the federal poverty line. }\end{array}$ & \multirow{2}{*}{$\begin{array}{l}\text { Hill (1992); } \\
\text { The National Governors } \\
\text { Association MCH } \\
\text { Updates (various years); }\end{array}$} \\
\hline & OBRA 1987 & $\begin{array}{l}\text { States were allowed to increase the income thresholds } \\
\text { up to } 185 \% \text { of the poverty line for pregnant women and } \\
\text { infants. }\end{array}$ & \\
\hline
\end{tabular}




\begin{tabular}{|c|c|c|c|}
\hline & OBRA 1988 & $\begin{array}{l}\text { States were mandated to cover pregnant women, infants, } \\
\text { and children up to } 133 \% \text { of the poverty line by April } \\
1990 \text {, again regardless of family structure type. Some } \\
\text { states choose thresholds above this mandated minimum. }\end{array}$ & Foundation \\
\hline $\begin{array}{l}\text { Single mothers } \\
\text { pregnant for the } \\
\text { first time }\end{array}$ & $\begin{array}{l}\text { Unborn children } \\
\text { and benefits } \\
\text { qualification }\end{array}$ & $\begin{array}{l}\text { DEFRA } 1984 \text { mandated coverage for all pregnant } \\
\text { women qualifying for AFDC under the typical } \\
\text { mechanisms, regardless of whether she already had } \\
\text { children. This policy became effective in } 1985 .\end{array}$ & $\begin{array}{l}\text { Currie and Gruber } \\
(1994)\end{array}$ \\
\hline $\begin{array}{l}\text { Programs for } \\
\text { married women } \\
\text { below income } \\
\text { requirements }\end{array}$ & DEFRA 1984 & $\begin{array}{l}\text { Coverage of all pregnant women in AFDC-UP type } \\
\text { families now required. Before this mandate, states } \\
\text { different in their timing and coverage of AFDC-UP type } \\
\text { families. }\end{array}$ & $\begin{array}{l}\text { Analysis of State } \\
\text { Medicaid Program } \\
\text { Characteristics (various } \\
\text { years) }\end{array}$ \\
\hline Minors & Ribicoff children & $\begin{array}{l}\text { Since the goal was to estimate the number of child-years } \\
\text { potentially covered by Medicaid, pregnant teens were } \\
\text { considered as their own family unit and, consequently, } \\
\text { the child qualified based upon the teenage mother's } \\
\text { income (and not the larger family unit that they may } \\
\text { have resided in). This simplifying assumption was } \\
\text { made because historical details regarding state-level } \\
\text { Ribicoff programs is limited. }\end{array}$ & \multirow[t]{2}{*}{$\begin{array}{l}\text { Currie and Gruber } \\
\text { (1994) }\end{array}$} \\
\hline $\begin{array}{l}\text { Other } \\
\text { categories }\end{array}$ & $\begin{array}{l}\text { Medically needy } \\
\text { program }\end{array}$ & $\begin{array}{l}\text { Lacking information on Medical expenditures at the } \\
\text { household level, it is difficult to identify medically } \\
\text { needy families. Consequently, they were not } \\
\text { incorporated into the simulations. }\end{array}$ & \\
\hline
\end{tabular}

\section{8-20 Year Old Dropout Rate using Current Population Survey Data}

Sharing the same underlying data - the CPS - simulated Medicaid eligibility and the 18 to 20 year old dropout rates are estimated in a similar manner. Given the necessity of the smoothing technique already discussed, as well limiting the CPS respondents to only those individuals born in the United States, the 18-20 year old Dropout Rate in a single CPS month is calculated as:

$$
(18-20 \text { Year Old Dropout Rate })_{s c}=\sum_{i=1}^{n} \frac{\text { CPS Weight }}{\text { isc } *(\text { No Degree, } \text { Not Enrolled })_{\text {isc }}}
$$

where: $\quad$ i represents a CPS observation for a relevant 18 to 20 year old;

No Degree, Not Enrolled identifies respondents who did not complete high school and are no longer enrolled in school - this defines a dropout; and

CPS Weight are the person weights reported by the individual CPS survey. 
As noted in the primary text, dropout rates are estimated using monthly data from the Current Population Survey. Thus, instead of only a single month, 12 distinct CPS samples actually feed into a single cohort calculation. Since the traditional secondary school year usual ends around June, rates for a graduation cohort are estimated using the July CPS of a particular year through the June CPS of the next. For example, the sample used to calculate dropout rates for the class of 2000 are taken from the July 2000 CPS through the June 2001 CPS. These twelve individuals samples, along with the estimation using 18 to 20 year olds, ensures that a sufficient sample size produces the most reliable statistics.

\section{Four-Year Graduation Rates using the Common Core of Data}

Although it is one of the best measure currently available to researchers, this choice of four-year graduation rate using CCD data is not an uncontroversial because of two possible sources of measurement error. Before proceeding to the issues associated with the four-year graduation rate measure, it is useful to first discuss how a perfect measure would be constructed and then reveal how the four-year graduation rate potentially falls short. In an ideal thought experiment, all students would (1) enter 9th grade at the same age and (2) never repeat grades but simply drop out in a readily identifiable manner. Under this scenario and with accurate administrative data, once could construct a graduation rate measure for state $(\mathrm{s})$ at time $(\mathrm{t})$ as:

$$
(\text { Graduation Rate })_{s t}=\frac{(\# \text { Actual Grads })_{s t}}{(\# \text { Potential Grads })_{s t}}
$$

Unfortunately, the two conditions listed above are not met in practice. Estimation of high school graduation rates can be surprisingly challenging, due largely in part to some students taking longer than the standard of 4 years to finish their diploma - an issue of degree duration - and because other students remain in administrative systems longer than 4 years but never finish their degrees - a matter of grade retention. To simplify these issues, I follow Heckman and LaFontaine (2010) in their calculation of the four-year graduation rate.

While issues associated with degree duration are discussed in detail in the primary text, the second form of measurement error, grade retention, invokes less controversial assumptions. Importantly, it also relates to how a graduation cohort is determined in this analysis. Returning to the ideal equation above, calculation of a graduation rate takes some measure of completion as the numerator and some baseline measure of potential graduates as the denominator. While the exclusion of GED holders from the high school graduation calculation is simple essentially one just subtracts these individuals from the numerator - the definition of the denominator is more challenging, given the problem of grade retention and the definition of a cohort. Since students who are held back in high school are much more likely to drop out, it is important to properly control for these individuals across cohorts so that they are not counted multiple times. ${ }^{[1]}$

To avoid the problems associated with grade retention, Warren (2005) proposed that the number of enrolled Grade 8 students be used as a proxy for the number of incoming Grade 9 students for a particular graduation cohort, ${ }^{[2]}$ an approach was later employed by Heckman and LaFontaine (2010). I follow this approach in my analysis. This implies that the cohort is defined by the year in which they graduate and not some other measure, such as the year they enter $9^{\text {th }}$ grade. ${ }^{[3]}$ With the lag structure required to estimate the graduation rate under this process, the first cohort for which a graduation rate can be estimated using the CCD data is the class of 1997. Conveniently, this covers a minimal pre-period before the rules governing child Medicaid coverage were significantly expanded in all states, which means that I can establish a baseline of graduation rates before estimating the impacts of the marked increases in Medicaid eligibility during early childhood. Moreover, trends and estimates are consistent with those presented by Heckman and LaFontaine (2010). 


\section{Section Endnotes:}

[1] As outlined by Warren (2005), a flawed estimation methodology using CCD data is to simply take the number of graduating seniors at time $t$ and to divide by the number of freshman reported at time $t-3$. The problem with this approach is that students can stay registered in Grade 9 when they remain in the system, attend school sparingly, and do not progress past Grade 9; this is true especially with the end of social promotion policies. Thus, including these individuals in the Grade 9 calculation could lead to the double-counting of select individuals and a dilution of the graduation rate.

[2] Under this assumption, graduation rates are calculated as the number of high school graduates at time $t$ divided by the number of 8th graders enrolled at time $\mathrm{t}-4$, an estimation strategy which can reduce the bias from repeating students.

[3] Thus, for example, students graduating in 2010 are referred to as the class of 2010 even though some individuals may have originally had other anticipated graduation years (e.g. the class of 2009 for those repeating one year). 
Appendix - Table C1

Estimated Percent of Early Childhood Years with Medicaid Eligibility

By Graduation Cohort - From Conception through Age 5

All Students

\begin{tabular}{|c|c|c|c|c|c|c|c|c|c|c|c|c|c|c|c|c|c|}
\hline State & 1994 & 1995 & 1996 & 1997 & 1998 & 1999 & 2000 & 2001 & 2002 & 2003 & 2004 & 2005 & 2006 & 2007 & 2008 & 2009 & 2010 \\
\hline Alabama & $.7 \%$ & $.4 \%$ & $.2 \%$ & $.9 \%$ & $1.6 \%$ & $2.3 \%$ & $2.7 \%$ & $3.3 \%$ & $4.1 \%$ & $7.5 \%$ & $0.7 \%$ & $4.8 \%$ & $0.4 \%$ & $4.2 \%$ & $37.5 \%$ & $38.6 \%$ & $38.7 \%$ \\
\hline Alaska & $2.7 \%$ & $12.7 \%$ & $2.9 \%$ & $16.0 \%$ & $20.0 \%$ & $23.9 \%$ & $27.2 \%$ & $31.2 \%$ & $34.8 \%$ & $36.1 \%$ & $37.3 \%$ & $40.9 \%$ & $41.6 \%$ & $43.0 \%$ & $44.0 \%$ & $45.3 \%$ & $45.3 \%$ \\
\hline Arizona & $0.0 \%$ & $0.0 \%$ & $1.6 \%$ & $4.4 \%$ & $7.3 \%$ & $10.5 \%$ & $13.4 \%$ & $16.5 \%$ & $20.3 \%$ & $22.8 \%$ & $27.1 \%$ & $30.9 \%$ & $33.4 \%$ & $36.3 \%$ & $37.7 \%$ & $39.1 \%$ & $39.4 \%$ \\
\hline Arkansas & $10.6 \%$ & $10.4 \%$ & $10.2 \%$ & $11.0 \%$ & $11.9 \%$ & $12.9 \%$ & $13.6 \%$ & $14.9 \%$ & $17.8 \%$ & $20.7 \%$ & $26.7 \%$ & $30.7 \%$ & $33.8 \%$ & $36.3 \%$ & $37.5 \%$ & $38.6 \%$ & $38.7 \%$ \\
\hline California & $19.3 \%$ & $19.1 \%$ & $18.7 \%$ & $20.2 \%$ & $22.5 \%$ & $24.8 \%$ & $26.9 \%$ & $29.0 \%$ & $31.4 \%$ & $32.4 \%$ & $33.0 \%$ & $35.8 \%$ & $36.4 \%$ & $39.0 \%$ & $41.3 \%$ & $43.4 \%$ & $43.3 \%$ \\
\hline Colorado & $7.2 \%$ & $16.7 \%$ & $16.2 \%$ & $17.0 \%$ & $18.3 \%$ & $19.4 \%$ & $20.2 \%$ & $21.3 \%$ & $22.5 \%$ & $24.5 \%$ & $26.6 \%$ & $29.8 \%$ & $31.9 \%$ & $34.5 \%$ & $36.6 \%$ & $38.6 \%$ & $38.7 \%$ \\
\hline Connecticut & $18.7 \%$ & $18.4 \%$ & $18.0 \%$ & $19.4 \%$ & $21.6 \%$ & $23.8 \%$ & $25.6 \%$ & $28.2 \%$ & $30.4 \%$ & $31.4 \%$ & $32.2 \%$ & $34.7 \%$ & $37.6 \%$ & $40.5 \%$ & $44.8 \%$ & $46.3 \%$ & $47.8 \%$ \\
\hline Delaware & $16.8 \%$ & $16.3 \%$ & $15.5 \%$ & $16.0 \%$ & $16.8 \%$ & $17.8 \%$ & $18.5 \%$ & $19.4 \%$ & $20.6 \%$ & $23.0 \%$ & $27.7 \%$ & $31.0 \%$ & $33.4 \%$ & $36.3 \%$ & $38.3 \%$ & $40.3 \%$ & $41.8 \%$ \\
\hline District of & $17.4 \%$ & $16.8 \%$ & $16.1 \%$ & $16.6 \%$ & $17.8 \%$ & $18.7 \%$ & $19.7 \%$ & $21.0 \%$ & $22.5 \%$ & $22.9 \%$ & $28.1 \%$ & $31.4 \%$ & $33.5 \%$ & $35.3 \%$ & $38.1 \%$ & $40.8 \%$ & $43.3 \%$ \\
\hline Florida & $11.4 \%$ & $11.2 \%$ & $11.1 \%$ & $12.3 \%$ & $13.6 \%$ & $14.9 \%$ & $16.0 \%$ & $17.3 \%$ & $20.2 \%$ & $22.7 \%$ & $27.1 \%$ & $30.5 \%$ & $33.2 \%$ & $36.8 \%$ & $38.5 \%$ & $40.1 \%$ & $41.2 \%$ \\
\hline Georgia & $10.4 \%$ & $10.4 \%$ & $10.4 \%$ & $11.4 \%$ & $12.7 \%$ & $13.9 \%$ & $14.9 \%$ & $16.4 \%$ & $17.8 \%$ & $20.4 \%$ & $25.1 \%$ & $29.0 \%$ & $31.8 \%$ & $34.9 \%$ & $37.5 \%$ & $38.6 \%$ & $39.2 \%$ \\
\hline Hawaii & $20.2 \%$ & $19.7 \%$ & $18.9 \%$ & $19.9 \%$ & $21.4 \%$ & $22.8 \%$ & $23.9 \%$ & $25.4 \%$ & $27.4 \%$ & $29.2 \%$ & $31.1 \%$ & $34.7 \%$ & $37.0 \%$ & $41.4 \%$ & $45.1 \%$ & $48.0 \%$ & $52.3 \%$ \\
\hline Idaho & $12.7 \%$ & $12.4 \%$ & $12.3 \%$ & $13.6 \%$ & $15.0 \%$ & $16.3 \%$ & $17.4 \%$ & $18.8 \%$ & $20.1 \%$ & $22.3 \%$ & $25.1 \%$ & $28.4 \%$ & $31.2 \%$ & $34.1 \%$ & $36.6 \%$ & $38.6 \%$ & $38.7 \%$ \\
\hline Illinois & $5.9 \%$ & $6.4 \%$ & $5.8 \%$ & $6.2 \%$ & $17.2 \%$ & $18.2 \%$ & $19.0 \%$ & $20.0 \%$ & $21.1 \%$ & $3.2 \%$ & $26.0 \%$ & $9.3 \%$ & $32.6 \%$ & $5.3 \%$ & $7.5 \%$ & $5 \%$ & $38.7 \%$ \\
\hline Indiana & $.4 \%$ & $11.3 \%$ & $1.2 \%$ & $2.4 \%$ & $13.8 \%$ & $15.1 \%$ & $16.1 \%$ & $17.6 \%$ & $18.9 \%$ & $21.3 \%$ & $24.3 \%$ & $28.1 \%$ & $30.6 \%$ & $3.6 \%$ & $6.1 \%$ & $39.2 \%$ & $39.7 \%$ \\
\hline Iowa & $7.8 \%$ & $17.4 \%$ & $6.7 \%$ & $7.3 \%$ & $18.5 \%$ & $19.6 \%$ & $20.4 \%$ & $21.6 \%$ & $22.8 \%$ & $24.7 \%$ & $27.1 \%$ & $31.1 \%$ & $34.5 \%$ & $38.6 \%$ & $2.2 \%$ & $43.4 \%$ & $43.3 \%$ \\
\hline Kansas & $18.5 \%$ & $7.9 \%$ & $7.1 \%$ & $7.7 \%$ & $18.9 \%$ & $20.0 \%$ & $21.0 \%$ & $22.0 \%$ & $23.6 \%$ & $25.6 \%$ & $27.5 \%$ & $31.3 \%$ & $33.2 \%$ & $36.1 \%$ & $38.5 \%$ & $40.1 \%$ & $40.2 \%$ \\
\hline Kentucky & $14.2 \%$ & $13.3 \%$ & $12.3 \%$ & $12.5 \%$ & $13.1 \%$ & $13.8 \%$ & $14.6 \%$ & $15.8 \%$ & $17.0 \%$ & $19.6 \%$ & $24.4 \%$ & $30.0 \%$ & $33.7 \%$ & $37.0 \%$ & $39.9 \%$ & $41.8 \%$ & $43.3 \%$ \\
\hline Louisiana & $11.1 \%$ & $10.9 \%$ & $10.8 \%$ & $11.8 \%$ & $13.0 \%$ & $13.9 \%$ & $14.8 \%$ & $15.9 \%$ & $18.7 \%$ & $21.4 \%$ & $24.6 \%$ & $28.2 \%$ & $31.2 \%$ & $34.6 \%$ & $37.5 \%$ & $38.6 \%$ & $38.7 \%$ \\
\hline Maine & $12.5 \%$ & $12.9 \%$ & $13.5 \%$ & $15.2 \%$ & $17.4 \%$ & $19.5 \%$ & $20.8 \%$ & $22.4 \%$ & $24.5 \%$ & $26.4 \%$ & $28.2 \%$ & $31.9 \%$ & $36.2 \%$ & $40.0 \%$ & $43.3 \%$ & $43.4 \%$ & $43.3 \%$ \\
\hline Maryland & $16.7 \%$ & $16.3 \%$ & $15.7 \%$ & $16.4 \%$ & $17.5 \%$ & $18.5 \%$ & $19.5 \%$ & $20.7 \%$ & $22.1 \%$ & $24.3 \%$ & $26.5 \%$ & $31.5 \%$ & $33.6 \%$ & $39.3 \%$ & $43.6 \%$ & $47.7 \%$ & $49.2 \%$ \\
\hline Massachuse & $18.6 \%$ & $18.2 \%$ & $17.5 \%$ & $18.2 \%$ & $19.5 \%$ & $20.9 \%$ & $22.4 \%$ & $24.0 \%$ & $26.0 \%$ & $27.8 \%$ & $29.7 \%$ & $32.8 \%$ & $37.1 \%$ & $40.5 \%$ & $43.3 \%$ & $43.4 \%$ & $43.3 \%$ \\
\hline Michigan & $19.3 \%$ & $18.8 \%$ & $18.2 \%$ & $19.1 \%$ & $20.6 \%$ & $22.3 \%$ & $23.5 \%$ & $25.2 \%$ & $27.0 \%$ & $28.5 \%$ & $30.2 \%$ & $35.7 \%$ & $39.6 \%$ & $43.0 \%$ & $43.8 \%$ & $44.3 \%$ & $44.8 \%$ \\
\hline Minnesota & $19.2 \%$ & $18.8 \%$ & $18.2 \%$ & $19.5 \%$ & $21.6 \%$ & $23.6 \%$ & $25.1 \%$ & $26.8 \%$ & $28.6 \%$ & $29.9 \%$ & $30.7 \%$ & $33.6 \%$ & $41.1 \%$ & $48.0 \%$ & $4.7 \%$ & $8.5 \%$ & $60.8 \%$ \\
\hline Mississippi & $9.9 \%$ & $9.7 \%$ & $9.7 \%$ & $10.2 \%$ & $10.8 \%$ & $11.4 \%$ & $12.0 \%$ & $12.9 \%$ & $13.8 \%$ & $16.9 \%$ & $22.8 \%$ & $29.0 \%$ & $35.1 \%$ & $40.5 \%$ & $3.3 \%$ & $1 \%$ & $43.3 \%$ \\
\hline $\mathrm{M}$ & $\%$ & $\%$ & $14.6 \%$ & 6 & $o$ & $\%$ & $\%$ & $\%$ & 0 & $.7 \%$ & $26.9 \%$ & & $\%$ & $6.3 \%$ & $\%$ & & $\%$ \\
\hline Montana & $.9 \%$ & $15.0 \%$ & $.1 \%$ & $.9 \%$ & $.2 \%$ & $\%$ & $.8 \%$ & $\%$ & $22.3 \%$ & $24.2 \%$ & $26.7 \%$ & $\%$ & $\%$ & $4.5 \%$ & $5 \%$ & $5 \%$ & $\%$ \\
\hline Nebraska & $17.7 \%$ & $17.4 \%$ & $.8 \%$ & $17.6 \%$ & $18.7 \%$ & $19.7 \%$ & $20.5 \%$ & $21.5 \%$ & $2.6 \%$ & $24.6 \%$ & $27.5 \%$ & $30.7 \%$ & $2.8 \%$ & $5.4 \%$ & $7.5 \%$ & $8.6 \%$ & $38.7 \%$ \\
\hline Nevada & $12.1 \%$ & $11.9 \%$ & $11.8 \%$ & $12.8 \%$ & $14.0 \%$ & $15.4 \%$ & $16.5 \%$ & $18.1 \%$ & $19.7 \%$ & $22.2 \%$ & $25.3 \%$ & $28.7 \%$ & $31.2 \%$ & $34.1 \%$ & $36.4 \%$ & $38.6 \%$ & $38.7 \%$ \\
\hline New Hampshire & $12.2 \%$ & $12.0 \%$ & $11.9 \%$ & $13.4 \%$ & $15.4 \%$ & $17.2 \%$ & $18.7 \%$ & $21.0 \%$ & $23.2 \%$ & $25.2 \%$ & $27.6 \%$ & $31.2 \%$ & $33.2 \%$ & $36.6 \%$ & $39.3 \%$ & $42.2 \%$ & $44.3 \%$ \\
\hline New Jersey & $17.7 \%$ & $17.2 \%$ & $16.5 \%$ & $17.1 \%$ & $18.5 \%$ & $19.8 \%$ & $20.7 \%$ & $22.1 \%$ & $23.4 \%$ & $23.6 \%$ & $26.0 \%$ & $30.3 \%$ & $32.9 \%$ & $35.3 \%$ & $36.5 \%$ & $39.2 \%$ & $41.7 \%$ \\
\hline New Mexico & $11.6 \%$ & $11.5 \%$ & $11.4 \%$ & $12.7 \%$ & $14.1 \%$ & $15.3 \%$ & $16.4 \%$ & $17.7 \%$ & $19.1 \%$ & $21.5 \%$ & $27.2 \%$ & $30.6 \%$ & $33.2 \%$ & $36.3 \%$ & $37.5 \%$ & $41.6 \%$ & $44.7 \%$ \\
\hline New York & $19.4 \%$ & $18.9 \%$ & $18.3 \%$ & $19.5 \%$ & $21.2 \%$ & $23.0 \%$ & $24.4 \%$ & $26.1 \%$ & $27.9 \%$ & $28.3 \%$ & $29.5 \%$ & $32.5 \%$ & $33.6 \%$ & $37.9 \%$ & $40.6 \%$ & $43.4 \%$ & $43.3 \%$ \\
\hline North Carolina & $11.0 \%$ & $10.8 \%$ & $10.7 \%$ & $11.6 \%$ & $12.8 \%$ & $13.9 \%$ & $14.9 \%$ & $16.3 \%$ & $17.6 \%$ & $20.3 \%$ & $26.8 \%$ & $30.3 \%$ & $33.1 \%$ & $36.8 \%$ & $39.6 \%$ & $42.3 \%$ & $43.3 \%$ \\
\hline North Dakota & $12.6 \%$ & $12.4 \%$ & $12.4 \%$ & $14.0 \%$ & $16.1 \%$ & $17.9 \%$ & $19.4 \%$ & $21.1 \%$ & $23.0 \%$ & $24.8 \%$ & $27.2 \%$ & $30.3 \%$ & $32.3 \%$ & $34.7 \%$ & $36.8 \%$ & $38.6 \%$ & $38.7 \%$ \\
\hline Ohio & $16.8 \%$ & $16.3 \%$ & $15.7 \%$ & $16.2 \%$ & $17.1 \%$ & $18.0 \%$ & $18.7 \%$ & $19.7 \%$ & $20.9 \%$ & $23.2 \%$ & $25.6 \%$ & $28.9 \%$ & $32.3 \%$ & $35.2 \%$ & $37.5 \%$ & $38.6 \%$ & $38.7 \%$ \\
\hline Oklahoma & $1.6 \%$ & $11.5 \%$ & $11.4 \%$ & $12.7 \%$ & $14.3 \%$ & $15.9 \%$ & $17.1 \%$ & $18.7 \%$ & $20.2 \%$ & $22.5 \%$ & $26.4 \%$ & $31.2 \%$ & $33.5 \%$ & $36.3 \%$ & $37.5 \%$ & $38.6 \%$ & $39.2 \%$ \\
\hline Oregon & $7.7 \%$ & $16.6 \%$ & $5.2 \%$ & $5.9 \%$ & $17.2 \%$ & $18.3 \%$ & $19.9 \%$ & $21.8 \%$ & $23.8 \%$ & $25.6 \%$ & $28.7 \%$ & $31.8 \%$ & $\%$ & $5.8 \%$ & $7.5 \%$ & $8.6 \%$ & $8.7 \%$ \\
\hline Pennsylvania & $18.3 \%$ & $17.7 \%$ & $16.9 \%$ & $17.6 \%$ & $18.8 \%$ & $20.0 \%$ & $21.0 \%$ & $21.9 \%$ & $23.2 \%$ & $25.1 \%$ & $28.4 \%$ & $32.0 \%$ & $33.9 \%$ & $36.3 \%$ & $37.5 \%$ & $38.6 \%$ & $40.1 \%$ \\
\hline Rhode Island & $18.7 \%$ & $18.2 \%$ & $17.7 \%$ & $18.8 \%$ & $20.7 \%$ & $22.5 \%$ & $24.0 \%$ & $25.4 \%$ & $27.5 \%$ & $28.9 \%$ & $30.4 \%$ & $33.3 \%$ & $37.2 \%$ & $40.5 \%$ & $46.6 \%$ & $49.8 \%$ & $52.9 \%$ \\
\hline South Carolina & $10.8 \%$ & $10.5 \%$ & $10.5 \%$ & $11.3 \%$ & $12.4 \%$ & $13.4 \%$ & $14.3 \%$ & $15.2 \%$ & $18.1 \%$ & $21.0 \%$ & $24.7 \%$ & $29.9 \%$ & $32.9 \%$ & $37.8 \%$ & $40.7 \%$ & $43.4 \%$ & $43.3 \%$ \\
\hline South Dakota & $12.8 \%$ & $12.5 \%$ & $12.4 \%$ & $13.8 \%$ & $15.4 \%$ & $16.8 \%$ & $18.1 \%$ & $19.3 \%$ & $20.9 \%$ & $23.0 \%$ & $25.7 \%$ & $29.4 \%$ & $32.7 \%$ & $35.3 \%$ & $37.5 \%$ & $38.6 \%$ & $38.7 \%$ \\
\hline Tennessee & $10.8 \%$ & $10.5 \%$ & $10.4 \%$ & $11.0 \%$ & $11.8 \%$ & $12.7 \%$ & $13.4 \%$ & $14.4 \%$ & $17.3 \%$ & $20.4 \%$ & $25.7 \%$ & $29.4 \%$ & $32.6 \%$ & $36.8 \%$ & $38.5 \%$ & $41.2 \%$ & $42.2 \%$ \\
\hline Texas & $10.1 \%$ & $9.8 \%$ & $9.7 \%$ & $10.5 \%$ & $11.6 \%$ & $12.6 \%$ & $13.5 \%$ & $14.7 \%$ & $15.8 \%$ & $18.8 \%$ & $22.2 \%$ & $28.1 \%$ & $31.1 \%$ & $34.6 \%$ & $37.5 \%$ & $40.2 \%$ & $41.7 \%$ \\
\hline Utah & $16.8 \%$ & $15.8 \%$ & $14.7 \%$ & $15.4 \%$ & $16.6 \%$ & $17.7 \%$ & $19.2 \%$ & $20.9 \%$ & $22.6 \%$ & $24.5 \%$ & $27.0 \%$ & $30.1 \%$ & $33.0 \%$ & $35.5 \%$ & $37.5 \%$ & $38.6 \%$ & $38.7 \%$ \\
\hline Vermont & $19.6 \%$ & $19.3 \%$ & $18.8 \%$ & $20.1 \%$ & $22.2 \%$ & $24.3 \%$ & $25.9 \%$ & $27.2 \%$ & $29.0 \%$ & $30.2 \%$ & $31.3 \%$ & $34.0 \%$ & $39.9 \%$ & $45.5 \%$ & $1.0 \%$ & $3.5 \%$ & $54.6 \%$ \\
\hline Virginia & $11.8 \%$ & $11.7 \%$ & $11.6 \%$ & $12.9 \%$ & $14.7 \%$ & $16.3 \%$ & $17.7 \%$ & $19.5 \%$ & $21.1 \%$ & $23.2 \%$ & $25.9 \%$ & $29.6 \%$ & $32.7 \%$ & $35.3 \%$ & $37.5 \%$ & $38.6 \%$ & $38.7 \%$ \\
\hline Washington & $17.8 \%$ & $16.8 \%$ & $15.6 \%$ & $16.7 \%$ & $18.5 \%$ & $20.3 \%$ & $22.2 \%$ & $24.5 \%$ & $26.7 \%$ & $27.9 \%$ & $29.7 \%$ & $32.6 \%$ & $33.8 \%$ & $37.2 \%$ & $42.3 \%$ & $47.1 \%$ & $49.0 \%$ \\
\hline West Virginia & $16.2 \%$ & $15.6 \%$ & $14.8 \%$ & $15.1 \%$ & $15.6 \%$ & $16.3 \%$ & $17.0 \%$ & $17.5 \%$ & $19.9 \%$ & $22.5 \%$ & $26.6 \%$ & $30.6 \%$ & $34.7 \%$ & $38.3 \%$ & $40.0 \%$ & $40.1 \%$ & $40.2 \%$ \\
\hline Wisconsin & $19.5 \%$ & $19.0 \%$ & $18.5 \%$ & $19.9 \%$ & $22.0 \%$ & $24.1 \%$ & $25.7 \%$ & $27.3 \%$ & $29.0 \%$ & $30.0 \%$ & $31.6 \%$ & $35.0 \%$ & $37.2 \%$ & $39.4 \%$ & $41.3 \%$ & $43.2 \%$ & $44.8 \%$ \\
\hline Wyoming & $12.6 \%$ & $12.4 \%$ & $12.4 \%$ & $13.8 \%$ & $15.4 \%$ & $16.9 \%$ & $18.2 \%$ & $19.7 \%$ & $21.2 \%$ & $23.3 \%$ & $26.1 \%$ & $29.3 \%$ & $32.6 \%$ & $35.3 \%$ & $37.5 \%$ & $38.6 \%$ & $38.7 \%$ \\
\hline
\end{tabular}


Appendix - Table C2

Estimated Percent of Early Childhood Years with Medicaid Eligibility

By Graduation Cohort - From Conception through Age 5 Black Students

\begin{tabular}{|c|c|c|c|c|c|c|c|c|c|c|c|c|c|c|c|c|c|}
\hline State & 1994 & 1995 & 1996 & 1997 & 1998 & 1999 & 2000 & 2001 & 2002 & 2003 & 2004 & 2005 & 2006 & 2007 & 2008 & 2009 & 2010 \\
\hline Alabama & $.1 \%$ & $.2 \%$ & $.9 \%$ & $5.1 \%$ & $.9 \%$ & $.1 \%$ & $.0 \%$ & $.7 \%$ & $.0 \%$ & $1.8 \%$ & $5.4 \%$ & $1.5 \%$ & $8.6 \%$ & $3.8 \%$ & $67.1 \%$ & $67.9 \%$ & $7.9 \%$ \\
\hline Alaska & $0.6 \%$ & $40.8 \%$ & $41.2 \%$ & $43.5 \%$ & $47.1 \%$ & $50.8 \%$ & $53.4 \%$ & $58.4 \%$ & $62.5 \%$ & $64.2 \%$ & $65.4 \%$ & $69.0 \%$ & $70.1 \%$ & $72.2 \%$ & $72.5 \%$ & $73.2 \%$ & $73.3 \%$ \\
\hline Arizona & $0.0 \%$ & $0.0 \%$ & $5.2 \%$ & $11.3 \%$ & $17.9 \%$ & $24.6 \%$ & $30.8 \%$ & $38.4 \%$ & $45.5 \%$ & $48.7 \%$ & $53.7 \%$ & $59.3 \%$ & $62.7 \%$ & $66.6 \%$ & $67.1 \%$ & $68.1 \%$ & $68.3 \%$ \\
\hline Arkansas & $35.8 \%$ & $35.4 \%$ & $35.0 \%$ & $35.1 \%$ & $35.5 \%$ & $6.2 \%$ & $36.3 \%$ & $38.3 \%$ & $41.9 \%$ & $45.5 \%$ & $53.3 \%$ & $59.1 \%$ & $63.3 \%$ & $66.6 \%$ & $57.1 \%$ & $67.9 \%$ & $67.9 \%$ \\
\hline California & $7.8 \%$ & $47.4 \%$ & $47.2 \%$ & $48.0 \%$ & $49.8 \%$ & $51.7 \%$ & $53.2 \%$ & $55.9 \%$ & $58.9 \%$ & $60.2 \%$ & $61.7 \%$ & $64.9 \%$ & $66.1 \%$ & $68.9 \%$ & $69.9 \%$ & $71.0 \%$ & $70.9 \%$ \\
\hline Colorado & $44.7 \%$ & $43.7 \%$ & $43.4 \%$ & $43.8 \%$ & $44.3 \%$ & $45.0 \%$ & $45.2 \%$ & $47.0 \%$ & $48.8 \%$ & $51.0 \%$ & $54.1 \%$ & $58.1 \%$ & $61.1 \%$ & $64.6 \%$ & $66.1 \%$ & $67.9 \%$ & $67.9 \%$ \\
\hline Connecticut & $46.1 \%$ & $45.8 \%$ & $45.5 \%$ & $46.0 \%$ & $47.9 \%$ & $50.1 \%$ & $51.3 \%$ & $55.1 \%$ & $57.8 \%$ & $59.0 \%$ & $60.8 \%$ & $63.9 \%$ & $67.1 \%$ & $70.2 \%$ & $72.9 \%$ & $73.3 \%$ & $74.6 \%$ \\
\hline Delaware & $44.1 \%$ & $42.9 \%$ & $42.2 \%$ & $42.2 \%$ & $42.5 \%$ & $42.9 \%$ & $43.0 \%$ & $44.9 \%$ & $46.8 \%$ & $49.4 \%$ & $55.1 \%$ & $59.3 \%$ & $62.7 \%$ & $66.6 \%$ & $67.6 \%$ & $69.0 \%$ & $70.0 \%$ \\
\hline District of & $45.1 \%$ & $44.0 \%$ & $43.3 \%$ & $43.3 \%$ & $43.6 \%$ & $44.2 \%$ & $44.7 \%$ & $46.9 \%$ & $49.1 \%$ & $49.6 \%$ & $56.1 \%$ & $60.1 \%$ & $63.2 \%$ & $65.7 \%$ & $67.2 \%$ & $69.1 \%$ & $70.9 \%$ \\
\hline Florida & $38.0 \%$ & $37.5 \%$ & $37.4 \%$ & $38.0 \%$ & $38.7 \%$ & $39.4 \%$ & $39.9 \%$ & $42.1 \%$ & $45.8 \%$ & $49.0 \%$ & $54.3 \%$ & $58.7 \%$ & $62.5 \%$ & $67.1 \%$ & $67.9 \%$ & $69.2 \%$ & $69.7 \%$ \\
\hline Georgia & $5.4 \%$ & $35.4 \%$ & $35.4 \%$ & $35.8 \%$ & $36.9 \%$ & $37.8 \%$ & $38.4 \%$ & $40.7 \%$ & $42.7 \%$ & $46.0 \%$ & $51.3 \%$ & $57.0 \%$ & $60.9 \%$ & $65.1 \%$ & $67.1 \%$ & $67.9 \%$ & $68.3 \%$ \\
\hline Hawaii & $8.9 \%$ & $48.1 \%$ & $47.5 \%$ & $47.9 \%$ & $48.7 \%$ & $49.8 \%$ & $50.1 \%$ & $52.4 \%$ & $54.8 \%$ & $56.8 \%$ & $59.4 \%$ & $63.4 \%$ & $66.3 \%$ & $70.7 \%$ & $72.8 \%$ & $74.8 \%$ & $77.7 \%$ \\
\hline Idaho & $1.0 \%$ & $40.4 \%$ & $40.1 \%$ & $40.8 \%$ & $41.5 \%$ & $42.0 \%$ & $42.3 \%$ & $44.4 \%$ & $46.4 \%$ & $49.1 \%$ & $52.6 \%$ & $56.7 \%$ & $60.5 \%$ & $64.3 \%$ & $66.1 \%$ & $67.9 \%$ & $67.9 \%$ \\
\hline Illinois & $43.5 \%$ & $42.9 \%$ & $42.0 \%$ & $41.8 \%$ & $42.4 \%$ & $43.3 \%$ & $43.3 \%$ & $45.2 \%$ & $46.7 \%$ & $49.1 \%$ & $53.5 \%$ & $57.6 \%$ & $61.8 \%$ & $65.4 \%$ & $67.1 \%$ & $67.9 \%$ & $67.9 \%$ \\
\hline Indiana & $37.7 \%$ & $37.6 \%$ & $37.3 \%$ & $37.7 \%$ & $38.7 \%$ & $39.5 \%$ & $39.8 \%$ & $42.2 \%$ & $44.0 \%$ & $46.9 \%$ & $50.6 \%$ & $56.1 \%$ & $59.7 \%$ & $63.8 \%$ & $65.6 \%$ & $68.3 \%$ & $68.7 \%$ \\
\hline Iowa & $44.9 \%$ & $44.4 \%$ & $43.6 \%$ & $43.5 \%$ & $44.2 \%$ & $44.9 \%$ & $45.3 \%$ & $47.4 \%$ & $48.8 \%$ & $50.9 \%$ & $55.0 \%$ & $59.8 \%$ & $64.2 \%$ & $68.4 \%$ & $70.6 \%$ & $71.0 \%$ & $70.9 \%$ \\
\hline Kansas & $46.9 \%$ & $45.8 \%$ & $45.1 \%$ & $45.1 \%$ & $45.5 \%$ & $45.9 \%$ & $46.5 \%$ & $48.2 \%$ & $50.5 \%$ & $52.7 \%$ & $55.6 \%$ & $60.1 \%$ & $62.8 \%$ & $66.4 \%$ & $67.9 \%$ & $69.2 \%$ & $69.1 \%$ \\
\hline Kentucky & $40.1 \%$ & $39.0 \%$ & $38.0 \%$ & $37.3 \%$ & $37.6 \%$ & $37.9 \%$ & $8.0 \%$ & $39.8 \%$ & $5 \%$ & $\%$ & $50.6 \%$ & $8.0 \%$ & $3.0 \%$ & $67.5 \%$ & $58.9 \%$ & $69.9 \%$ & $70.9 \%$ \\
\hline Louisiana & $7.2 \%$ & $36.6 \%$ & $36.6 \%$ & $37.1 \%$ & $37.6 \%$ & $8.1 \%$ & $8.3 \%$ & $40.0 \%$ & $3.6 \%$ & $47.0 \%$ & $51.0 \%$ & $55.6 \%$ & $59.8 \%$ & $64.4 \%$ & $67.1 \%$ & $67.9 \%$ & $67.9 \%$ \\
\hline Maine & $3.7 \%$ & $39.0 \%$ & $39.5 \%$ & $40.7 \%$ & $42.6 \%$ & $4.7 \%$ & $5.6 \%$ & $48.2 \%$ & $50.7 \%$ & $52.7 \%$ & $5.5 \%$ & $60.7 \%$ & $65.6 \%$ & $69.7 \%$ & $71.6 \%$ & $71.0 \%$ & $70.9 \%$ \\
\hline Maryland & $44.0 \%$ & $43.0 \%$ & $42.6 \%$ & $42.8 \%$ & $43.3 \%$ & $43.9 \%$ & $44.3 \%$ & $46.4 \%$ & $48.5 \%$ & $51.0 \%$ & $54.0 \%$ & $59.9 \%$ & $63.0 \%$ & $68.8 \%$ & $71.5 \%$ & $74.4 \%$ & $75.7 \%$ \\
\hline Massachusetts & $46.9 \%$ & $46.1 \%$ & $45.5 \%$ & $45.7 \%$ & $46.3 \%$ & $47.3 \%$ & $48.2 \%$ & $50.7 \%$ & $53.1 \%$ & $55.2 \%$ & $57.9 \%$ & $61.6 \%$ & $66.5 \%$ & $70.2 \%$ & $71.6 \%$ & $71.0 \%$ & $70.9 \%$ \\
\hline Michigan & $47.8 \%$ & $47.0 \%$ & $46.5 \%$ & $46.9 \%$ & $47.5 \%$ & $49.0 \%$ & $49.6 \%$ & $52.1 \%$ & $54.4 \%$ & $56.0 \%$ & $58.5 \%$ & $64.3 \%$ & $68.5 \%$ & $72.2 \%$ & $72.2 \%$ & $72.1 \%$ & $72.4 \%$ \\
\hline Minnesota & $47.8 \%$ & $47.1 \%$ & $46.5 \%$ & $47.3 \%$ & $48.9 \%$ & $50.5 \%$ & $51.4 \%$ & $53.9 \%$ & $56.1 \%$ & $57.6 \%$ & $59.2 \%$ & $62.6 \%$ & $69.0 \%$ & $75.0 \%$ & $79.0 \%$ & $81.1 \%$ & $83.0 \%$ \\
\hline Mississippi & $33.6 \%$ & $33.5 \%$ & $33.2 \%$ & $33.0 \%$ & $32.9 \%$ & $33.0 \%$ & $33.2 \%$ & $34.8 \%$ & $36.3 \%$ & $40.5 \%$ & $48.1 \%$ & $56.8 \%$ & $64.0 \%$ & $70.2 \%$ & $71.6 \%$ & $71.0 \%$ & $70.9 \%$ \\
\hline Miss & 6 & $\%$ & 40 & $.2 \%$ & $40.8 \%$ & $41.2 \%$ & $1.3 \%$ & $43.2 \%$ & $44.6 \%$ & $47.4 \%$ & $\%$ & $.0 \%$ & $62.7 \%$ & $66.6 \%$ & 67. & $67.9 \%$ & $7.9 \%$ \\
\hline Mon & $\%$ & $\%$ & $\%$ & 10 & 4 & 6 & 6 & $\%$ & $\%$ & o & $4.2 \%$ & $8.3 \%$ & $\%$ & $64.7 \%$ & $\%$ & $\%$ & $9 \%$ \\
\hline Nebraska & $45.6 \%$ & $44.9 \%$ & $44.3 \%$ & $44.6 \%$ & $44.8 \%$ & $5.4 \%$ & $45.6 \%$ & $47.3 \%$ & $49.0 \%$ & $51.2 \%$ & $55.0 \%$ & $59.0 \%$ & $.0 \%$ & $65.5 \%$ & $67.1 \%$ & $67.9 \%$ & $7.9 \%$ \\
\hline Nevada & $39.6 \%$ & $39.0 \%$ & $38.8 \%$ & $39.1 \%$ & $39.6 \%$ & $40.4 \%$ & $40.9 \%$ & $43.2 \%$ & $45.5 \%$ & $48.7 \%$ & $52.5 \%$ & $56.9 \%$ & $60.5 \%$ & $64.3 \%$ & $66.0 \%$ & $67.9 \%$ & $67.9 \%$ \\
\hline New Hamps & $39.5 \%$ & $39.4 \%$ & $39.1 \%$ & $39.8 \%$ & $41.3 \%$ & $42.8 \%$ & $43.8 \%$ & $47.0 \%$ & $49.4 \%$ & $51.9 \%$ & $54.9 \%$ & $60.1 \%$ & $62.9 \%$ & $66.8 \%$ & $68.5 \%$ & $70.7 \%$ & $72.5 \%$ \\
\hline New Jersey & $44.6 \%$ & $44.1 \%$ & $43.2 \%$ & $43.2 \%$ & $44.2 \%$ & $45.1 \%$ & $45.7 \%$ & $47.9 \%$ & $49.5 \%$ & $49.8 \%$ & $53.1 \%$ & $59.0 \%$ & $62.6 \%$ & $65.7 \%$ & $66.2 \%$ & $68.2 \%$ & $70.0 \%$ \\
\hline New Mexico & $38.7 \%$ & $38.1 \%$ & $38.1 \%$ & $38.8 \%$ & $39.5 \%$ & $40.2 \%$ & $40.7 \%$ & $42.8 \%$ & $44.7 \%$ & $47.7 \%$ & $54.4 \%$ & $58.7 \%$ & $62.5 \%$ & $66.6 \%$ & $67.1 \%$ & $70.0 \%$ & $72.4 \%$ \\
\hline New York & $48.0 \%$ & $47.2 \%$ & $46.7 \%$ & $47.2 \%$ & $48.2 \%$ & $49.6 \%$ & $50.5 \%$ & $52.8 \%$ & $55.2 \%$ & $55.9 \%$ & $58.1 \%$ & $61.6 \%$ & $63.3 \%$ & $67.7 \%$ & $69.1 \%$ & $71.0 \%$ & $70.9 \%$ \\
\hline North Car & $8 \%$ & $36.6 \%$ & 36 & $4 \%$ & $37.2 \%$ & $\%$ & $38.5 \%$ & $40.7 \%$ & 42 & 45 & $\%$ & $\%$ & $\%$ & $\%$ & $5 \%$ & $70.4 \%$ & $0.9 \%$ \\
\hline North Dakota & 6 & $4 \%$ & 40 & $41.6 \%$ & $42.8 \%$ & $.1 \%$ & $45.0 \%$ & $47.6 \%$ & $49.8 \%$ & $52.1 \%$ & $.1 \%$ & $9.0 \%$ & $61.9 \%$ & $65.0 \%$ & $66.3 \%$ & $67.9 \%$ & $67.9 \%$ \\
\hline Ohio & $.2 \%$ & $43.0 \%$ & $42.5 \%$ & $42.5 \%$ & $42.8 \%$ & $43.2 \%$ & $43.3 \%$ & $45.2 \%$ & $47.1 \%$ & $49.6 \%$ & $53.1 \%$ & $2 \%$ & $1.6 \%$ & $65.4 \%$ & $67.1 \%$ & $67.9 \%$ & $67.9 \%$ \\
\hline Oklahoma & $38.2 \%$ & $38.0 \%$ & $37.9 \%$ & $38.5 \%$ & $39.7 \%$ & $41.0 \%$ & $41.5 \%$ & $43.9 \%$ & $45.9 \%$ & $48.5 \%$ & $53.2 \%$ & $59.5 \%$ & $62.8 \%$ & $66.6 \%$ & $67.1 \%$ & $67.9 \%$ & $68.3 \%$ \\
\hline Oregon & $46.2 \%$ & $44.7 \%$ & $43.5 \%$ & $43.7 \%$ & $44.3 \%$ & $44.9 \%$ & $45.7 \%$ & $48.3 \%$ & $50.7 \%$ & $53.0 \%$ & $56.7 \%$ & $60.5 \%$ & $63.1 \%$ & $66.2 \%$ & $67.1 \%$ & $67.9 \%$ & $67.9 \%$ \\
\hline Pennsylvania & $46.4 \%$ & $45.4 \%$ & $44.7 \%$ & $44.9 \%$ & $45.3 \%$ & $45.9 \%$ & $46.4 \%$ & $47.6 \%$ & $49.3 \%$ & $51.4 \%$ & $55.4 \%$ & $60.7 \%$ & $63.4 \%$ & $66.6 \%$ & $67.1 \%$ & $67.9 \%$ & $68.9 \%$ \\
\hline Rhode Island & $6.9 \%$ & $46.1 \%$ & $45.7 \%$ & $46.3 \%$ & $47.6 \%$ & $49.2 \%$ & $50.1 \%$ & $52.4 \%$ & $55.0 \%$ & $56.6 \%$ & $58.8 \%$ & $62.3 \%$ & $66.6 \%$ & $70.2 \%$ & $73.9 \%$ & $75.7 \%$ & $78.3 \%$ \\
\hline South Carolina & $36.5 \%$ & $35.7 \%$ & $35.6 \%$ & $36.1 \%$ & $36.8 \%$ & $37.1 \%$ & $37.5 \%$ & $38.9 \%$ & $42.5 \%$ & $46.1 \%$ & $51.2 \%$ & $57.9 \%$ & $62.0 \%$ & $67.7 \%$ & $69.1 \%$ & $71.0 \%$ & $70.9 \%$ \\
\hline South Dakota & $1.1 \%$ & $40.6 \%$ & $40.4 \%$ & $41.2 \%$ & $42.0 \%$ & $42.7 \%$ & $43.4 \%$ & $44.8 \%$ & $46.7 \%$ & $49.3 \%$ & $52.5 \%$ & $57.9 \%$ & $62.1 \%$ & $65.6 \%$ & $67.1 \%$ & $67.9 \%$ & $67.9 \%$ \\
\hline Tennessee & $36.3 \%$ & $35.5 \%$ & $35.3 \%$ & $35.4 \%$ & $35.4 \%$ & $35.8 \%$ & $35.9 \%$ & $37.7 \%$ & $41.6 \%$ & $45.4 \%$ & $52.2 \%$ & $57.1 \%$ & $61.6 \%$ & $67.1 \%$ & $67.9 \%$ & $69.9 \%$ & $70.4 \%$ \\
\hline Texas & $34.3 \%$ & $33.9 \%$ & $33.5 \%$ & $33.7 \%$ & $34.5 \%$ & $35.5 \%$ & $36.0 \%$ & $37.9 \%$ & $39.8 \%$ & $43.6 \%$ & $47.9 \%$ & $55.5 \%$ & $59.7 \%$ & $64.4 \%$ & $67.1 \%$ & $69.0 \%$ & $70.0 \%$ \\
\hline Utah & $45.0 \%$ & $43.7 \%$ & $42.7 \%$ & $43.0 \%$ & $43.4 \%$ & $44.0 \%$ & $44.8 \%$ & $47.3 \%$ & $49.3 \%$ & $51.7 \%$ & $54.8 \%$ & $58.7 \%$ & $62.5 \%$ & $65.7 \%$ & $67.1 \%$ & $67.9 \%$ & $67.9 \%$ \\
\hline Vermont & $48.3 \%$ & $47.7 \%$ & $47.4 \%$ & $48.1 \%$ & $49.7 \%$ & $51.5 \%$ & $52.4 \%$ & $53.9 \%$ & $55.8 \%$ & $57.1 \%$ & $59.9 \%$ & $63.1 \%$ & $68.3 \%$ & $73.5 \%$ & $77.1 \%$ & $78.4 \%$ & $79.6 \%$ \\
\hline Virginia & $38.6 \%$ & $38.5 \%$ & $38.2 \%$ & $38.9 \%$ & $40.2 \%$ & $41.7 \%$ & $42.4 \%$ & $45.0 \%$ & $46.9 \%$ & $49.3 \%$ & $52.6 \%$ & $58.0 \%$ & $62.0 \%$ & $65.5 \%$ & $67.1 \%$ & $67.9 \%$ & $67.9 \%$ \\
\hline Washington & $6.6 \%$ & $45.4 \%$ & $44.4 \%$ & $45.0 \%$ & $46.1 \%$ & $47.6 \%$ & $48.8 \%$ & $51.6 \%$ & $54.1 \%$ & $55.7 \%$ & $58.1 \%$ & $61.6 \%$ & $63.3 \%$ & $67.0 \%$ & $70.3 \%$ & $74.0 \%$ & $75.6 \%$ \\
\hline West Virginia & $43.4 \%$ & $42.2 \%$ & $41.5 \%$ & $40.9 \%$ & $40.8 \%$ & $40.9 \%$ & $41.0 \%$ & $41.8 \%$ & $44.7 \%$ & $47.9 \%$ & $53.0 \%$ & $58.7 \%$ & $64.0 \%$ & $68.6 \%$ & $69.5 \%$ & $69.2 \%$ & $69.1 \%$ \\
\hline Wisconsin & $48.1 \%$ & $47.4 \%$ & $47.1 \%$ & $47.7 \%$ & $49.3 \%$ & $51.2 \%$ & $52.0 \%$ & $54.4 \%$ & $56.4 \%$ & $57.7 \%$ & $59.9 \%$ & $63.7 \%$ & $66.5 \%$ & $69.4 \%$ & $70.6 \%$ & $71.6 \%$ & $73.0 \%$ \\
\hline Wyoming & $40.8 \%$ & $40.4 \%$ & $40.5 \%$ & $41.3 \%$ & $42.2 \%$ & $43.2 \%$ & $43.8 \%$ & $46.0 \%$ & $47.9 \%$ & $50.5 \%$ & $53.8 \%$ & $57.9 \%$ & $62.0 \%$ & $65.5 \%$ & $67.1 \%$ & $67.9 \%$ & $67.9 \%$ \\
\hline
\end{tabular}


Appendix - Table C3

Estimated Percent of Early Childhood Years with Medicaid Eligibility

By Graduation Cohort - From Conception through Age 5

Hispanic Students

\begin{tabular}{|c|c|c|c|c|c|c|c|c|c|c|c|c|c|c|c|c|c|}
\hline State & 1994 & 1995 & 1996 & 1997 & 1998 & 1999 & 2000 & 2001 & 2002 & 2003 & 2004 & 2005 & 2006 & 2007 & 2008 & 2009 & 2010 \\
\hline Alabama & $.8 \%$ & $4.6 \%$ & $4.9 \%$ & $6.6 \%$ & $.6 \%$ & $.6 \%$ & $2.3 \%$ & $3.9 \%$ & $5.8 \%$ & $1.0 \%$ & $6.4 \%$ & $3.1 \%$ & $1.8 \%$ & $7.5 \%$ & $2.5 \%$ & $3.7 \%$ & $3.6 \%$ \\
\hline Alaska & $5.7 \%$ & $16.9 \%$ & $17.7 \%$ & $23.0 \%$ & $0.1 \%$ & $37.2 \%$ & $43.4 \%$ & $50.3 \%$ & $6.9 \%$ & $58.4 \%$ & $60.7 \%$ & $66.3 \%$ & $66.9 \%$ & $68.6 \%$ & $59.5 \%$ & $0.9 \%$ & $70.9 \%$ \\
\hline Arizona & $0 \%$ & $0.0 \%$ & $2.8 \%$ & $7.5 \%$ & $.7 \%$ & $.7 \%$ & $.1 \%$ & $29.9 \%$ & 3 & $\%$ & $7.8 \%$ & $4.0 \%$ & $\%$ & $\%$ & $2.7 \%$ & $4.2 \%$ & $4.5 \%$ \\
\hline Arkansas & $1.8 \%$ & $14.6 \%$ & $14.9 \%$ & $16.7 \%$ & $19.1 \%$ & $1.8 \%$ & $23.9 \%$ & $26.8 \%$ & $32.5 \%$ & $37.0 \%$ & $47.1 \%$ & $3.6 \%$ & $57.7 \%$ & $1.0 \%$ & $2.5 \%$ & $3.7 \%$ & $3.6 \%$ \\
\hline California & $27.0 \%$ & $27.1 \%$ & $27.7 \%$ & $30.7 \%$ & $35.2 \%$ & $40.3 \%$ & $45.0 \%$ & $49.3 \%$ & $54.1 \%$ & $55.4 \%$ & $56.1 \%$ & $61.0 \%$ & $61.2 \%$ & $64.1 \%$ & $66.6 \%$ & $68.6 \%$ & $68.4 \%$ \\
\hline Colorado & $24.9 \%$ & $24.6 \%$ & $24.7 \%$ & $26.3 \%$ & $29.2 \%$ & $32.4 \%$ & $35.1 \%$ & $38.0 \%$ & $41.2 \%$ & $43.9 \%$ & $47.0 \%$ & $52.3 \%$ & $54.8 \%$ & $58.3 \%$ & $60.9 \%$ & $63.7 \%$ & $63.6 \%$ \\
\hline Connecticut & $26.4 \%$ & $26.3 \%$ & $26.9 \%$ & $29.7 \%$ & $34.0 \%$ & $39.1 \%$ & $43.3 \%$ & $48.3 \%$ & $53.0 \%$ & $54.4 \%$ & $55.4 \%$ & $59.7 \%$ & $62.4 \%$ & $65.5 \%$ & $70.1 \%$ & $71.6 \%$ & $73.2 \%$ \\
\hline Delaware & $4.5 \%$ & $24.1 \%$ & $24.1 \%$ & $25.1 \%$ & $27.2 \%$ & $30.1 \%$ & $32.5 \%$ & $35.0 \%$ & $37.9 \%$ & $41.4 \%$ & $48.5 \%$ & $54.1 \%$ & $57.1 \%$ & $61.0 \%$ & $63.4 \%$ & $65.5 \%$ & $67.0 \%$ \\
\hline District of & $5.0 \%$ & $24.6 \%$ & $24.6 \%$ & $25.7 \%$ & $28.4 \%$ & $31.4 \%$ & $34.3 \%$ & $37.4 \%$ & $41.0 \%$ & $41.8 \%$ & $49.9 \%$ & $55.3 \%$ & $57.9 \%$ & $59.9 \%$ & $63.1 \%$ & $65.8 \%$ & $8.4 \%$ \\
\hline Florida & $15.6 \%$ & $15.6 \%$ & $15.9 \%$ & $18.4 \%$ & $21.8 \%$ & $25.0 \%$ & $27.9 \%$ & $31.1 \%$ & $36.7 \%$ & $40.6 \%$ & $47.4 \%$ & $53.1 \%$ & $56.6 \%$ & $61.6 \%$ & $63.7 \%$ & $65.5 \%$ & $66.4 \%$ \\
\hline Georgia & $14.6 \%$ & $14.6 \%$ & $15.1 \%$ & $17.4 \%$ & $20.3 \%$ & $23.3 \%$ & $26.0 \%$ & $29.4 \%$ & $32.6 \%$ & $36.7 \%$ & $44.3 \%$ & $50.6 \%$ & $54.4 \%$ & $58.9 \%$ & $62.5 \%$ & $63.7 \%$ & $64.3 \%$ \\
\hline Hawaii & $27.8 \%$ & $27.4 \%$ & $27.7 \%$ & $30.0 \%$ & $33.5 \%$ & $37.5 \%$ & $40.9 \%$ & $44.4 \%$ & $48.9 \%$ & $51.5 \%$ & $53.9 \%$ & $59.5 \%$ & $61.8 \%$ & $66.4 \%$ & $70.0 \%$ & $72.8 \%$ & $75.9 \%$ \\
\hline Idaho & $16.8 \%$ & $16.9 \%$ & $17.2 \%$ & $20.0 \%$ & $23.5 \%$ & $27.0 \%$ & $30.1 \%$ & $33.2 \%$ & $36.4 \%$ & $39.7 \%$ & $44.2 \%$ & $49.9 \%$ & $53.5 \%$ & $57.6 \%$ & $60.9 \%$ & $63.7 \%$ & $63.6 \%$ \\
\hline Illinois & $24.6 \%$ & $24.1 \%$ & $24.3 \%$ & $25.4 \%$ & $27.7 \%$ & $30.7 \%$ & $33.1 \%$ & $36.0 \%$ & $38.9 \%$ & $41.9 \%$ & $45.9 \%$ & $51.5 \%$ & $55.9 \%$ & $59.6 \%$ & $62.5 \%$ & $63.7 \%$ & $53.6 \%$ \\
\hline Indiana & $15.7 \%$ & $15.7 \%$ & $16.2 \%$ & $18.7 \%$ & $22.1 \%$ & $25.4 \%$ & $28.0 \%$ & $31.5 \%$ & $34.6 \%$ & $38.3 \%$ & $43.0 \%$ & $49.1 \%$ & $52.3 \%$ & $56.7 \%$ & $60.0 \%$ & $64.3 \%$ & $64.8 \%$ \\
\hline Iowa & $25.6 \%$ & $25.2 \%$ & $25.5 \%$ & $26.8 \%$ & $29.5 \%$ & $32.8 \%$ & $35.5 \%$ & $38.5 \%$ & $41.6 \%$ & $44.4 \%$ & $47.9 \%$ & $54.5 \%$ & $58.3 \%$ & $63.2 \%$ & $67.6 \%$ & $68.6 \%$ & $68.4 \%$ \\
\hline Kansas & $.2 \%$ & $.7 \%$ & $25.8 \%$ & $27.3 \%$ & $30.0 \%$ & $.5 \%$ & $5.5 \%$ & $.2 \%$ & $3.0 \%$ & $45.7 \%$ & $48.6 \%$ & $5.0 \%$ & $7.0 \%$ & $60.6 \%$ & $.7 \%$ & $5.5 \%$ & $5.4 \%$ \\
\hline Kentucky & $.0 \%$ & $19.9 \%$ & $18.9 \%$ & $19.3 \%$ & $21.0 \%$ & $23.1 \%$ & $5.3 \%$ & $28.2 \%$ & $30.9 \%$ & $35.2 \%$ & $42.9 \%$ & $52.0 \%$ & $56.9 \%$ & $61.8 \%$ & $65.0 \%$ & $66.9 \%$ & $68.4 \%$ \\
\hline Louisiana & $5.2 \%$ & $15.2 \%$ & $15.5 \%$ & $17.8 \%$ & $20.6 \%$ & $23.2 \%$ & $25.5 \%$ & $28.0 \%$ & $33.7 \%$ & $37.8 \%$ & $43.1 \%$ & $49.1 \%$ & $53.2 \%$ & $58.2 \%$ & $62.5 \%$ & $63.7 \%$ & $63.6 \%$ \\
\hline Maine & $17.5 \%$ & $18.2 \%$ & $20.0 \%$ & $23.4 \%$ & $28.1 \%$ & $33.0 \%$ & $36.4 \%$ & $40.2 \%$ & $44.8 \%$ & $47.6 \%$ & $50.3 \%$ & $56.0 \%$ & $60.5 \%$ & $64.9 \%$ & $68.7 \%$ & $68.6 \%$ & $68.4 \%$ \\
\hline Maryland & $24.4 \%$ & $24.1 \%$ & $24.2 \%$ & $25.5 \%$ & $28.0 \%$ & $31.1 \%$ & $33.9 \%$ & $36.8 \%$ & $40.3 \%$ & $43.6 \%$ & $46.8 \%$ & $54.9 \%$ & $57.5 \%$ & $64.3 \%$ & $68.9 \%$ & $73.2 \%$ & $74.8 \%$ \\
\hline Massachuse & $26.3 \%$ & $26.1 \%$ & $26.2 \%$ & $27.9 \%$ & $30.9 \%$ & $34.8 \%$ & $38.7 \%$ & $42.4 \%$ & $46.9 \%$ & $49.4 \%$ & $52.1 \%$ & $57.3 \%$ & $61.7 \%$ & $65.5 \%$ & $68.7 \%$ & $68.6 \%$ & $68.4 \%$ \\
\hline Michigan & $26.9 \%$ & $26.6 \%$ & $27.0 \%$ & $28.9 \%$ & $32.5 \%$ & $36.9 \%$ & $40.8 \%$ & $44.4 \%$ & $48.8 \%$ & $50.8 \%$ & $52.9 \%$ & $60.8 \%$ & $64.5 \%$ & $68.3 \%$ & $69.1 \%$ & $69.5 \%$ & $70.0 \%$ \\
\hline Minnesota & $26.8 \%$ & $26.6 \%$ & $26.9 \%$ & $29.5 \%$ & $33.5 \%$ & $3.2 \%$ & $.5 \%$ & $\%$ & $\%$ & . & $\%$ & $8.5 \%$ & 65. & $71.9 \%$ & $78.0 \%$ & $81.1 \%$ & $82.6 \%$ \\
\hline Mississippi & $14.1 \%$ & $13.8 \%$ & $14.2 \%$ & $15.7 \%$ & $17.4 \%$ & $19.3 \%$ & $21.1 \%$ & $23.3 \%$ & $25.4 \%$ & $30.2 \%$ & $39.9 \%$ & $50.5 \%$ & $58.2 \%$ & $65.5 \%$ & $68.7 \%$ & $68.6 \%$ & $68.4 \%$ \\
\hline Missouri & $23.0 \%$ & $22.7 \%$ & $23.1 \%$ & $23.9 \%$ & $26.0 \%$ & $28.7 \%$ & $30.7 \%$ & $33.2 \%$ & $35.7 \%$ & $39.3 \%$ & $47.3 \%$ & $53.5 \%$ & $56.8 \%$ & $61.0 \%$ & $62.5 \%$ & $63.7 \%$ & $63.6 \%$ \\
\hline Montana & $22.9 \%$ & $22.0 \%$ & $21.0 \%$ & $22.8 \%$ & $25.6 \%$ & $28.8 \%$ & $32.6 \%$ & $36.4 \%$ & $40.4 \%$ & $43.1 \%$ & $47.1 \%$ & $52.4 \%$ & $54.9 \%$ & $58.3 \%$ & $61.0 \%$ & $63.7 \%$ & $63.6 \%$ \\
\hline Nebraska & $25.5 \%$ & $25.3 \%$ & $25.5 \%$ & $27.1 \%$ & $29.8 \%$ & $32.9 \%$ & $35.5 \%$ & $38.2 \%$ & $41.3 \%$ & $44.0 \%$ & $48.5 \%$ & $53.8 \%$ & $56.3 \%$ & $59.7 \%$ & $62.5 \%$ & $63.7 \%$ & $63.6 \%$ \\
\hline Nevada & $16.3 \%$ & $16.4 \%$ & $16.8 \%$ & $19.2 \%$ & $22.3 \%$ & $25.8 \%$ & $28.9 \%$ & $32.3 \%$ & $35.9 \%$ & $39.8 \%$ & $44.6 \%$ & $50.4 \%$ & $53.4 \%$ & $57.6 \%$ & $60.6 \%$ & $63.7 \%$ & $63.6 \%$ \\
\hline New Hampsh & $16.3 \%$ & $16.4 \%$ & $16.9 \%$ & $19.8 \%$ & $24.2 \%$ & $28.7 \%$ & $32.5 \%$ & $37.1 \%$ & $41.9 \%$ & $45.0 \%$ & $49.0 \%$ & $54.7 \%$ & $56.9 \%$ & $61.2 \%$ & $64.2 \%$ & $67.5 \%$ & $69.9 \%$ \\
\hline New & $5.4 \%$ & $25.1 \%$ & $25.2 \%$ & $26.7 \%$ & $29.6 \%$ & $33.3 \%$ & $36.1 \%$ & $39.4 \%$ & $42.7 \%$ & $\%$ & $47.0 \%$ & $3.9 \%$ & $6.9 \%$ & $9.9 \%$ & $61.3 \%$ & $64.0 \%$ & $66.7 \%$ \\
\hline New Mexicc & 6 & $\%$ & $16.3 \%$ & $\%$ & 22 & 25 & 6 & $\%$ & 3 & $\%$ & $\%$ & $\%$ & $\%$ & $\%$ & $\%$ & $\%$ & $0.0 \%$ \\
\hline New York & $1 \%$ & 2 & 2 & $\%$ & 3. & 3 & $\%$ & $.4 \%$ & $49.8 \%$ & $50.7 \%$ & $\%$ & $\%$ & $58.0 \%$ & $62.8 \%$ & $65.9 \%$ & $68.6 \%$ & $68.4 \%$ \\
\hline North Carolina & $15.2 \%$ & $15.1 \%$ & $15.6 \%$ & $17.6 \%$ & $20.4 \%$ & $23.5 \%$ & $26.1 \%$ & $29.2 \%$ & $32.1 \%$ & $36.3 \%$ & $46.8 \%$ & $52.7 \%$ & $56.4 \%$ & $61.6 \%$ & $64.8 \%$ & $67.5 \%$ & $68.4 \%$ \\
\hline North Dakota & $16.7 \%$ & $16.9 \%$ & $17.3 \%$ & $20.8 \%$ & $25.3 \%$ & $29.8 \%$ & $33.8 \%$ & $37.6 \%$ & $41.6 \%$ & $44.3 \%$ & $48.2 \%$ & $53.4 \%$ & $55.5 \%$ & $58.6 \%$ & $61.2 \%$ & $63.7 \%$ & $63.6 \%$ \\
\hline Ohio & $24.6 \%$ & $24.2 \%$ & $24.2 \%$ & $25.3 \%$ & $27.6 \%$ & $30.4 \%$ & $32.8 \%$ & $35.3 \%$ & $38.3 \%$ & $41.6 \%$ & $45.2 \%$ & $50.8 \%$ & $55.5 \%$ & $59.4 \%$ & $62.5 \%$ & $63.7 \%$ & $63.6 \%$ \\
\hline Oklahoma & $15.8 \%$ & $15.8 \%$ & $16.3 \%$ & $18.9 \%$ & $22.5 \%$ & $26.4 \%$ & $29.7 \%$ & $33.4 \%$ & $37.0 \%$ & $40.5 \%$ & $46.6 \%$ & $54.5 \%$ & $57.2 \%$ & $61.0 \%$ & $62.5 \%$ & $63.7 \%$ & $64.3 \%$ \\
\hline Oregon & $.5 \%$ & $23.4 \%$ & $22.1 \%$ & $23.7 \%$ & $26.7 \%$ & $30.3 \%$ & $34.4 \%$ & $38.5 \%$ & $42.7 \%$ & $45.4 \%$ & $50.5 \%$ & $5.7 \%$ & $57.5 \%$ & $60.4 \%$ & $62.5 \%$ & $63.7 \%$ & $63.6 \%$ \\
\hline Pennsylva & $.8 \%$ & $5.5 \%$ & $25.5 \%$ & $27.1 \%$ & $30.0 \%$ & $33.5 \%$ & $36.6 \%$ & $39.2 \%$ & $42.5 \%$ & $45.3 \%$ & $50.3 \%$ & $.0 \%$ & $8.0 \%$ & $61.0 \%$ & $2.5 \%$ & $63.7 \%$ & $65.2 \%$ \\
\hline Rhode Island & $26.4 \%$ & $26.1 \%$ & $26.5 \%$ & $28.9 \%$ & $32.7 \%$ & $37.2 \%$ & $41.4 \%$ & $44.6 \%$ & $49.3 \%$ & $51.3 \%$ & $53.1 \%$ & $58.1 \%$ & $61.9 \%$ & $65.5 \%$ & $71.2 \%$ & $74.0 \%$ & $76.7 \%$ \\
\hline South Carolina & $14.9 \%$ & $14.8 \%$ & $15.1 \%$ & $17.0 \%$ & $19.8 \%$ & $22.5 \%$ & $24.8 \%$ & $27.2 \%$ & $32.9 \%$ & $37.6 \%$ & $43.3 \%$ & $52.0 \%$ & $56.0 \%$ & $62.7 \%$ & $65.9 \%$ & $68.6 \%$ & $68.4 \%$ \\
\hline South Dakota & $16.9 \%$ & $17.0 \%$ & $17.4 \%$ & $20.3 \%$ & $24.0 \%$ & $27.7 \%$ & $31.3 \%$ & $34.4 \%$ & $37.9 \%$ & $41.2 \%$ & $45.6 \%$ & $51.6 \%$ & $56.2 \%$ & $59.7 \%$ & $62.5 \%$ & $63.7 \%$ & $63.6 \%$ \\
\hline Tennessee & $14.9 \%$ & $14.8 \%$ & $15.0 \%$ & $16.7 \%$ & $18.9 \%$ & $21.2 \%$ & $23.3 \%$ & $25.8 \%$ & $31.6 \%$ & $36.3 \%$ & $44.9 \%$ & $51.2 \%$ & $55.7 \%$ & $61.6 \%$ & $63.7 \%$ & $66.4 \%$ & $67.3 \%$ \\
\hline Texas & $14.3 \%$ & $14.0 \%$ & $14.3 \%$ & $16.1 \%$ & $18.8 \%$ & $21.4 \%$ & $23.6 \%$ & $26.5 \%$ & $29.1 \%$ & $33.7 \%$ & $39.2 \%$ & $48.9 \%$ & $53.1 \%$ & $58.2 \%$ & $62.5 \%$ & $65.2 \%$ & $66.7 \%$ \\
\hline Utah & $3.7 \%$ & $22.8 \%$ & $21.7 \%$ & $23.3 \%$ & $26.0 \%$ & $29.4 \%$ & $33.2 \%$ & $37.0 \%$ & $40.8 \%$ & $43.6 \%$ & $47.6 \%$ & $52.9 \%$ & $56.6 \%$ & $59.8 \%$ & $62.5 \%$ & $63.7 \%$ & $63.6 \%$ \\
\hline Vermont & $7.2 \%$ & $27.3 \%$ & $27.8 \%$ & $30.4 \%$ & $34.6 \%$ & $39.5 \%$ & $43.8 \%$ & $47.0 \%$ & $51.2 \%$ & $53.1 \%$ & $54.2 \%$ & $59.1 \%$ & $64.7 \%$ & $70.2 \%$ & $75.6 \%$ & $78.0 \%$ & $78.8 \%$ \\
\hline Virginia & $15.9 \%$ & $15.9 \%$ & $16.5 \%$ & $19.3 \%$ & $23.0 \%$ & $27.1 \%$ & $30.6 \%$ & $34.6 \%$ & $38.3 \%$ & $41.6 \%$ & $46.0 \%$ & $52.0 \%$ & $56.2 \%$ & $59.7 \%$ & $62.5 \%$ & $63.7 \%$ & $63.6 \%$ \\
\hline Washington & $24.5 \%$ & $23.6 \%$ & $22.5 \%$ & $24.7 \%$ & $28.6 \%$ & $33.1 \%$ & $38.1 \%$ & $42.6 \%$ & $47.7 \%$ & $49.6 \%$ & $52.4 \%$ & $57.3 \%$ & $58.2 \%$ & $61.9 \%$ & $67.3 \%$ & $72.4 \%$ & $74.3 \%$ \\
\hline West Virginia & $23.6 \%$ & $23.2 \%$ & $23.0 \%$ & $23.7 \%$ & $25.3 \%$ & $27.8 \%$ & $29.9 \%$ & $31.7 \%$ & $36.6 \%$ & $40.5 \%$ & $46.9 \%$ & $53.2 \%$ & $58.2 \%$ & $63.2 \%$ & $65.3 \%$ & $65.5 \%$ & $65.4 \%$ \\
\hline Wisconsin & $27.2 \%$ & $27.0 \%$ & $27.5 \%$ & $30.1 \%$ & $34.5 \%$ & $39.3 \%$ & $43.5 \%$ & $47.0 \%$ & $51.2 \%$ & $52.7 \%$ & $54.6 \%$ & $60.1 \%$ & $62.1 \%$ & $64.6 \%$ & $66.6 \%$ & $68.9 \%$ & $70.6 \%$ \\
\hline Wyoming & $5.7 \%$ & $16.8 \%$ & $17.4 \%$ & $20.4 \%$ & $24.0 \%$ & $27.9 \%$ & $31.3 \%$ & $34.8 \%$ & $38.2 \%$ & $41.4 \%$ & $45.8 \%$ & $51.4 \%$ & $55.9 \%$ & $59.6 \%$ & $62.5 \%$ & $63.7 \%$ & $63.6 \%$ \\
\hline
\end{tabular}


Appendix - Table C4

Estimated Percent of Early Childhood Years with Medicaid Eligibility

By Graduation Cohort - From Conception through Age 5 White Students

\begin{tabular}{|c|c|c|c|c|c|c|c|c|c|c|c|c|c|c|c|c|c|}
\hline State & 1994 & 1995 & 1996 & 1997 & 1998 & 1999 & 2000 & 2001 & 2002 & 2003 & 2004 & 2005 & 2006 & 2007 & 2008 & 2009 & 2010 \\
\hline labama & 5\% & $3 \%$ & $.2 \%$ & $6.7 \%$ & $7.3 \%$ & $7.9 \%$ & $4 \%$ & $.6 \%$ & $.0 \%$ & $1.8 \%$ & $4.5 \%$ & $17.8 \%$ & $2.3 \%$ & $25.3 \%$ & $8.0 \%$ & $8.7 \%$ & $8.4 \%$ \\
\hline Alaska & $8.3 \%$ & $8.2 \%$ & $8.3 \%$ & $11.1 \%$ & $4.9 \%$ & $18.4 \%$ & $21.4 \%$ & $24.7 \%$ & $27.6 \%$ & $28.7 \%$ & $29.5 \%$ & $32.5 \%$ & $32.9 \%$ & $33.8 \%$ & $34.7 \%$ & $35.6 \%$ & $35.2 \%$ \\
\hline Arizona & $0.0 \%$ & $0.0 \%$ & $1.0 \%$ & $3.0 \%$ & $5.1 \%$ & $7.4 \%$ & $9.5 \%$ & $11.4 \%$ & $14.1 \%$ & $16.1 \%$ & $19.7 \%$ & $22.8 \%$ & $24.7 \%$ & $27.0 \%$ & $28.2 \%$ & $29.2 \%$ & $29.1 \%$ \\
\hline Arkansas & $6.5 \%$ & $6.3 \%$ & $6.1 \%$ & $6.8 \%$ & $7.6 \%$ & $8.4 \%$ & $9.1 \%$ & $9.9 \%$ & $12.1 \%$ & $14.5 \%$ & $19.4 \%$ & $22.6 \%$ & $25.1 \%$ & $27.0 \%$ & $8.0 \%$ & $28.7 \%$ & $28.4 \%$ \\
\hline California & $14.3 \%$ & $14.1 \%$ & $13.5 \%$ & $14.8 \%$ & $17.1 \%$ & $19.0 \%$ & $20.9 \%$ & $22.4 \%$ & $24.2 \%$ & $24.9 \%$ & $25.1 \%$ & $27.3 \%$ & $27.6 \%$ & $29.7 \%$ & $31.9 \%$ & $33.8 \%$ & $33.4 \%$ \\
\hline Colorado & $12.3 \%$ & $11.9 \%$ & $11.3 \%$ & $11.9 \%$ & $13.1 \%$ & $14.0 \%$ & $14.8 \%$ & $15.3 \%$ & $16.0 \%$ & $17.6 \%$ & $19.2 \%$ & $21.7 \%$ & $23.4 \%$ & $25.3 \%$ & $27.2 \%$ & $28.7 \%$ & $28.4 \%$ \\
\hline Connecticut & $13.9 \%$ & $13.5 \%$ & $13.0 \%$ & $14.3 \%$ & $16.3 \%$ & $18.2 \%$ & $19.7 \%$ & $21.6 \%$ & $23.2 \%$ & $23.9 \%$ & $24.3 \%$ & $26.2 \%$ & $28.9 \%$ & $31.3 \%$ & $35.7 \%$ & $36.9 \%$ & $38.0 \%$ \\
\hline Delaware & $12.0 \%$ & $11.5 \%$ & $10.7 \%$ & $11.1 \%$ & $11.9 \%$ & $12.6 \%$ & $13.2 \%$ & $13.6 \%$ & $14.3 \%$ & $16.2 \%$ & $20.2 \%$ & $22.8 \%$ & $24.8 \%$ & $27.0 \%$ & $28.9 \%$ & $30.5 \%$ & $31.7 \%$ \\
\hline District o & $12.5 \%$ & $12.0 \%$ & $11.2 \%$ & $11.6 \%$ & $12.7 \%$ & $13.5 \%$ & $14.3 \%$ & $15.0 \%$ & $15.9 \%$ & $16.1 \%$ & $20.5 \%$ & $23.0 \%$ & $24.7 \%$ & $26.0 \%$ & $28.8 \%$ & $31.2 \%$ & $33.4 \%$ \\
\hline Florida & $7.1 \%$ & $6.9 \%$ & $6.8 \%$ & $7.8 \%$ & $9.0 \%$ & $10.0 \%$ & $11.0 \%$ & $11.9 \%$ & $14.0 \%$ & $16.1 \%$ & $19.8 \%$ & $22.5 \%$ & $24.6 \%$ & $27.4 \%$ & $28.9 \%$ & $30.3 \%$ & $31.0 \%$ \\
\hline eorgia & $6.4 \%$ & $6.3 \%$ & $6.2 \%$ & $7.1 \%$ & $8.2 \%$ & $9.2 \%$ & $10.2 \%$ & $11.1 \%$ & $12.0 \%$ & $14.1 \%$ & $18.0 \%$ & $21.1 \%$ & $23.4 \%$ & $25.8 \%$ & $28.0 \%$ & $28.7 \%$ & $28.9 \%$ \\
\hline Hawaii & $15.2 \%$ & $14.7 \%$ & $13.8 \%$ & $14.6 \%$ & $16.0 \%$ & $17.1 \%$ & $18.0 \%$ & $18.9 \%$ & $20.2 \%$ & $21.7 \%$ & $23.3 \%$ & $26.2 \%$ & $28.2 \%$ & $32.3 \%$ & $36.0 \%$ & $38.7 \%$ & $43.3 \%$ \\
\hline Idaho & $8.2 \%$ & $8.0 \%$ & $7.7 \%$ & $8.8 \%$ & $10.1 \%$ & $11.2 \%$ & $12.2 \%$ & $13.1 \%$ & $13.9 \%$ & $15.7 \%$ & $18.0 \%$ & $20.6 \%$ & $22.8 \%$ & $25.0 \%$ & $27.1 \%$ & $28.7 \%$ & $28.4 \%$ \\
\hline Illinois & $12.2 \%$ & $11.7 \%$ & $11.0 \%$ & $11.4 \%$ & $12.3 \%$ & $13.1 \%$ & $13.7 \%$ & $14.2 \%$ & $14.7 \%$ & $16.5 \%$ & $18.7 \%$ & $21.3 \%$ & $24.0 \%$ & $26.1 \%$ & $28.0 \%$ & $28.7 \%$ & $28.4 \%$ \\
\hline Indiana & $7.2 \%$ & $7.0 \%$ & $6.9 \%$ & $8.0 \%$ & $9.2 \%$ & $10.2 \%$ & $11.2 \%$ & $12.1 \%$ & $13.0 \%$ & $14.9 \%$ & $17.3 \%$ & $20.3 \%$ & $22.3 \%$ & $24.6 \%$ & $26.7 \%$ & $29.3 \%$ & $29.5 \%$ \\
\hline Iowa & $13.0 \%$ & $12.5 \%$ & $11.8 \%$ & $12.3 \%$ & $13.4 \%$ & $14.3 \%$ & $14.9 \%$ & $15.5 \%$ & $16.2 \%$ & $17.8 \%$ & $19.6 \%$ & $22.9 \%$ & $25.9 \%$ & $29.4 \%$ & $32.9 \%$ & $33.8 \%$ & $33.4 \%$ \\
\hline Kansas & $13.6 \%$ & $13.0 \%$ & $12.1 \%$ & $12.6 \%$ & $13.7 \%$ & $14.6 \%$ & $15.4 \%$ & $15.9 \%$ & $16.9 \%$ & $3.5 \%$ & $.0 \%$ & $23.1 \%$ & $24.5 \%$ & $26.8 \%$ & $28.9 \%$ & $0.3 \%$ & $0.0 \%$ \\
\hline Kentucky & $9.7 \%$ & $8.8 \%$ & $7.8 \%$ & $8.0 \%$ & $8.6 \%$ & $9.1 \%$ & $9.8 \%$ & $10.6 \%$ & $11.3 \%$ & $13.5 \%$ & $17.5 \%$ & $22.0 \%$ & $25.1 \%$ & $27.7 \%$ & $0.5 \%$ & $2.2 \%$ & $33.4 \%$ \\
\hline ouisiana & $6.9 \%$ & $7 \%$ & $6.5 \%$ & $.4 \%$ & $8.4 \%$ & $3 \%$ & $.0 \%$ & $.7 \%$ & $.8 \%$ & $5.0 \%$ & $7.7 \%$ & $20.5 \%$ & $22.9 \%$ & $25.6 \%$ & $3.0 \%$ & $8.7 \%$ & $8.4 \%$ \\
\hline Iaine & $8.2 \%$ & $6 \%$ & $9.0 \%$ & $0.4 \%$ & $2.5 \%$ & $4.1 \%$ & $5.2 \%$ & $16.2 \%$ & $17.7 \%$ & $19.3 \%$ & $20.7 \%$ & $23.5 \%$ & $27.6 \%$ & $30.8 \%$ & $34.1 \%$ & $33.8 \%$ & $33.4 \%$ \\
\hline Maryland & $1.9 \%$ & $11.5 \%$ & $10.8 \%$ & $11.4 \%$ & $2.4 \%$ & $13.3 \%$ & $14.1 \%$ & $14.7 \%$ & $15.6 \%$ & $17.4 \%$ & $19.1 \%$ & $23.2 \%$ & $25.0 \%$ & $30.0 \%$ & $34.4 \%$ & $38.4 \%$ & $39.4 \%$ \\
\hline Massachusetts & $13.7 \%$ & $13.2 \%$ & $12.4 \%$ & $13.0 \%$ & $14.2 \%$ & $15.4 \%$ & $16.6 \%$ & $17.7 \%$ & $19.0 \%$ & $20.5 \%$ & $22.0 \%$ & $24.4 \%$ & $28.3 \%$ & $31.3 \%$ & $34.1 \%$ & $33.8 \%$ & $33.4 \%$ \\
\hline Michigan & $14.3 \%$ & $13.8 \%$ & $13.1 \%$ & $13.8 \%$ & $15.2 \%$ & $16.6 \%$ & $17.6 \%$ & $18.7 \%$ & $19.9 \%$ & $21.1 \%$ & $22.4 \%$ & $27.3 \%$ & $30.9 \%$ & $33.9 \%$ & $34.5 \%$ & $34.7 \%$ & $34.8 \%$ \\
\hline Minnesota & $14.2 \%$ & $13.9 \%$ & $13.1 \%$ & $14.3 \%$ & $16.2 \%$ & $17.8 \%$ & $19.2 \%$ & $20.2 \%$ & $21.4 \%$ & $22.4 \%$ & $22.8 \%$ & $25.1 \%$ & $32.8 \%$ & $39.6 \%$ & $46.7 \%$ & $50.6 \%$ & $52.7 \%$ \\
\hline Mississippi & $6.0 \%$ & $5.9 \%$ & $5.7 \%$ & $6.3 \%$ & $6.8 \%$ & $7.3 \%$ & $7.8 \%$ & $8.3 \%$ & $8.8 \%$ & $11.4 \%$ & $16.2 \%$ & $21.2 \%$ & $26.7 \%$ & $31.3 \%$ & $34.1 \%$ & $33.8 \%$ & $33.4 \%$ \\
\hline IV & $\%$ & $10.4 \%$ & $9.9 \%$ & $10.4 \%$ & $\%$ & 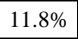 & o & o & $13.2 \%$ & $15.3 \%$ & $19.6 \%$ & $22.6 \%$ & $24.7 \%$ & $27.0 \%$ & $28.0 \%$ & $8.7 \%$ & $4 \%$ \\
\hline Montana & $11.1 \%$ & $10.3 \%$ & $9.3 \%$ & $10.0 \%$ & $1.2 \%$ & $12.1 \%$ & $13.4 \%$ & $14.6 \%$ & $15.8 \%$ & $17.3 \%$ & $19.3 \%$ & $21.8 \%$ & $23.4 \%$ & $25.3 \%$ & $27.2 \%$ & $28.7 \%$ & $8.4 \%$ \\
\hline Nebraska & $12.8 \%$ & $12.5 \%$ & $11.9 \%$ & $12.5 \%$ & $13.5 \%$ & $14.3 \%$ & $15.0 \%$ & $15.5 \%$ & $16.1 \%$ & $17.7 \%$ & $20.0 \%$ & $22.5 \%$ & $24.2 \%$ & $26.1 \%$ & $28.0 \%$ & $28.7 \%$ & $28.4 \%$ \\
\hline Nevada & $7.7 \%$ & $7.5 \%$ & $7.3 \%$ & $8.2 \%$ & $9.3 \%$ & $10.4 \%$ & $11.4 \%$ & $12.5 \%$ & $13.5 \%$ & $15.6 \%$ & $18.1 \%$ & $20.8 \%$ & $22.8 \%$ & $25.0 \%$ & $27.0 \%$ & $28.7 \%$ & $28.4 \%$ \\
\hline New Hamp & $7.8 \%$ & $7.6 \%$ & $7.4 \%$ & $8.7 \%$ & $10.5 \%$ & $12.0 \%$ & $13.3 \%$ & $15.0 \%$ & $16.6 \%$ & $18.2 \%$ & $20.1 \%$ & $22.9 \%$ & $24.4 \%$ & $27.3 \%$ & $29.8 \%$ & $32.5 \%$ & $34.1 \%$ \\
\hline New Jersey & $12.9 \%$ & $12.4 \%$ & $11.6 \%$ & $12.2 \%$ & $13.4 \%$ & $14.4 \%$ & $15.2 \%$ & $15.9 \%$ & $16.8 \%$ & $16.7 \%$ & $18.6 \%$ & $22.1 \%$ & $24.2 \%$ & $26.0 \%$ & $27.0 \%$ & $29.5 \%$ & $31.6 \%$ \\
\hline New Mexico & $7.3 \%$ & $7.1 \%$ & $7.0 \%$ & $8.1 \%$ & $9.3 \%$ & $10.4 \%$ & $11.4 \%$ & $12.2 \%$ & $13.0 \%$ & $15.0 \%$ & $19.9 \%$ & $22.6 \%$ & $24.6 \%$ & $27.0 \%$ & $28.0 \%$ & $32.0 \%$ & $34.7 \%$ \\
\hline New York & $14.5 \%$ & $14.0 \%$ & $13.2 \%$ & $14.2 \%$ & $15.9 \%$ & $17.3 \%$ & $18.5 \%$ & $19.6 \%$ & $20.8 \%$ & $20.9 \%$ & $21.7 \%$ & $24.0 \%$ & $24.8 \%$ & $28.6 \%$ & $1.3 \%$ & $3.8 \%$ & $33.4 \%$ \\
\hline North Car & $6.8 \%$ & $6.6 \%$ & $6.5 \%$ & $7.3 \%$ & $\%$ & $\%$ & $10.1 \%$ & $1.0 \%$ & $\%$ & $\%$ & $\%$ & $22.3 \%$ & $24.6 \%$ & $27.4 \%$ & $.2 \%$ & $2.6 \%$ & $33.4 \%$ \\
\hline North Dakota & $1 \%$ & $7.9 \%$ & $8 \%$ & $9.2 \%$ & $.0 \%$ & $12.6 \%$ & $.9 \%$ & $\%$ & $.3 \%$ & $7.8 \%$ & $19.7 \%$ & $22.1 \%$ & $23.7 \%$ & $25.5 \%$ & $27.3 \%$ & $28.7 \%$ & $28.4 \%$ \\
\hline Ohio & $11.9 \%$ & $11.5 \%$ & $10.8 \%$ & $11.2 \%$ & $12.1 \%$ & $12.8 \%$ & $13.4 \%$ & $13.9 \%$ & $14.5 \%$ & $16.5 \%$ & $18.4 \%$ & $21.0 \%$ & $23.8 \%$ & $26.0 \%$ & $28.0 \%$ & $28.7 \%$ & $28.4 \%$ \\
\hline Oklahoma & $7.3 \%$ & $7.2 \%$ & $7.0 \%$ & $8.2 \%$ & $9.6 \%$ & $10.9 \%$ & $12.0 \%$ & $13.0 \%$ & $14.0 \%$ & $15.8 \%$ & $19.1 \%$ & $23.1 \%$ & $24.9 \%$ & $27.0 \%$ & $28.0 \%$ & $28.7 \%$ & $28.9 \%$ \\
\hline Oregon & $12.8 \%$ & $11.7 \%$ & $10.3 \%$ & $10.8 \%$ & $12.1 \%$ & $13.0 \%$ & $14.3 \%$ & $15.7 \%$ & $17.1 \%$ & $18.6 \%$ & $21.0 \%$ & $23.4 \%$ & $24.8 \%$ & $26.6 \%$ & $28.0 \%$ & $28.7 \%$ & $28.4 \%$ \\
\hline Pennsylvania & $13.4 \%$ & $12.8 \%$ & $11.9 \%$ & $12.4 \%$ & $13.6 \%$ & $14.5 \%$ & $15.4 \%$ & $15.8 \%$ & $16.6 \%$ & $18.2 \%$ & $20.8 \%$ & $23.7 \%$ & $25.1 \%$ & $27.0 \%$ & $28.0 \%$ & $28.7 \%$ & $29.9 \%$ \\
\hline Rhode Island & $13.7 \%$ & $13.3 \%$ & $12.6 \%$ & $13.6 \%$ & $15.3 \%$ & $16.8 \%$ & $18.1 \%$ & $19.0 \%$ & $20.4 \%$ & $21.5 \%$ & $22.6 \%$ & $24.9 \%$ & $28.4 \%$ & $31.3 \%$ & $7.7 \%$ & $10.9 \%$ & $43.8 \%$ \\
\hline South Carolina & $6.6 \%$ & $6.4 \%$ & $6.3 \%$ & $7.0 \%$ & $8.0 \%$ & $8.8 \%$ & $9.6 \%$ & $10.1 \%$ & $12.3 \%$ & $14.8 \%$ & $17.8 \%$ & $22.0 \%$ & $24.4 \%$ & $28.6 \%$ & $31.4 \%$ & $33.8 \%$ & $33.4 \%$ \\
\hline South Dakota & $8.3 \%$ & $8.0 \%$ & $7.8 \%$ & $9.0 \%$ & $10.4 \%$ & $11.6 \%$ & $12.8 \%$ & $13.5 \%$ & $14.6 \%$ & $16.3 \%$ & $18.5 \%$ & $21.4 \%$ & $24.2 \%$ & $26.1 \%$ & $28.0 \%$ & $28.7 \%$ & $28.4 \%$ \\
\hline Tennessee & $6.6 \%$ & $6.4 \%$ & $6.2 \%$ & $6.8 \%$ & $7.5 \%$ & $8.3 \%$ & $8.9 \%$ & $9.5 \%$ & $11.7 \%$ & $14.2 \%$ & $18.6 \%$ & $21.6 \%$ & $24.2 \%$ & $27.4 \%$ & $28.9 \%$ & $31.4 \%$ & $32.1 \%$ \\
\hline Texas & $6.1 \%$ & $5.9 \%$ & $5.8 \%$ & $6.4 \%$ & $7.3 \%$ & $8.2 \%$ & $9.0 \%$ & $9.8 \%$ & $10.4 \%$ & $12.9 \%$ & $15.7 \%$ & $20.4 \%$ & $22.9 \%$ & $25.5 \%$ & $28.0 \%$ & $30.4 \%$ & $31.6 \%$ \\
\hline Utah & $12.0 \%$ & $11.0 \%$ & $9.8 \%$ & $10.4 \%$ & $11.5 \%$ & $12.4 \%$ & $13.7 \%$ & $14.9 \%$ & $16.0 \%$ & $17.5 \%$ & $19.5 \%$ & $22.0 \%$ & $24.3 \%$ & $26.2 \%$ & $28.0 \%$ & $28.7 \%$ & $28.4 \%$ \\
\hline Vermont & $14.6 \%$ & $14.2 \%$ & $13.6 \%$ & $14.8 \%$ & $16.7 \%$ & $18.5 \%$ & $19.9 \%$ & $20.7 \%$ & $21.9 \%$ & $22.8 \%$ & $23.4 \%$ & $25.5 \%$ & $31.4 \%$ & $36.8 \%$ & $42.3 \%$ & $44.8 \%$ & $45.5 \%$ \\
\hline Virginia & $7.5 \%$ & $7.3 \%$ & $7.2 \%$ & $8.4 \%$ & $9.9 \%$ & $11.3 \%$ & $12.5 \%$ & $13.7 \%$ & $14.8 \%$ & $16.5 \%$ & $18.7 \%$ & $21.6 \%$ & $24.1 \%$ & $26.1 \%$ & $28.0 \%$ & $28.7 \%$ & $28.4 \%$ \\
\hline Washington & $12.9 \%$ & $11.9 \%$ & $10.6 \%$ & $11.6 \%$ & $13.3 \%$ & $14.7 \%$ & $16.4 \%$ & $18.0 \%$ & $19.6 \%$ & $20.6 \%$ & $21.9 \%$ & $24.2 \%$ & $25.0 \%$ & $28.0 \%$ & $33.1 \%$ & $37.8 \%$ & $39.2 \%$ \\
\hline West Virginia & $11.4 \%$ & $10.9 \%$ & $10.0 \%$ & $10.2 \%$ & $10.7 \%$ & $11.4 \%$ & $12.0 \%$ & $12.0 \%$ & $13.8 \%$ & $16.0 \%$ & $19.4 \%$ & $22.5 \%$ & $26.1 \%$ & $28.9 \%$ & $30.5 \%$ & $30.3 \%$ & $30.0 \%$ \\
\hline Wisconsin & $14.5 \%$ & $14.0 \%$ & $13.4 \%$ & $14.6 \%$ & $16.6 \%$ & $18.3 \%$ & $19.7 \%$ & $20.7 \%$ & $21.8 \%$ & $22.5 \%$ & $23.7 \%$ & $26.6 \%$ & $28.5 \%$ & $30.1 \%$ & $31.8 \%$ & $33.5 \%$ & $34.7 \%$ \\
\hline Wyoming & $8.1 \%$ & $7.9 \%$ & $7.8 \%$ & $9.0 \%$ & $10.4 \%$ & $11.7 \%$ & $12.8 \%$ & $13.9 \%$ & $14.8 \%$ & $16.5 \%$ & $18.8 \%$ & $21.3 \%$ & $24.1 \%$ & $26.1 \%$ & $28.0 \%$ & $28.7 \%$ & $28.4 \%$ \\
\hline
\end{tabular}

